\title{
Arquitectura foliar de Anacardiaceae
}

\section{Leaf architecture of Anacardiaceae}

\author{
Marcela Martínez-Millán ${ }^{1 *}$ y Sergio R. S. Cevallos-Ferriz². \\ ${ }^{1}$ Posgrado en Ciencias Biológicas, Sede Instituto de Geología, UNAM, Ciudad Universitaria, Circuito de la Investigación Científica, Del. Coyoacán, 04510 \\ México D.F., México. \\ *Correspondencia:mm383@cornell.edu \\ ${ }^{2}$ Laboratorio de Paleobotánica, Instituto de Geología, UNAM, Ciudad Universitaria, Circuito de la Investigación Científica, Del. Coyoacán, 04510 México \\ D.F., México.scrscfpb@servidor.unam.mx
}

Resumen. Anacardiaceae es una familia moderadamente grande que incluye unas 600 especies en 74 géneros. La familia tiene un registro fósil amplio que en gran parte consiste de impresiones de láminas foliares y se remonta, por lo menos, al Maastrichtiano (Cretácico superior). En el presente trabajo se realiza la descripción de la arquitectura foliar de 61 géneros de la familia Anacardiaceae. Las hojas (o folíolos) de 102 especies se aclararon y montaron para después observarse tanto en el microscopio estereoscópico como en el óptico.

Palabras clave: Anacardiaceae, arquitectura foliar, hoja.

\begin{abstract}
Anacardiaceae is a moderately large family. It includes 74 genera and approximately 600 species. The family has an extensive fossil record that dates back at least to the Maastrichtian (Upper Cretaceous), and that consists to a large extent of leaf impressions. In this work, the description of the leaf architecture of 61 genera of Anacardiaceae is presented. The leaves (or leaflets) of 102 species were cleared, mounted and observed under both dissection and compound microscopes.
\end{abstract}

Key words: Anacardiaceae, leaf architecture, leaf.

\section{Introducción}

La familia Anacardiaceae Lindl. es moderadamente grande; incluye unas 600 especies que se encuentran principalmente en zonas tropicales de todo el mundo. Aunque también hay algunos representantes en zonas templadas, éstos pertenecen sólo a unos cuantos géneros (por ejemplo, Rhus, Toxicodendron, Cotinus). Los ambientes donde se pueden encontrar son variados, desde las comunidades clímax de las selvas altas perennifolias y las selvas bajas caducifolias hasta los ambientes perturbados, donde funcionan como colonizadoras tempranas, o las zonas costeras tipo manglar, así como en zonas xerófilas. Los miembros de esta familia se conocen por producir reacciones alérgicas al contacto, debido a la presencia de compuestos fenólicos en la resina (Judd et al., 2002); esta característica es el origen de algunos nombres comunes; entre otros, poison oak (encino venenoso), poison ivy (hiedra venenosa), poison sumac (zumaque venenoso), teclate que quema, hincha huevos y mala mujer. Otros miembros de la familia son de importancia económica debido a sus frutos comestibles y, por tanto, prácticamente se cultivan en todo el mundo. Tal es el caso del mango (Mangifera indica), el pistache (Pistacia vera) y el anacardo o nuez marañón (Anacardium occidentale).

Recibido: 18 agosto 2004; aceptado: 04 junio 2005
El hábito predominante en la familia es el arbóreo, seguido del arbustivo y de las lianas; muy pocos representantes son herbáceos. Una característica considerada típica de la familia es la presencia de canales resiníferos en la corteza, cuya resina es clara pero al contacto con el aire se ennegrece (Ding Hou, 1978; Judd et al., 2002). Las flores son usualmente muy pequeñas, actinomorfas pentámeras y unisexuales, por lo común se encuentran en inflorescencias determinadas, complejas o cimosas; tanto los sépalos como los pétalos tienden a estar separados aunque pueden encontrarse ligeramente connados, los estambres suelen ser de 5 a 10 y generalmente están libres, el ovario es súpero y se compone de 3 carpelos connados (en ocasiones 5), típicamente, sólo un carpelo es fértil e incluye un solo óvulo apótropo con placentación apical y el fruto es una drupa dispersada por animales (mamíferos y aves), aunque algunos géneros utilizan la dispersión por viento (Cronquist, 1981; Judd et al., 2002).

Tanto los sistemas de clasificación tradicionales más utilizados (Cronquist, 1981, 1988; Thorne, 1992), como el más reciente, de APG (1998, 2003), sitúan la familia Anacardiaceae en el orden Sapindales, el cual incluye las familias Burseraceae, Sapindaceae, Meliaceae, Rutaceae y Simaroubaceae (Rutales de Thorne, 1992). Una de las diferencias más importantes es la inclusión de la familia Julianiaceae como parte de Anacardiaceae, o su 
reconocimiento como una familia por sí sola. El sistema de Thorne (1992) y el sistema del APG $(1998,2003)$ coinciden en incluir Julianiaceae en Anacardiaceae, mientras que Cronquist $(1981,1988)$ reconoce la existencia de la familia Julianiaceae (Cuadro 1).

Los límites de la familia Anacardiaceae han sido difíciles de establecer; por ejemplo, antiguamente se solía incluir a los miembros de Anacardiaceae junto con los miembros de Burseraceae en una sola familia, Terebinthaceae (Kryn, 1952; Terrazas, 1994). Otros autores dieron a algunos géneros de Anacardiaceae la categoría de familia, segregándolos asî de Anacardiaceae (por ejemplo, Pistacia, Blepharocarya; Reveal, 1998). Aún en la actualidad, el problema persiste cuando se trata de las familias Julianiaceae y Podoaceae. Esta diferente concepción ha dado como resultado la existencia de varios sinónimos para la familia (Reveal, 1998).

Tradicionalmente, la familia se ha dividido en 5 tribus, siguiendo la propuesta de Engler $(1883,1896)$. Las primeras 4 tribus, tal como las nombró Engler en 1883 son Mangifereae, Spondieae, Rhoideae y Semecarpeae; en 1896, agregó la quinta, Dobineeae, para incluir 2 géneros que a veces se segregan como la familia Podoaceae. En 1973, Airy Shaw, en el Diccionario de Willis (octava edición) renombra las 5 tribus para dar el esquema que se utilizó hasta fechas recientes: Anacardieae, Spondiadeae, Rhoeae, Semecarpeae y Dobineeae (Airy-Shaw, 1973). Los estudios más recientes indican que este esquema de 5 tribus es artificial y, al parecer, la familia está compuesta de 2 linajes principales, que divergen muy temprano en la historia de la familia con algunos géneros por fuera de estos 2 grupos (Heimsch, 1942; Terrazas, 1994; Terrazas y Chase, 1996; Pell y Urbatsch, 2000, 2001; Pell, 2004); sin embargo, los géneros que forman los 2 linajes no siempre se conservan en las diferentes filogenias.

Los géneros que se han descrito para la familia son aproximadamente 110; sin embargo, muchos caen en sinonimia. La lista aceptada por Brummitt (1992) indica que la familia consta de 68 géneros; esta lista incluye en Anacardiaceae los 2 géneros que ocasionalmente son tratados como Julianiaceae, Amphipterygium y Orthopterygium (compárese Hemsley, 1906, 1908 con Kryn, 1952; Stern, 1952; Young, 1976 y Wannan y Quinn, 1988), pero descarta los géneros de Podoaceae, Dobinea y Campylopetalum a pesar de la evidencia que indica que sí son parte de Anacardiaceae (Engler, 1896; Ding Hou, 1978; Terrazas, 1994; Pell y Urbatsch, 2001; Pell, 2004). Brummitt (1992) también sinonimiza 4 géneros que han sido segregados de Rhus: Malosma, Melanococca, Toxicodendron y Searsia (véase Barkley, 1937, 1942, 1957, 1965; Miller et al., 2001 y Yi et al., 2004). Malosma y Melanococca constan cada uno de una sola especie de distribución restringida, mientras que Toxicodendron es un género con amplia distribución en las zonas templadas y tropicales tanto del Nuevo como del Viejo Mundo. Las diferencias entre Rhus y Toxicodendron se relacionan con el tipo de fruto y las resinas (Rhus no causa reacción alérgica; Toxicodendron sí la causa) y son lo suficientemente distintivas como para considerarlos géneros independientes (Gillis, 1971; Judd et al., 1999, 2002). Searsia por otro lado, comprende más de 100 especies, principalmente sudafricanas, que difieren de Rhus s.s. por sus drupas blancas y glabras (Barkley, 1942, 1943, 1965); aunque algunos autores siguen considerándolo parte de Rhus (Archer, 2000 por ejemplo) los análisis más recientes muestran que estos géneros no están cercanamente relacionados (Miller et al., 2001; Yi et al., 2004; Pell, 2004). Baronia no se encuentra mencionado en la lista de Brummit (1992), tal vez porque fue reducido a una sección de Rhus (Perrier de la Bâthie, 1944, 1946); sin embargo, estudios recientes indican que estas especies malgaches no son parte de Rhus (Randrianasolo, 1998; Pell, 2004) aunque su status como género no se ha reinstituido válidamente. Un caso similar ocurre con Myracrodruon, que ocasionalmente se incluye en Astronium; sin embargo, la presencia de pistilodios, el tipo de fruto y los caracteres anatómicos de la madera apoyan el reconocimiento de los dos géneros (Santin y Leitão, 1991; Terrazas, 1994, 1999). Respecto al género Euleria, el material tipo no es fértil y nunca se ha vuelto a colectar, por tanto, se excluye de la familia ya que no es posible demostrar su existencia (Terrazas, com. pers., 2001). La inclusión (Dobinea, Campylopetalum, Malosma, Melanococca, Toxicodendron, Searsia, "Baronia”, Myracrodruon) / exclusión (Euleria) de estos géneros amplía la lista de los pertenecientes a Anacardiaceae a 74/75.

En la actualidad se estudian las relaciones filogenéticas

Cuadro 1. Posición taxonómica de la familia Anacardiaceae según tres diferentes esquemas de clasificación.

\begin{tabular}{ccc}
\hline Cronquist, 1981, 1988 & Thorne, 1992 & APG, 1998, 2003 \\
\hline Magnoliophyta & Angiospermae & Angiospermas \\
Magnoliopsida & Dicotyledonae & Eudicotiledóneas \\
Rosidae & Rutanae & "Core" eudicotiledóneas \\
Sapindales & Rutales & Rosidas \\
Anacardiaceae & Anacardiaceae & Eurosidas II \\
Julianiaceae & & Sapindales \\
& & Anacardiaceae \\
\hline
\end{tabular}


del orden, la familia y de los diferentes géneros que la forman (Pell y Urbatsch, 2000, 2001; Pell, 2004; Randrianasolo, com. pers., 2002). Los resultados hasta ahora indican que la familia muy probablemente es monofilética y que su grupo hermano es la familia Burseraceae, también monofilética (Terrazas, 1994; Gadek et al., 1996; Soltis et al., 2000; Pell y Urbatsch, 2000, 2001; Clarkson et al., 2002; Pell, 2004; Weeks et al., 2005). Sin embargo, es necesario refinar estos estudios ya que, ocasionalmente, algunos miembros de las dos familias se mezclan pero, en cuanto a características generales, ambas están bien diferenciadas.

La mayoría de los estudios taxonómicos se enfocan en caracteres reproductivos, rara vez los caracteres vegetativos reciben un tratamiento sistemático y detallado, a excepción de los que explícitamente se refieren a ellos. Christophel y Hyland (1993) mencionan que el estudio de las hojas per se cobra mayor importancia en los campos forestal y de la paleobotánica; sin embargo, los estudios taxonómicos no alcanzan el nivel de profundidad que los investigadores en estas áreas requieren.

En este trabajo se pretende describir la arquitectura foliar de géneros de Anacardiaceae de una manera sistemática, de modo que sirva como referencia para investigadores en las áreas de paleobotánica, ciencias forestales y taxonomía. Éste no es el primer estudio sobre la arquitectura foliar de Anacardiaceae pero es el más amplio, ya que involucra a toda la familia y no sólo a las especies específicas de alguna zona geográfica. Estudios previos incluyen el de Dames E. Silva (1973) que describe la arquitectura foliar de las anacardiáceas de la caatinga de Brasil y el Atlas de hojas de Christophel y Hyland (1993) que es un suplemento a la clave de identificación de árboles de selva tropical australiana de Hyland et al. (1993, 2003). Otros estudios sobre hojas de Anacardiaceae (Wilkinson, 1983; Torres y Jáuregui, 1999, por ejemplo) se enfocan más en la anatomía que en la arquitectura foliar; sin embargo, hay un cierto traslape en estas áreas de estudio, principalmente relacionado con la epidermis, los tricomas, los cristales y los canales resiníferos.

\section{Materiales y métodos}

Aclarado de hojas. Los ejemplares con que se trabajó son muestras de hojas o folíolos laterales (se evitó el uso de folíolos apicales) que provienen de ejemplares de herbario identificados hasta especie y depositados en varios herbarios del mundo. Estas muestras forman parte de la Colección de Hojas Aclaradas dentro de la Colección de Material Reciente del Museo de Paleontología, Instituto de Geología, UNAM.

Debido a que muchas características, especialmente las relacionadas con altos niveles de venación, son difíciles de observar en el material de herbario, se optó por utilizar la técnica de aclarado de hojas propuesta por Payne (1969).
Esta técnica tiene la ventaja de permitir la observación de características que de otra manera son obscurecidas por los propios tejidos de la hoja, como el mesofilo, una cutícula gruesa o la presencia de esclereidas; permite, además, la observación al microscopio tanto estereoscópico como óptico, de tal manera que estructuras como los estomas, los tricomas y los cristales pueden observarse sin necesidad de dañar permanentemente el material.

La técnica de aclarado de hojas consta de varios pasos; sin embargo, debido a que cada hoja tiene características diferentes de grosor, contenido de clorofila, alcaloides y otras sustancias, cada una reacciona de manera diferente a la técnica, por lo que las concentraciones y los tiempos sugeridos pueden variar. Asimismo, se hicieron algunas modificaciones a la técnica original de Payne (1969):

1. Las muestras de herbario no se hirvieron antes del tratamiento con $\mathrm{NaOH}$.

2. La solución de $\mathrm{NaOH}$ se utilizó al $20 \%$ en lugar de al $5 \%$.

3. Las muestras de hojas se introdujeron en la solución de $\mathrm{NaOH}$ después de que ésta hubo hervido. $50 \%$.

4. La solución de cloro se utilizó al $10 \%$ en lugar de al

5. Las muestras se pasaron de la solución de $\mathrm{NaOH}$ a la de cloro, omitiendo el enjuague intermedio con agua.

6. De los colorantes recomendados por Payne (1969), se utilizó safranina en $\mathrm{OH} 50^{\circ}$.

7. El medio de montaje elegido fue Permount.

Ejemplares. Para el presente estudio, se aclaró, tiñó y montó un total de 116 muestras de hojas, 2 más (Pistacia khinjuk y P. weinmannifolia) las proporcionó el M. en C. José Luis Ramírez Garduño (Posgrado en Ciencias Biológicas, Instituto de Geología, UNAM), lo que da un total de 118 muestras. Debido a que algunas especies están representadas por una o más muestras, el número de especies representadas es ligeramente menor (Cuadro 2). Varios géneros están representados por más de una especie, mientras que otros no pudieron ser representados, ya sea por la rareza del material o por la delicadeza de las hojas que no soportan la técnica. Una lista completa de las especies y géneros representados se presenta en el Cuadro 3, mientras que el Cuadro 4 presenta una lista de los géneros no representados.

Siempre que fue posible, se representó el género con su

Cuadro 2. Relación de las muestras aclaradas y los géneros y especies de Anacardiaceae representados.

\begin{tabular}{lc} 
Muestras de hojas aclaradas & 118 \\
Especies representadas & 102 \\
Especies tipo representadas & 38 \\
Géneros representados & 61 \\
Géneros no representados & 13 \\
Géneros en la familia & 74 \\
\hline
\end{tabular}


Cuadro 3. Relación de géneros y especies de Anacardiaceae representados en el presente estudio.

Actinocheita F. A. Barkley

A. filicina (Moç et Sessé ex DC) Barkley ${ }^{1}$

Amphipterygium Schiede ex Standl.

A. adstringens (Schltdl.) Standl. ${ }^{1}$

Anacardium L.
A. excelsum Skeels ${ }^{2}$

A. occidentale L. ${ }^{1}$

Antrocaryon Pierre

A. micraster A. Chevalier et A. Guillaumin Astronium Jacq.

A. conzattii S. F. Blake

A. fraxinifolium Schott

A. graveolens Jacq. ${ }^{1}$

A. lecointei Ducke

"Baronia" — ver Rhus

Blepharocarya F. Muell.

B. depauperata Specht

Bonetiella Rzed.

B. anomala (I. M. Johnston) Rzedowski ${ }^{1}$

Bouea Meisn.

B. oppositifolia (Roxb.) Meissn ${ }^{1}$

Buchanania Spreng.

B. acuminata Turcz

B. acuminatissima Merrill

B. florida Schau

B. palawensis Lauterb. ${ }^{2}$

B. reticulata Hance.

Campnosperma Thwaites

C. auriculata Hook. f.

C. montana Lauterb.

Cardenasiodendron F. A. Barkley

C. brachypterum (Loes.) F. A. Barkley ${ }^{1,2}$

Choerospondias B. L. Burtt et A. W. Hill ${ }^{2}$

C. axillaris (Roxb.) B. L. Burtt et A. W. Hill ${ }^{1}$

Comocladia P. Browne

C. engleriana Loes. ${ }^{2}$

C. guatemalensis Donn.Sm.

C. ilicifolia $\mathrm{Sw}$.

C. mollissima H. B. K. ${ }^{2}$

C. palmeri Rose

C. platyphylla A. Rich. ex Griseb.
Cotinus Mill.

Cyrtocarpa Kunth

C. procera H. B. K. ${ }^{1}$

Dracontomelon Blume

D. cumingianum Baill.

D. dao Merrill et Rolfe

Euroschinus Hook. F.

Gluta L.

E. falcatus Hook. f. ${ }^{1}$

G. tavoyana Hook. f.

Haplorhus Engl.

H. peruviana Engl. ${ }^{1}$

Harpephyllum Bernh. ex Krauss

H. caffrum Bernh. ex Krauss ${ }^{1}$

Koordersiodendron Engl.

K. pinnatum Merrill

Lannea A. Rich.

L. grandis Engl.

Laurophyllus Thunb.

L. capensis Thunb. ${ }^{1}$

Lithraea Miers ex Hook. et Arn.

L. caustica Hook. et Arn. ${ }^{1,2}$

L. ternifolia (Gillies ex Hook.) F. A. Barkley

Loxopterygium Hook. f.

L. grisebachii Hiern ex Griseb.

L. sagotii Hook. f. ${ }^{1}$

Loxostylis A. Spreng. ex Rchb.

L. alata Spreng. ex Reichb. ${ }^{1}$

Malosma Engl.

M. laurina (Nutt.) Nutt. ex Abrams ${ }^{1}$

Mangifera L.

M. indica $\mathrm{L} .{ }^{1}$

M. verticillata C. B. Robinson ${ }^{2}$

Mauria Kunth

M. aurantiodora Engl.

M. sessiliflora Standley

M. simplicifolia H. B. K. ${ }^{1,2}$

Melanochyla Hook. f.

M. auriculata Hook. f. 
Cuadro 3. Continuación

Metopium P. Browne

M. brownei Urb. ${ }^{2}$

Mosquitoxylum Krug et Urb.

M. jamaicense Krug et Urb. ${ }^{1}$

Myracrodruon Allemão

M. balansae (Engl.) D. A. Santin

M. urundeuva M. Allemao ${ }^{1}$

Nothopegia Blume

$N$. beddomei Gamble

Ochoterenaea F. A. Barkley

O. colombiana F. A. Barkley ${ }^{1}$

Operculicarya H. Perrier

O. decaryi H. Perrier

Ozoroa Delile

O. paniculosa (Sond.) R. et A. Fernandes ${ }^{2}$

Pachycormus Coville ex Standl.

P. discolor (Benth.) Coville ${ }^{1}$

Parishia Hook. f.

P. insignis Hook. f. ${ }^{1}$

Pegia Colebr.

P. nitida Colebr $^{1}$

Pentaspadon Hook. f.

Pistacia L.

P. motleyi Hook. f. ${ }^{1}$

P. khinjuk Stocks

P. mexicana H. B. K.

P. weinmannifolia Poiss. ex Franch.

Pleiogynium Engl.

P. solandri (Benth.) Engl. ${ }^{1,2}$

Poupartia Comm. ex Juss.

$P$. pinnata $\mathrm{Blanco}^{2}$

Protorhus Engl.

P. longifolia Engl. ${ }^{1}$

Pseudosmodingium Engl.

P. andrieuxii Engl.

P. barkleyi Miranda

P. perniciosum Engl.

Pseudospondias Engl.

P. microcarpa Engl. ${ }^{1}$

Rhodosphaera Engl.

$R$. rhodanthema Engl. ${ }^{1}$
Rhus L.

R. galeottii Standl.

R. nelsonii F. A. Barkley

$R$. taratana (Baker) H. Perrier

$R$. terebinthifolia Schlecht. et Cham.

Schinopsis Engl.

S. brasiliensis Engl.

S. lorentzii Engl.

Schinus L.
S. dependens Orteg. ${ }^{2}$
S. latifolius Engl.
S. lentiscifolius March.
S. meyeri F. A. Barkley
S. molle L., ${ }^{1,2}$
S. venturii F. A. Barkley
S. weinmanniaefolius Engl.

Sclerocarya Hochst.

S. birrea Hochst. ${ }^{1}$

Semecarpus L. f.

S. curtisii King

S. venenosa Volk.

Smodingium E. Mey. ex Sond.

S. argutum E. Mey. ${ }^{1}$

Sorindeia Thouars

S. madagascariensis Baill. ${ }^{1}$

Spondias L.
S. lutea L.
S. mombin L.
S. nigrescens Pittier
S. philippinensis (Elmer) Airy Shaw et Forman
S. purpurea L.
S. radlkoferi Donn.Sm.

Swintonia Griff.

S. floribunda Griff. ${ }^{1}$

Tapirira Aubl.

T. mexicana $\mathrm{March}^{2}$

Thyrsodium Salzm. ex Benth.

T. paraense Huber

Toxicodendron Mill.

T. radicans (L.) Kuntze

Trichoscypha Hook. f.

T. acuminata Engl.

${ }^{1}$ Especie tipo. ${ }^{2}$ Especie representada por 2 o más muestras. 
Cuadro 4. Relación de géneros de Anacardiaceae no representados y su distribución.

\begin{tabular}{|c|c|}
\hline Androtium Stapf & Península malaya, Borneo \\
\hline Campylopetalum Forman & Myanmar \\
\hline $\begin{array}{l}\text { Dobinea Buch.-Ham. ex } \\
\text { D. Don }\end{array}$ & Himalaya, China \\
\hline Drimycarpus Hook.f. & $\begin{array}{l}\text { India, Myanmar, } \\
\text { Bangladesh, Malasia }\end{array}$ \\
\hline Faguetia Marchand & Madagascar \\
\hline Fegimanra Pierre & África del Oeste \\
\hline Haematostaphis Hook.f. & $\begin{array}{l}\text { Africa tropical del Oeste, } \\
\text { Nigeria }\end{array}$ \\
\hline Heeria Meisn. & Sudáfrica \\
\hline $\begin{array}{l}\text { Holigarna Buch.-Ham. } \\
\text { ex Roxb. }\end{array}$ & $\begin{array}{l}\text { India, Myanmar, Tailandia, } \\
\text { Indochina }\end{array}$ \\
\hline Melanococca Blume & $\begin{array}{l}\text { Polinesia, Java, Filipinas, } \\
\text { Nueva Guinea }\end{array}$ \\
\hline Micronychia Oliv. & Madagascar \\
\hline Orthopterygium Hemsl. & Perú \\
\hline Searsia F. A. Barkley & Sudáfrica \\
\hline
\end{tabular}

especie tipo (Cuadros 2 y 3). Este criterio se escogió como una forma de decidir qué especie utilizar, especialmente en aquellos géneros que cuentan con un gran número de especies. Una ventaja de utilizar las especies tipo es que si en el futuro hay cambios nomenclaturales, la especie tipo siempre permanecerá ligada al género, y por tanto seguirá sirviendo como referencia para el género. Por ejemplo, la arquitectura foliar de la especie tipo de Protorhus, $P$. longifolia, se describe en este trabajo, pero de acuerdo con algunos estudios recientes, la circunscripción de Protorhus puede cambiar, dejando únicamente esta especie en el género (Randrianasolo, 1998). Si esto sucede, la presente descripción seguirá aplicándose al género Protorhus, ya que la especie tipo es estable.

Todas las muestras se observaron al microscopio estereoscópico y óptico. En el primero, se registraron los caracteres que corresponden a la organización macroscópica de la hoja/folíolo (forma de la lámina, forma de la base, forma del ápice, largo, ancho y venación). Los ángulos del ápice y la base fueron medidos sobre fotografías de las muestras, mientras que el largo de la lámina, el ancho de la lámina y el número de dientes por centímetro se midieron directamente sobre la muestra mediante el uso de un vernier. En el microscopio óptico se observaron los patrones de los órdenes de venación altos, las características epidérmicas (tricomas y estomas) y la presencia de cristales prismáticos o drusas en el interior de los tejidos.

Debido a que la mayoría de las muestras son donaciones, no fue posible observar el material de herbario del que proceden, así que en muchos casos no se pudo determinar a partir de la muestra si se trataba de una hoja o de un folíolo, excepto cuando toda la hoja compuesta fue proporcionada o la muestra se tomó personalmente. En algunas ocasiones, el pecíolo se desprende de la lámina dando la impresión de que la lámina carece de éste; sin embargo, la condición sésil también se presenta en algunos géneros. Debido a esto, y a que a partir de las muestras tampoco se puede determinar la filotaxia, se realizaron visitas al Herbario Nacional MEXU con el fin de observar en otros ejemplares estas condiciones. También se buscaron estos datos en la literatura para aquellas especies que no se encuentran representadas en el Herbario Nacional MEXU (Maiden, 1904; Barkley, 1954; Airy Shaw, 1965; Ding Hou, 1978; Wannan et al., 1987; Santin y Leitão, 1991; Cunningham, 1997; Petitjean y Samyn, 1999; Robertson, 2000; Archer, 2000; Archer y Reynolds, 2001; Armstrong, 2001; Breteler, 2004) y, adicionalmente, se consultaron ejemplares en línea pertenecientes al Jardín Botánico de Nueva York, el Herbario del Jardín Tropical Fairchild en Florida, el Jardín Botánico de Missouri y la Colección para el estudio de la Vegetación y Flora de la Universidad Kagoshima, Japón y el Museo de Brunei, Borneo.

En algunos casos, los ejemplares depositados en el Herbario Nacional MEXU incluían especies que no se encuentran representadas en las muestras aclaradas. En estos casos, las características macroscópicas como la filotaxia, la inserción del pecíolo, la forma de la hoja/folíolo, el tipo de ápice, el tipo de base y el tipo de margen fueron registradas para documentar más ampliamente la variación dentro del género; sin embargo, estos datos no fueron extrapolados a las especies representadas en las muestras aclaradas aun cuando no fuera posible encontrar dichos datos para la especie aclarada en cuestión.

Caracteres. Los caracteres utilizados para describir a las hojas se basan principalmente en el sistema presentado en el Manual de Arquitectura Foliar propuesto por el Leaf Architecture Working Group (1999). Este sistema se basa a su vez en la terminología propuesta por Hickey $(1973,1979)$ para los tipos de hoja y venación y Dilcher (1974) para las características de la epidermis. Sin embargo, al observar la variación dentro de la familia, resultó evidente que algunos caracteres son invariables mientras que otros requieren ser subdivididos o modificados en alguno(s) de sus estados de carácter para poder representar la variación observada; incluso, algunos más tuvieron que agregarse, ya que no están definidos en el Manual de Arquitectura Foliar (Figs. 1-4).

A continuación se presenta una lista de los caracteres que se agregaron o modificaron de los que se encuentran definidos en el Manual de Arquitectura Foliar (Leaf 
Architecture Working Group, 1999). Para aquellos caracteres en los que únicamente se modificaron estados de carácter, se indica el nombre del carácter, el nombre con que se definió a este nuevo estado de carácter en este estudio, así como una pequeña descripción de dicho estado de carácter con un esquema (Fig. 1). Para los caracteres que fueron agregados, se proporciona de igual manera una descripción del carácter así como de los estados que lo componen (Figs. 2-4).

Caracteres con estados de carácter modificados (Fig. 1)

Arreglo de las hojas (Fig. 1a)

i) pseudoverticilado: se encuentra una sola hoja por nudo pero los entrenudos son muy cortos, dando la apariencia de ser verticilado; comúnmente, las hojas son terminales.

Simetría de la lámina (Fig. 1b)

i) ligeramente asimétrica: la lámina tiene forma diferente a cada lado de la vena media aunque su tamaño es aproximadamente el mismo.

ii) ligeramente asimétrica en la base: la base de la lámina tiene forma diferente a cada lado pero el punto de unión con el pecíolo es el mismo en ambos lados.

Forma de la base (Fig. 1c)

i) convexa/cuneada: la base es convexa de un lado y cuneada del otro.

ii) convexa/cordada: la base es convexa de un lado y cordada del otro.

iii) convexa/cóncavo: convexa-la base es convexa de un lado y cóncavo-convexa del otro.

iv) cuneada/cóncavo: convexa-la base es cuneada de un lado y cóncavo-convexa del otro.

Inserción del pecíolo/peciólulo (Fig. 1d)

i) sésil: la lámina carece de pecíolo/peciólulo.

Forma del ápice (Fig. 1e)

i) retuso-acuminado: el ápice es acuminado pero, además, presenta una muesca que no alcanza a rebasar el 5\% de la longitud de la lámina.

Venación secundaria (Fig. 1f)

i) cladódroma I: se refiere a la venación cladódroma típica, donde las venas secundarias se ramifican (dicotomizan) libremente hacia el margen.

ii) cladódroma II: es un tipo de cladódroma, donde las venas se dicotomizan, y las ramificaciones de dos venas adyacentes pueden llegar a tocarse dando la apariencia de formar arcos (parece broquidódroma); sin embargo, éstos "arcos" no son producto de una vena que se curva hasta tocar a su adyacente, sino de ramificaciones de venas dicótomas. Espaciado de las venas secundarias (Fig. 1g)

i) disminuye hacia los extremos: el espacio entre las venas es menor conforme se acerca al ápice o a la base, encontrándose el mayor espaciado en la parte media de la lámina.

Venación de tercer orden (Fig. 1h)

i) mezcla de opuesta/alterna/dicótoma:se presentan venas que cruzan de una vena secundaria a la adyacente sin ramificarse (opuestas), venas que cruzan de una vena secundaria a la adyacente teniendo un cambio abrupto en su dirección (alternas) así como venas que no llegan a la vena secundaria adyacente, sino que se ramifican libremente (dicótomas).

Ángulo de las venas de tercer orden (Fig. 1i)

i) obtuso/agudo: algunas venas presentan ángulo obtuso mientras que a la vez otras presentan ángulo agudo con respecto a la vena primaria.

Venación de cuarto orden (Fig. 1j)

i) mezcla de opuesta/alterna: se presentan algunas venas que cruzan de una vena terciaria a la adyacente sin ramificarse (opuestas) así como otras venas que cruzan de una vena terciaria a la adyacente mostrando un cambio abrupto de dirección en su curso (alternas).

Caracteres nuevos (Figs. 2-4)

Arreglo de los folíolos: de manera semejante al arreglo de las hojas sobre el tallo (filotaxia), los folíolos presentan distintos arreglos sobre el raquis (Fig. 2a)

i) alterno: nace un solo folíolo en cada punto de ramificación del raquis.

ii) opuesto: nacen dos folíolos en cada punto de ramificación del raquis, uno frente al otro.

Raquis: En hojas compuestas, la continuación del pecíolo dentro de la lámina es el raquis (Fig. 2b)

i) simple: el raquis no presenta proyecciones de lámina.

ii) alado: el raquis presenta proyecciones de lámina a los lados.

Proyección de la vena media: La vena media de la hoja se proyecta más allá del margen de la hoja formando lo que se conoce como mucrón; en ocasiones, forma una espina (Fig. 2c)

i) ausente: no se presenta la proyección.

ii) presente: la proyección se presenta.

Ubicación de los dientes: en hojas dentadas, crenadas o serradas, los dientes pueden encontrarse sólo en una zona (Fig. 2d)

i) en todo el margen: los dientes se encuentran a todo lo largo del margen, desde la base hasta el ápice.

ii) 2/5 distales: los dientes sólo se encuentran en la parte distal de la lámina; en la parte basal, el margen carece de dientes.

Venación del diente: la vena principal es la vena que entra al diente y llega al ápice de éste (Fig. 2e)

i) no hay venas: el diente no presenta venas; en general, son dientes muy pequeños.

ii) pequeñas venas: no hay una vena principal, pero sí hay pequeñas venas al interior del diente.

iii) vena primaria: la vena principal del diente es una vena primaria.

iv) vena secundaria: la vena principal del diente es una vena secundaria que no presenta ramificaciones mayores en su curso. 


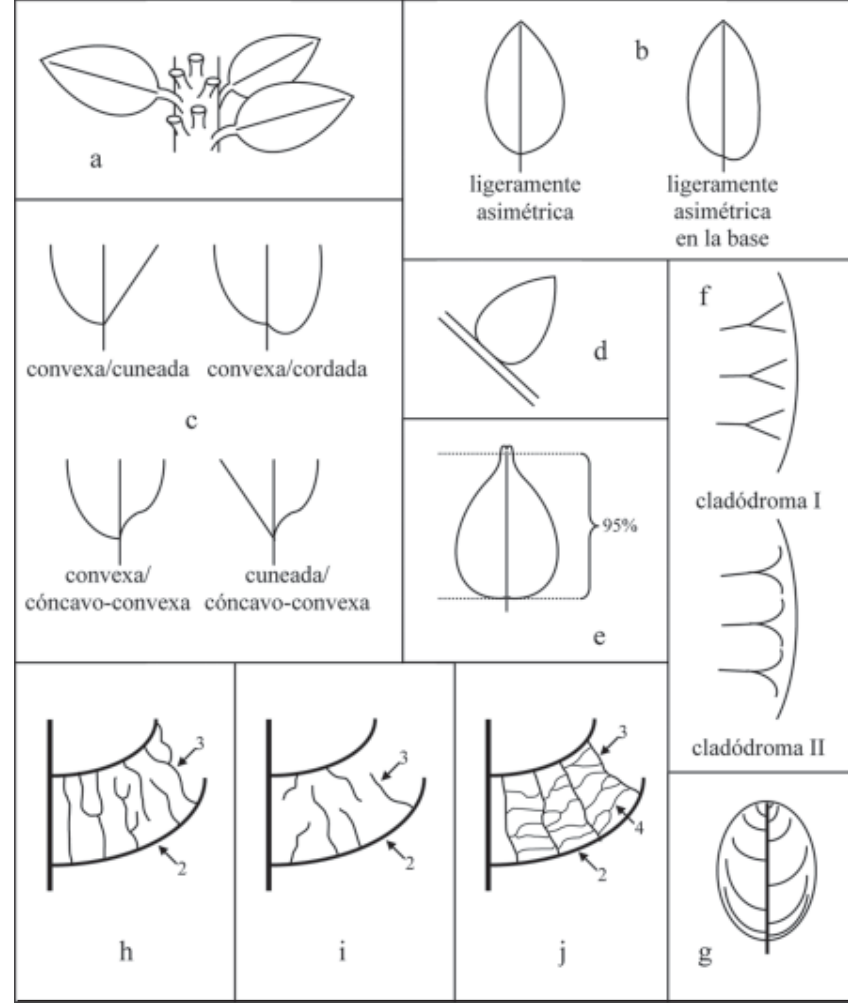

Figura 1. Caracteres definidos en Leaf Architecture Working Group (1999) con estados de carácter modificados. a, arreglo de las hojas: pseudoverticilado; b, simetría de la lámina; c, forma de la base; d, inserción del pecíolo/peciólulo: sésil; e, forma del ápice: retuso-acuminado; f, venación secundaria; g, espaciado de las venas secundarias: disminuye hacia los extremos; h, venación de tercer orden: mezcla de opuesta/alterna/dicótoma; i, ángulo de las venas terciarias: obtuso/agudo; j, venación de cuarto orden: mezcla de opuesta/alterna.

v) dicotomía distal: la vena principal del diente corresponde con la rama distal proveniente de una dicotomía de una vena secundaria.

vi) dicotomía proximal: la vena principal del diente corresponde con la rama proximal proveniente de una dicotomía de una vena secundaria.

vii) dicotomía al seno: la vena secundaria forma una dicotomía, la rama distal se dirige al diente pero llega al seno, no al ápice; hay además pequeñas venas al interior del diente.

viii) vena terciaria: la vena principal del diente es una vena de tercer orden.

ix) vena de cuarto orden: la vena principal del diente es una vena de cuarto orden.

Ubicación de los estomas: los estomas pueden encontrarse únicamente en una de las superficies de la hoja o en ambas (Fig. 3a)

i) en el envés: los estomas sólo se encuentran en el envés, hoja hipostomática.

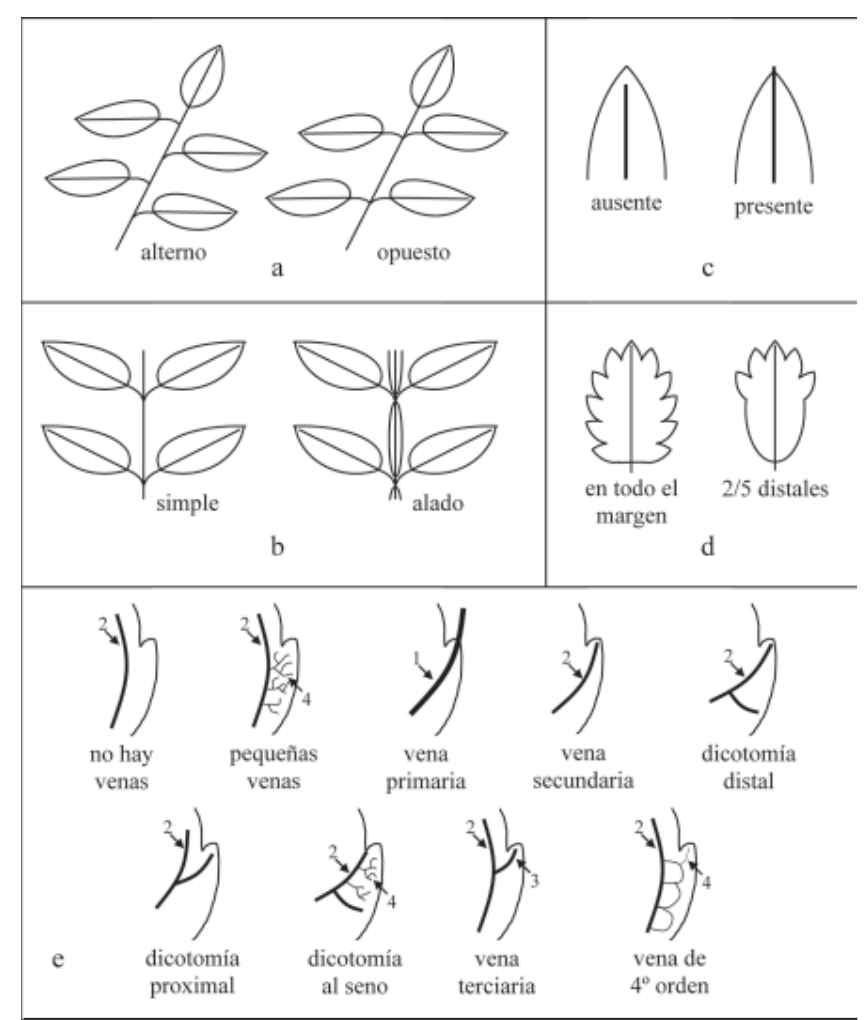

Figura 2. Caracteres no definidos en Leaf Architecture Working Group (1999). a, arreglo de los folíolos; b, raquis; c, proyección de la vena media; d, ubicación de los dientes; e, venación del diente.

ii) en ambas: los estomas se encuentran tanto en el haz como en el envés, hoja anfistomática.

Tricomas: son células epidérmicas modificadas a manera de pelos (Fig. 3b)

i) ausentes-no se presentan tricomas en la hoja.

ii) escasos-se presentan pocos tricomas, muy espaciados entre sí, a 200x se observan menos de 10 tricomas en un campo.

iii) moderados-se presentan tricomas en cantidad suficiente para ser evidentes incluso a simple vista pero al microscopio permiten la observación de las células epidérmicas.

iv) abundantes-se presentan tricomas en cantidad tan grande que al microscopio dificultan la observación de las células epidérmicas.

Distribución de los tricomas no glandulares: los tricomas pueden encontrarse zonificados, es decir, sólo se desarrollan en algunas partes de la hoja (Fig. 3c)

i) sobre las venas: los tricomas se asocian a las venas, creciendo únicamente sobre ellas.

ii) toda la superficie: los tricomas crecen sobre toda la lámina, en áreas intercostales.

iii) en el margen: los tricomas únicamente están en el margen de la hoja, no en su superficie. 


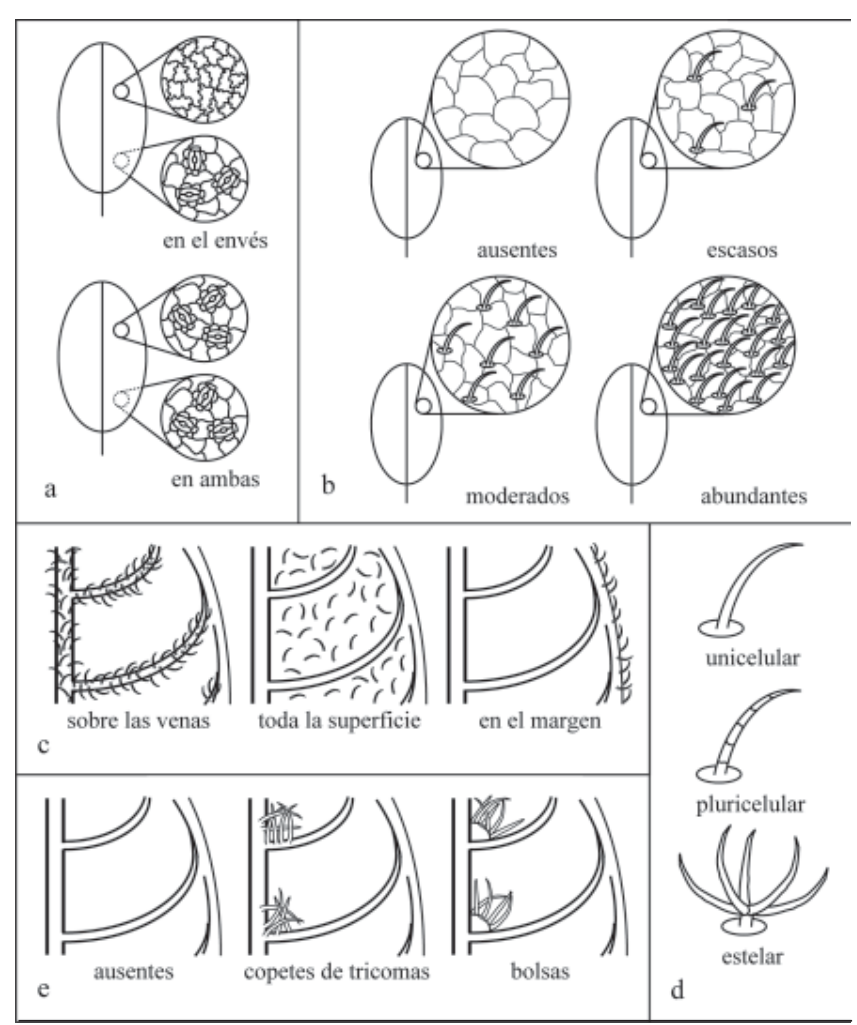

Figura 3. Caracteres no definidos en Leaf Architecture Working Group (1999). a, ubicación de los estomas; b, tricomas; c, distribución de los tricomas no glandulares; d, tipo de tricoma no glandular; e, domacios.

Tipo de tricoma no glandular: los tricomas de revestimiento, pueden estar formados por una sola célula o por varias, y su forma puede variar (Fig. 3d)

i) unicelular: el tricoma esta formado por una sola célula, en forma de pelo simple.

ii) pluricelular: el tricoma esta formado por varias células, formadas en línea y con forma de pelo.

iii) estelar:el tricoma presenta varios brazos y un corto pedúnculo.

Domacios: por definición, son depresiones, sacos, bolsas o copetes de tricomas que se encuentran en las axilas de la vena primaria y que ocurren únicamente en la cara abaxial de la hoja, presumiblemente son lugares de habitación para huéspedes que están al servicio de la planta pero que no le causan daño (Wilkinson, 1979) (Fig. 3e)

i) ausentes: no se presentan domacios.

ii) copetes de tricomas: los domacios están formados únicamente por tricomas.

iii) bolsas con tricomas: los domacios son de tipo bolsa o bolsillo donde nacen tricomas.

Tricomas glandulares: algunos tricomas son de forma globosa con un pedúnculo, estos tricomas son de tipo glandular (Fig. 4a).

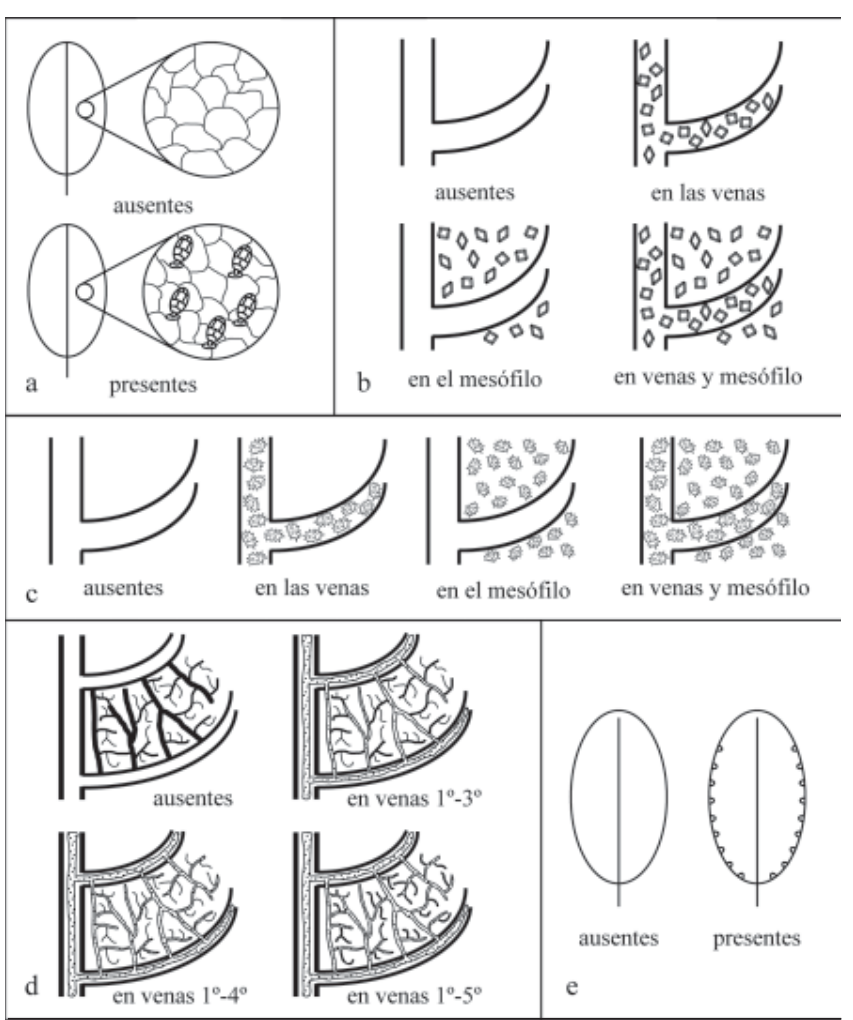

Figura 4. Caracteres no definidos en Leaf Architecture Working Group (1999). a, tricomas glandulares; b, cristales prismáticos; c, drusas; d, depósitos en canales resiníferos; e, glándulas marginales.

i) ausentes: no se presentan tricomas glandulares.

ii) presentes: se presentan tricomas glandulares.

Cristales prismáticos: material ergástico al interior de las células, los cristales prismáticos tienen forma romboidal y están formados por oxalato de calcio (Fig. 4b)

i) ausentes: no se presentan cristales prismáticos.

ii) sólo en las venas: los cristales se encuentran únicamente al interior de las venas.

iii) sólo en el mesofilo: los cristales se encuentran únicamente al interior de las células del mesofilo.

iv) en las venas y el mesofilo: los cristales se encuentran tanto al interior de las venas como en las células del mesofilo.

Drusas: material ergástico en el interior de las células, las drusas tienen forma de estrella y están formadas generalmente por oxalato de calcio (Fig. 4c)

i) ausentes: no se presentan drusas.

ii) sólo en las venas: las drusas se encuentran únicamente al interior de las venas.

iii) sólo en el mesofilo: las drusas se encuentran únicamente al interior de las células del mesofilo.

iv) en las venas y el mesofilo: las drusas se encuentran tanto al interior de las venas como en las células del mesofilo. 
Depósitos en canales resiníferos: asociados a las venas, se pueden encontrar canales productores de resina. Algunas resinas se tornan obscuras al aplicar la técnica de aclarado y hacen que el canal resinífero sea observable (debido precisamente a estos depósitos obscuros) (Fig. 4d)

i) ausente: no se encuentran depósitos obscuros (los canales, si los hay, no se observan).

ii) en venas primarias a terciarias: se observan depósitos en los canales en venas primarias, secundarias y terciarias.

iii) en venas primarias a las de cuarto orden: se observan depósitos en los canales en venas primarias, secundarias, terciarias y de cuarto orden.

iv) en venas primarias a las de quinto orden: se observan depósitos en los canales en venas primarias, secundarias, terciarias, de cuarto orden y de quinto orden.

Glándulas marginales: a lo largo del margen se pueden encontrar glándulas pluricelulares (Fig. 4e)

i) ausentes: no se presentan glándulas.

ii) presentes: se presentan glándulas.

\section{Resultados}

Arquitectura foliar de Anacardiaceae

La arquitectura foliar de cada uno de los géneros estudiados de Anacardiaceae se describe a continuación. Los nombres de especies marcados con asterisco indican que sólo se observaron en material de herbario y que no hay ejemplares aclarados. En dichos ejemplares, sólo se observaron las características bajo el apartado "organización macroscópica”. La proporción largo/ancho, el ángulo del ápice y el ángulo de la base no fueron medidos en esos ejemplares; por tanto, las medidas registradas se refieren únicamente a los ejemplares aclarados. Dichas medidas se registran en el Cuadro 5 para cada especie. En esta sección, la notación indica el valor mínimo y el valor máximo observado para cada género, el número entre paréntesis corresponde al promedio de las observaciones; así por ejemplo, el ángulo de la base de Actinocheita, registrado como $54^{\circ}-\left(59.625^{\circ}\right)-74^{\circ}$ indica que el ángulo varía entre $54^{\circ}$ y $74^{\circ}$ pero el promedio de todas las observaciones realizadas es $59.625^{\circ}$. En el caso de los cristales, únicamente se registran aquellos observados, de modo que si no se registra el tipo de cristal, significa que las muestras observadas carecen de ese tipo de cristal. Los canales resiníferos se distinguieron gracias a los depósitos obscuros que algunos presentan; sin embargo, es posible que en algunos casos no se hayan detectado, lo cual se debe a la técnica empleada para aclarar las hojas y a que no se realizaron cortes transversales donde hubiera sido posible observarlos. Los géneros están en orden alfabético.

1) Género: Actinocheita F. A. Barkley. (Fig. 5a-d). Especie tipo: A. filicina (Moç. et Sessé ex DC.) F. A. Barkley.
Ejemplares aclarados: A. filicina (Moç. et Sessé ex DC.) F. A. Barkley (FCME-FTSVC 449, México).

Ejemplares complementarios: A. filicina (Moç. et Sessé ex DC.) F. A. Barkley (MEXU-E. Guízar 1074, México).

Distribución: México.

Descripción: Organización macroscópica. Hojas alternas, compuestas imparipinnadas con folíolos alternos sésiles de textura cartácea, de forma ovada simétrica, con base cordada, ápice recto y margen dentado (A. filicina* puede presentar a veces forma oblonga ó ápice acuminado). El tamaño de los folíolos es micrófilo, la proporción largo/ancho 2.26:1(3.48:1)-4.72:1. Ángulo de la base de $54^{\circ}\left(59.625^{\circ}\right)-74^{\circ}$ y el del ápice, $41^{\circ}\left(46.22^{\circ}\right)-57^{\circ}$.

Venación. La primaria es de tipo pinnada. La secundaria craspedódroma con 3 venas basales espaciadas uniformemente, y su ángulo con respecto a la vena primaria aumenta ligeramente hacia labase. Hay venas intersecundarias aunque son débiles. La venación terciaria presenta arreglo mixto/dicótomo (algunas venas opuestas, algunas alternas percurrentes y otras dicótomas), su curso es ramificado exmedialmente y el ángulo con respecto a la vena primaria, obtuso que decrece exmedialmente. La de cuarto orden presenta tanto patrón dicótomo como opuesto percurrente. Las del quinto orden forman un retículo poligonal regular con areolas moderadamente desarrolladas donde las últimas venas libres pueden ser no ramificadas ó ramificadas una o más veces. El orden más alto de venación es el sexto, y el cuarto es el último que presenta ramificación excurrente. La venación marginal es libre (arcos incompletos). El grado de organización de la hoja es $2 \mathrm{r}$.

Dientes. Hay dos órdenes de dientes (de dos tamaños diferentes) distribuidos regularmente, dos por centímetro a todo lo largo del margen. El lado apical y el basal son convexos; el ápice es simple y el seno angular. La vena principal del diente es una vena secundaria que nace directamente de la primaria.

Características epidérmicas. Los estomas son de tipo policítico-anomocítico ubicados únicamente en el envés. Tricomas abundantes; los de tipo simple unicelular están en toda la superficie y los pluricelulares principalmente sobre las venas.

Cristales y canales resiníferos. Se encuentran drusas tanto en el interior de las venas como en el mesofilo. Se localizan canales resiníferos en las venas del primero al cuarto orden.

2) Género: Amphipterygium Schiede ex Standl. (Fig. 5e-g, j). Especie tipo: A. adstringens (Schltdl.) Standl.

Ejemplares aclarados: A. adstringens (Schltdl.) Standl (MEXU-M. Provance 1567, México).

Ejemplares complementarios: A. molle Hemsl. et Rose (MEXU-J. González 375, Costa Rica).

Distribución: México, Guatemala, Honduras, Costa Rica.

Descripción: Organización macroscópica. Hojas con arreglo pseudoverticilado, compuestas imparipinnadas con folíolos 
opuestos sésiles de textura membranácea (A. molle* tiene hojas trifoliadas con textura cartácea), de forma ovada con base asimétrica, convexa en ambos lados; ápice recto (convexo en A. molle*) y margen serrado. El tamaño de los folíolos es micrófilo, la proporción largo/ancho es 3.84:1. Ángulo de la base de $53^{\circ}$ y el del ápice $24^{\circ}$.

Venación. La venación primaria es pinnada. La secundaria es craspedódroma con 4 venas basales, el espacio entre las venas secundarias disminuye hacia la base y hacia el ápice y su ángulo, respecto a la vena primaria, disminuye hacia la base. Las venas intersecundarias son débiles. La venación terciaria presenta un arreglo mixto, con venas opuestas y alternas percurrentes, su curso es sinuoso y el ángulo respecto a la vena primaria es obtuso pero inconsistente. La de cuarto orden presenta el patrón reticulado poligonal regular. Las venas de quinto orden también forman un retículo poligonal regular. Las areolas están bien desarrolladas y las últimas venas libres son muy ramificadas (dos o más veces). El orden más alto de venación es el sexto; el último que presenta ramificación excurrente, el quinto. La venación marginal forma arcos. El grado de organización de la hoja es 3r.

Dientes. Hay dos órdenes de dientes distribuidos regularmente a todo lo largo del margen; se encuentran unos 3 por centímetro. El lado apical del diente puede ser recto o convexo; el basal es convexo, recto o flexo; el ápice es glandular y el seno es angular. La vena principal es una secundaria que nace directamente de la primaria.

Características epidérmicas. Los estomas son de tipo policítico-actinocítico; se localizan únicamente en el envés. En toda la superficie del folíolo, se presentan tricomas de tipo pluricelular y glandular en cantidad moderada.

Cristales y canales resiníferos. Cristales prismáticos únicamente al interior de las venas, las drusas se encuentran dentro de las venas y en el mesofilo. No se observan canales resiníferos.

3) Género: Anacardium L. (Fig. 5h-i).

Especie tipo: A. occidentale L.

Ejemplares aclarados: A. excelsum Skeels (CAS-Almeda 4216, Costa Rica), A. occidentale L. (Colección personal de la Dra. Terrazas, Costa Rica).

Ejemplares complementarios: A. excelsum Skeels (MEXUW. Burger, G. Visconti y J. Gentry, Costa Rica), A. giganteum Hancock ex Engl (MEXU-R. Vázquez y N. Jaramillo 6079, Perú), A. humile A. St.-Hil (MEXU-I. G. Vargas C. 3857, Bolivia), A. microcarpum Ducke (MEXU-J. Elías de Paula 3.315, Brasil), A. nanum St. Hil. (MEXU-G. Hatschbach 49618 y R. Kummrow, Brasil), A. occidentale L. (MEXUA. Benítez Paredes 3817, México), A. parvifolium Ducke (MEXU-G. Hartshorn et al. 2977, Perú).

Distribución: México, Centroamérica, Sudamérica tropical. Descripción: Organización macroscópica. Hojas simples con arreglo pseudoverticilado, textura coriácea e inserción del pecíolo marginal, de forma elíptica u obovada (elíptica en
A. excelsum, A. occidentale y A. parvifolium* y obovada en A. excelsum*, A. giganteum*, A. humile*, A. microcarpum*, A. nanum* y A. parvifolium*), simétricas, con base cuneada, decurrente o convexa (cuneada en A. excelsum*, A. humile*, A. occidentale y A. parvifolium*, decurrente en A. giganteum* y convexa en $A$. excelsum, A. microcarpum*, A. nanum* y A. occidentale). El ápice convexo y el margen entero (ápice retuso en A. microcarpum*, A. nanum* y A. parvifolium* y ocasionalmente retuso en $A$. excelsum). El tamaño de las hojas es principalmente mesófilo aunque puede ser notófilo en algunos ejemplares de $A$. excelsum. La proporción largo/ancho es 1.92:1 (1.93 en $A$. excelsum y 1.91:1 en $A$. occidentale). El ángulo de la base es de $79.25^{\circ}\left(81.5^{\circ}\right.$ en $A$. excelsum y $77^{\circ}$ en $A$. occidentale $)$ y el del ápice $87.75^{\circ}\left(89.5^{\circ}\right.$ en $A$. excelsum y $86^{\circ}$ en $A$. occidentale).

Venación. La venación primaria es pinnada. La secundaria eucamptódroma(A.excelsum)o cladódromaII(A.occidentale) con 4 o 5 venas basales ( 4 en A. occidentale, 5 en A. excelsum). Las venas secundarias están espaciadas uniformemente y su ángulo respecto a la vena primaria aumenta ligeramente hacia la base. Hay venas intersecundarias, aunque son débiles (en ocasiones ausentes en A. excelsum). La terciaria es principalmente alterna percurrente (A. occidentale), a veces se puede mezclar con la opuesta percurrente formando el patrón mixto (A. excelsum) o incluso también con el dicótomo formando un patrón opuesto/alterno/dicótomo (A. excelsum), curso ramificado exmedialmente (algunas son rectas en algunos ejemplares de $A$. excelsum) y el ángulo respecto a la vena primaria es obtuso (ocasionalmente algunas son agudas en $A$. excelsum). El ángulo puede ser uniforme (A. excelsum), decrecer exmedialmente (A. excelsum) o aumentar basalmente (A. occidentale). La venación de cuarto orden presenta el patrón reticulado poligonal regular. Las venas de quinto orden forman un retículo poligonal regular con areolas bien desarrolladas donde las últimas venas libres están ramificadas dos o más veces (en ocasiones son dicótomas o forman areolas moderadamente desarrolladas en A. excelsum). El orden más alto de venación es el sexto, y el último que presenta ramificación excurrente, el cuarto (quinto en algunos ejemplares de A. excelsum). La venación marginal forma arcos. El grado de organización de la hoja es $3 r$.

Características epidérmicas. Estomas de tipo policíticoanomocítico ubicados únicamente en el envés. Tricomas de escasos a moderados en $A$. excelsum o completamente ausentes en A. occidentale. Cuando se presentan, se localizan en toda la superficie de la hoja, son de tipo simple unicelular y más raramente pluricelular.

Cristales y canales resiníferos. Ocasionalmente se presentan cristales prismáticos en las venas y drusas en el mesofilo de A. excelsum. No se observan canales resiníferos.

4) Género: Antrocaryon Pierre (Fig. 6a-d). Especie tipo: A. klaineanum Pierre. 
Cuadro 5. Relación de medidas de la lámina de las diferentes especies de Anacardiaceae.

\begin{tabular}{|c|c|c|c|c|}
\hline Especie & $\operatorname{Largo}(\mathrm{cm}) *$ & Ancho $(\mathrm{cm})^{*}$ & Ángulo del ápice & Ángulo de la base \\
\hline Actinocheita filicina & $3.58-5.57$ & $1.15-1.63$ & $41-57$ & $49-74$ \\
\hline Amphipterygium adstringens & 5.35 & 1.39 & 24 & 53 \\
\hline Anacardium excelsum & $9.91-13.06$ & $5.55-6.25$ & $77-102$ & $77-86$ \\
\hline Anacardium occidentale & 11.55 & 6.02 & 86 & 77 \\
\hline Antrocaryon micraster & $?$ & $?$ & $?$ & $?$ \\
\hline Astronium conzattii & $5.21-6.75$ & $1.96-2.54$ & $41-49$ & $70-74$ \\
\hline Astronium fraxinifolium & 7.17 & 2.73 & 48 & 81 \\
\hline Astronium graveolens & $2.29-3.31$ & $0.79-1.32$ & $38-55$ & $63-84$ \\
\hline Astronium lecointei & 11.55 & 5.15 & 60 & 88 \\
\hline Blepharocarya depauperata & 4.15 & 2.28 & 83 & 77 \\
\hline Bonetiella anomala & $2.03-2.62$ & $0.45-0.49$ & $34-39$ & $28-30$ \\
\hline Bouea oppositifolia & 11.28 & 3.68 & 43 & 58 \\
\hline Buchanania acuminata & 10.72 & 4.68 & 70 & 63 \\
\hline Buchanania acuminatissima & 10.17 & 3.64 & 64 & 49 \\
\hline Buchanania florida & 8.90 & 3.86 & 72 & 63 \\
\hline Buchanania palawensis & $12.23-12.83$ & $5.86-5.96$ & $83-84$ & $70-72$ \\
\hline Buchanania reticulata & 12.19 & 3.67 & 54 & 55 \\
\hline Campnosperma auriculata & 11.80 & 4.05 & $?$ & 52 \\
\hline Campnosperma montana & 11.24 & 3.25 & 57 & 39 \\
\hline Cardenasiodendron brachypterum & $4.39-5.43$ & $1.37-1.62$ & $28-34$ & $59-63$ \\
\hline Comocladia engleriana & $6.55-11.42(9.39)$ & $4.26-6.73(5.15)$ & $87-99$ & $87-112$ \\
\hline Comocladia guatemalensis & $6.23-6.71$ & $4.27-4.54$ & $98-101$ & $103-108$ \\
\hline Comocladia ilicifolia & 1.64-1.67 & $1.45-1.56$ & $105-108$ & $134-138$ \\
\hline Comocladia mollissima & $4.96-7.19(6.05)$ & $2.93-4.88(3.54)$ & $75-102$ & $83-123$ \\
\hline Comocladia palmeri & $6.16-6.93(10.03)$ & $3.24-3.81(5.85)$ & $85-95$ & $89-95$ \\
\hline Comocladia platyphylla & 9.63 & $5.23-5.72$ & 69 & $89-95$ \\
\hline Cotinus coggygria & 4.05 & 3.27 & 106 & 110 \\
\hline Cyrtocarpa procera & $3.00-4.67(4.17)$ & $1.34-1.53(1.45)$ & $41-61$ & $58-89$ \\
\hline Choerospondias axillaris & 7.04 & 2.88 & 37 & 72 \\
\hline Dracontomelon cumingianum & $10.41-10.93$ & $3.10-3.17$ & $48-50$ & $56-67$ \\
\hline Dracontomelon dao & 5.94 & 2.26 & 48 & 67 \\
\hline Euroschinus falcatus & 8.13 & 3.78 & 64 & 83 \\
\hline Gluta tavoyana & 10.09 & 3.96 & 62 & 60 \\
\hline Haplorhus peruviana & $9.08-9.67$ & $0.46-0.63$ & $12-15$ & $11-13$ \\
\hline Harpephyllum caffrum & 5.35 & 1.64 & 31 & 60 \\
\hline Koordersiodendron pinnatum & 9.37 & 2.93 & 47 & 69 \\
\hline Lannea grandis & 9.87 & 4.85 & 64 & 87 \\
\hline Laurophyllus capensis & 5.08 & 1.85 & 68 & 52 \\
\hline Lithraea caustica & $3.48-4.73$ & $1.86-2.54$ & $76-83$ & $75-78$ \\
\hline Lithraea ternifolia & $3.76-5.05(5.62)$ & $0.73-1.08(0.87)$ & $21-31$ & $36-43$ \\
\hline Loxopterygium grisebachii & $5.91-6.18$ & $2.64-3.18$ & $50-63$ & $80-91$ \\
\hline Loxopterygium sagotii & 6.01 & 3.28 & 75 & 90 \\
\hline Loxostylis alata & 4.32 & 0.85 & 30 & 39 \\
\hline Malosma laurina & 7.94 & 2.96 & 43 & 77 \\
\hline Mangifera indica & 12.66 & 4.55 & 71 & 60 \\
\hline Mangifera verticillata & $10.17-10.97$ & $4.65-5.65$ & $72-89$ & $52-65$ \\
\hline Mauria aurantiodora & 8.82 & 3.84 & 68 & 72 \\
\hline Mauria sessiliflora & $7.22-10.54$ & $2.38-2.92$ & $36-60$ & $46-61$ \\
\hline Mauria simplicifolia & $6.75-9.94$ & $3.68-5.17$ & $65-109$ & 64-108 \\
\hline Melanochyla auriculata & 5.01 & 2.93 & 95 & 96 \\
\hline Metopium brownei & $5.12-7.65$ & $3.88-4.08$ & $74-91$ & $90-107$ \\
\hline
\end{tabular}


Cuadro 5. Continuación

\begin{tabular}{|c|c|c|c|c|}
\hline Especie & Largo $(\mathrm{cm}) *$ & Ancho $(\mathrm{cm})^{*}$ & Ángulo del ápice & Ángulo de la base \\
\hline Mosquitoxylum jamaicense & 7.33 & 2.82 & 68 & 59 \\
\hline Myracrodruon balansae & 4.46 & 1.85 & 55 & 73 \\
\hline Myracrodruon urundeuva & 6.29 & 2.87 & 56 & 79 \\
\hline Nothopegia beddomei & 7.37 & 1.90 & 47 & 41 \\
\hline Ochoterenaea colombiana & 9.02 & 2.95 & 57 & 68 \\
\hline Operculicarya decaryi & 0.96 & 0.65 & 115 & 90 \\
\hline Ozoroa paniculosa & 4.64-7.38 & $1.41-2.00$ & $45-50$ & $50-56$ \\
\hline Pachycormus discolor & $0.44-0.65(0.58)$ & $0.28-0.47(0.57)$ & $94-116$ & $81-118$ \\
\hline Parishia insignis & 7.20 & 4.14 & 72 & 100 \\
\hline Pegia nitida & 4.34 & 2.26 & 58 & 90 \\
\hline Pentaspadon motleyi & 10.14 & 4.05 & 55 & 67 \\
\hline Pistacia khinjuk & 4.68-4.76 & $2.75-2.77$ & $82-87$ & $89-93$ \\
\hline Pistacia mexicana & $1.83-2.26(2.13)$ & $0.64-0.93(0.83)$ & $55-71$ & $54-80$ \\
\hline Pistacia weinmannifolia & $1.20-1.53$ & $0.57-0.62$ & $67-80$ & $62-92$ \\
\hline Pleiogynium solandri & $6.16-7.96$ & $2.78-2.80$ & $50-65$ & $59-76$ \\
\hline Poupartia pinnata & $9.89-11.02$ & $4.03-4.41$ & $52-55$ & $72-73$ \\
\hline Protorhus longifolia & 6.00 & 1.56 & 50 & 40 \\
\hline Pseudosmodingium andrieuxii & $2.19-3.30(2.77)$ & $0.28-0.53(0.34)$ & $15-19$ & $22-37$ \\
\hline Pseudosmodingium barkleyi & $5.32-6.71$ & $4.37-5.87$ & $115-133$ & $114-126$ \\
\hline Pseudosmodingium perniciosum & $4.41-5.03(4.99)$ & $2.66-3.54(3.06)$ & $95-112$ & $61-84$ \\
\hline Pseudospondias microcarpa & 13.76 & 4.49 & 64 & 61 \\
\hline Rhodosphaera rhodanthema & 5.44 & 2.32 & 64 & 66 \\
\hline Rhus galeottii & $3.44-4.37(5.13)$ & $2.06-2.57(3.15)$ & $82-95$ & $90-95$ \\
\hline Rhus nelsonii & $3.55-4.96(5.57)$ & $1.14-2.19(2.37)$ & $47-71$ & $67-91$ \\
\hline Rhus taratana & 8.77 & 4.08 & 87 & 75 \\
\hline Rhus terebinthifolia & $4.68-4.96(6.55)$ & $2.91-3.33(3.65)$ & $75-94$ & $97-113$ \\
\hline Sclerocarya birrea & 2.37 & 1.30 & 81 & 81 \\
\hline Schinopsis brasiliensis & $1.57-2.07$ & $0.72-1.05$ & $87-97$ & $70-83$ \\
\hline Schinopsis lorentzii & $1.73-2.16$ & $0.63-0.71$ & $40-44$ & $58-69$ \\
\hline Schinus dependens & $2.94-3.37$ & $0.55-0.64$ & $23-39$ & $20-28$ \\
\hline Schinus latifolius & $3.41-5.43$ & $2.41-3.00$ & $82-94$ & $83-98$ \\
\hline Schinus lentiscifolius & $2.32-2.76$ & $0.46-0.65$ & $35-45$ & $33-43$ \\
\hline Schinus meyeri & 6.80 & 3.26 & 63 & 83 \\
\hline Schinus molle & $1.08-4.28$ & $0.27-0.64$ & $15-30$ & $22-39$ \\
\hline Schinus venturii & 5.37 & 1.99 & 52 & 60 \\
\hline Schinus weinmanniaefolius & $2.06-2.86(3.25)$ & $1.19-1.69$ (1.94) & $79-94$ & $67-85$ \\
\hline Semecarpus curtisii & 17.58 & 4.96 & 50 & 45 \\
\hline Semecarpus venenosa & 20.06 & 3.82 & 29 & 15 \\
\hline Smodingium argutum & 5.85 & 1.24 & 31 & 36 \\
\hline Sorindeia madagascariensis & 7.09 & 4.65 & 83 & 104 \\
\hline Spondias lutea & $5.47-6.75$ & 2.91-3.02 & $65-76$ & $75-87$ \\
\hline Spondias mombin & 8.37 & 2.87 & 43 & 61 \\
\hline Spondias nigrescens & 10.88 & $4.56-5.63$ & 66 & $67-82$ \\
\hline Spondias philippinensis & 9.93 & $3.57-4.94$ & 48 & $70-77$ \\
\hline Spondias purpurea & $3.73-5.74(3.97-5.33)$ & $1.64-2.49(2.10-2.34)$ & $62-89$ & $48-75$ \\
\hline Spondias radlkoferi & $11.07-11.38$ & $4.17-4.58$ & $57-64$ & $66-71$ \\
\hline Swintonia floribunda & 14.89 & 6.15 & 73 & 72 \\
\hline Tapirira mexicana & $8.74-14.98$ & $3.04-5.46$ & $42-43$ & $66-68$ \\
\hline Thyrsodium paraense & 9.15 & 3.62 & 68 & 64 \\
\hline Toxicodendron radicans & $5.55-6.45(6.02)$ & $3.00-3.38(4.11)$ & $60-65$ & $88-90$ \\
\hline Trichoscypha acuminata & 19.83 & 6.41 & 47 & 66 \\
\hline
\end{tabular}

*La medida se registra como mínimo-máximo cuando se revisó más de una muestra o como una sola medida si sólo se revisó una muestra de la especie. Las medidas se refieren a hojas en aquellas especies con hojas simples y a folíolos laterales en las especies con hojas compuestas. En las hojas imparipinnadas, el número entre paréntesis indica la medida del folíolo apical. 


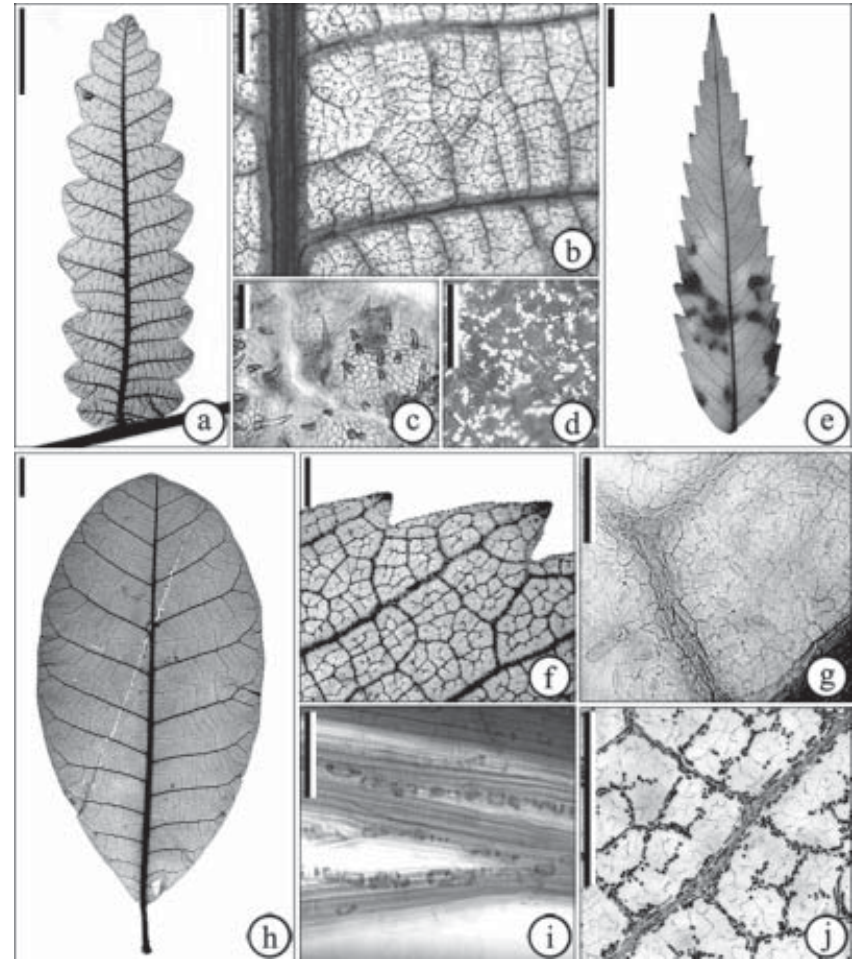

Figura 5. Actinocheita, Amphipterygium y Anacardium. a-d, Actinocheita. a, folíolo de A. filicina (escala $=1 \mathrm{~cm}) ; \mathrm{b}$, venación de tercer orden de $A$. filicina (escala $=1 \mathrm{~mm}$ ); c, tricomas de $A$. filicina $($ escala $=100 \mu) ; d$, drusas en el mesofilo de A. filicina (escala $=500 \mu)$. e-g, j, Amphipterygium; e, folíolo de A. adstringens (escala=1 cm); $\mathrm{f}$, dientes con ápice glandular de $A$. adstringens (escala $=1 \mathrm{~mm}$ ) $\mathrm{g}$, estomas y tricomas glandulares de $A$. adstringens (escala $=100$ $\mu) ; \mathrm{j}$, drusas en las venas de $A$. adstringens (escala $=1 \mathrm{~mm}$ ). h-i, Anacardium. h, hoja de $A$. occidentale (escala $=1 \mathrm{~cm}$ ); i, cristales prismáticos en las venas de $A$. excelsum (escala $=100 \mu$ ).

Ejemplares aclarados: A. micraster A. Chevalier et A. Guillaumin (US-J. Vouis 11388, Congo).

Ejemplares complementarios: A. amazonicum (Ducke) B. L. Burtt et A. W. Hill (MEXU-M. Silveira et al. s/n, Brasil).

Distribución: Brasil, Zaire, Congo, Costa de Marfil.

Descripción: Organización macroscópica. Hojas compuestas paripinnadas de arreglo pseudoverticilado y folíolos opuestos (A. amazonicum*). Folíolos de forma elíptica u ovada, asimétricos, de textura membranácea (A. micraster) o cartácea (A. amazonicum*) e inserción del pecíolo marginal. La base es convexa, el ápice acuminado y el margen, entero. El tamaño de la lámina es micrófilo.

Venación. La venación primaria es pinnada. La secundaria semicraspedódroma; el espaciado de las venas es irregular, aunque su ángulo, respecto a la vena primaria, es uniforme. Hay venas intersecundarias robustas. La terciaria presenta un arreglo mixto/dicótomo (algunas venas opuestas, algunas alternas y otras dicótomas), su curso es ramificado exmedialmente y su ángulo respecto a la vena primaria es obtuso y varía en forma inconsistente en la lámina. La

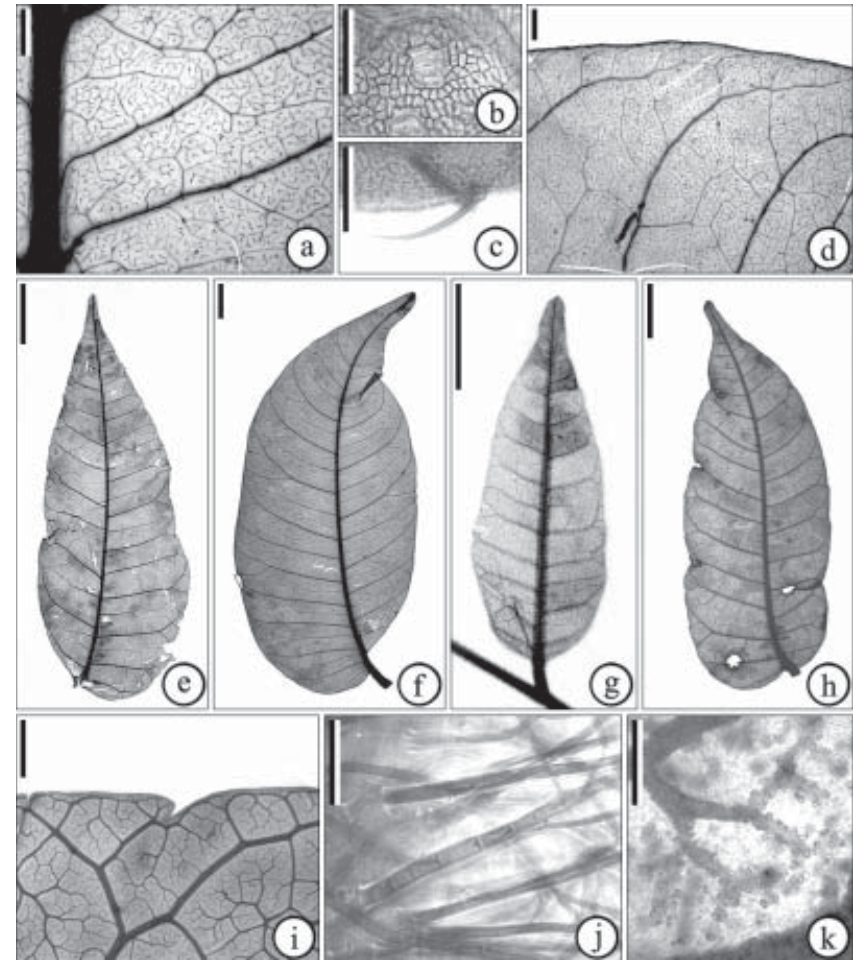

Figura 6. Antrocaryon y Astronium. a-d, Antrocaryon . a, venación de tercer orden de $A$. micraster (escala $=1 \mathrm{~mm}$ ); $\mathrm{b}$, estoma de $A$. micraster (escala $=100 \mu$ ); c, tricoma de A. micraster (escala $=100$ $\mu)$; , venación semicraspedódroma de $A$. micraster (escala $=1$ $\mathrm{mm}$ ). e-k, Astronium. e, folíolo de A. conzattii (escala=1 cm); $\mathrm{f}$, folíolo de A. lecontei (escala=1 cm); g, folíolo de A. graveolens (escala $=1 \mathrm{~cm}) ; \mathrm{h}$, folíolo de $A$. fraxinifolium (escala=1 cm); i, margen crenado de $A$. conzattii (escala $=1 \mathrm{~mm}$ ); $\mathrm{j}$, tricomas de $A$. graveolens (escala $=100 \mu$ ); $\mathrm{k}$, cristales prismáticos en las venas de A. fraxinifolium (escala $=100 \mu)$.

de cuarto orden es dicótoma. Las venas de quinto orden también presentan un patrón dicótomo. Las areolas están moderadamente desarrolladas cuyas últimas venas libres se ramifican dos o más veces. El orden más alto de venación es el quinto y el último que presenta ramificación excurrente, el tercero. La venación marginal es libre (arcos incompletos). El grado de organización de la hoja es $3 r$.

Características epidérmicas. Estomas de tipo policíticoanficiclocítico, ubicados únicamente en el envés. Se presentan escasos tricomas de tipo simple pluricelular, localizados en toda la superficie de la hoja.

Cristales y canales resiníferos. Únicamente se encuentran drusas en el mesofilo. Los canales resiníferos se ubican en las venas del primero al cuarto orden.

5) Género: Astronium Jacq. (Fig. 6e-k).

Especie tipo: A. graveolens Jacq.

Ejemplares aclarados: A. conzattii S. F. Blake (DS-Morton y Makrinius 2436, México), A. fraxinifolium Schott (MEXUM. Saldias 799, Bolivia), A. graveolens Jacq. (FCME-CGH 
420, México), A. lecontei Ducke (US-J. Lizot 1972-17, Venezuela).

Ejemplares complementarios: A. conzattii S. F. Blake (MEXU-F. Miranda 4349, México), A. fraxinifolium Schott (MEXU-F. Miranda 4231, México), A. graveolens Jacq. (MEXU-J. Arturo, S. Magallanes 4065, México).

Distribución: sur de México, Centroamérica, Colombia, Venezuela, Brasil y Paraguay.

Descripción: Organización macroscópica. Hojas con arreglo alterno, compuestas imparipinnadas, con folíolos alternos peciolulados (paripinnadas con folíolos opuestos en A. graveolens); la textura es membranácea (cartácea en $A$. fraxinifolium); el raquis suele ser simple, aunque en A. conzattii es ligeramente alado. La forma de los folíolos es ovada (oblonga en A. fraxinifolium). La simetría de los folíolos es muy variable; son simétricos o asimétricos sólo en la base en $A$. graveolens, ligeramente asimétricos en la base en $A$. conzattii y asimétricos en $A$. fraxinifolium y $A$. lecontei. Base convexa, cordada o cóncavo-convexa (convexa en A. conzattii y A. graveolens, cordada en A. fraxinifolium, convexa/cordada en $A$. lecontei y convexa/cóncavo-convexa en A. graveolens). Ápice acuminado, y en A. graveolens presenta una proyección de la vena primaria más allá del margen del folíolo (mucrón). Esta proyección está ausente en las demás especies revisadas. Margen serrado, crenado o entero (serrado en $A$. fraxinifolium, crenado en A. conzattii y A. graveolens, entero en A. lecontei). El tamaño de los folíolos es micrófilo (notófilo en A. lecontei), la proporción largo/ancho es 2.24:1-(2.54:1)-2.67:1. El ángulo de la base varía entre $71^{\circ}-\left(78.125^{\circ}\right)-88^{\circ}$ y el del ápice, $45.5^{\circ}-\left(49.8125^{\circ}\right)$ $60^{\circ}$.

Venación. La venación primaria es pinnada. La secundaria es cladódroma II, con 4 venas basales (es eucamptódroma en A. lecontei; hay 5 venas basales en $A$. fraxinifolium y 9 en $A$. lecontei). El espaciado de las venas puede ser irregular ( $A$. conzattii y A. graveolens) o puede disminuir hacia la base y el ápice (A. fraxinifolium y A. lecontei) mientras que su ángulo respecto a la vena primaria aumenta ligeramente hacia la base (es uniforme en A. graveolens). Las venas intersecundarias son débiles (A. fraxinifolium y A. graveolens) o robustas ( $A$. conzattii y A. lecontei). La terciaria es variable; en $A$. conzattii y A. fraxinifolium es mixta (mezcla de opuestas y alternas percurrentes), en A. graveolens es alterna percurrente y en $A$. lecontei es reticulada al azar. El curso de las venas terciarias es ramificado exmedialmente excepto en $A$. conzattii donde es ramificado admedialmente pero en todos los casos, el ángulo respecto a la vena primaria es obtuso; sin embargo, la variación del ángulo puede presentar diferentes estados; decrece exmedialmente en A. fraxinifolium y A. graveolens, es inconsistente en $A$. lecontei y aumenta exmedialmente en A. conzattii. La venación de cuarto orden presenta tanto el patrón dicótomo (A. conzattii y A. fraxinifolium) como el reticulado poligonal regular (A. graveolens y A. lecontei), aunque ocasionalmente también puede presentar el patrón mixto (A. fraxinifolium). Las venas de quinto orden son dicótomas con areolas poco a moderadamente desarrolladas donde las últimas venas libres están ramificadas dos o más veces (en $A$. conzattii están poco desarrolladas). El orden más alto de venación es el sexto (quinto en A. graveolens) y los últimos que presentan ramificación excurrente son el tercero, cuarto y quinto (tercero en A. graveolens, cuarto en A. conzattii y A. fraxinifolium o quinto en A. lecontei). La venación marginal forma arcos. El grado de organización de la hoja es $3 r$ ( $2 r$ en $A$. lecontei).

Dientes. Hay sólo un orden de dientes (de un solo tamaño) distribuidos de forma regular o irregular, 2 a 4 dientes por centímetro, a todo lo largo del margen (la distribución es regular en $A$. conzattii e irregular en A. fraxinifolium y A. graveolens; 2 dientes por centímetro en A. conzattii, 3 en A. fraxinifolium y 4 en $A$. graveolens). El lado apical del diente es recto o convexo en $A$. conzattii y A. graveolens y convexo en $A$. fraxinifolium; el lado basal es convexo en A. graveolens, convexo o recto en $A$. conzattii y convexo o retroflexo en $A$. fraxinifolium. El ápice del diente es simple y el seno es angular excepto en $A$. graveolens donde es redondo. La vena principal que entra al diente puede ser una de cuarto orden (A. conzattii y A. fraxinifolium) o la rama distal de una dicotomía de una vena secundaria (A. graveolens).

Características epidérmicas. Estomas de tipo policíticoanomocítico, ubicados únicamente en el envés. Tricomas ausentes en A. conzattii; moderados en A. fraxinifolium y A. lecontei, y abundantes en A. graveolens. Se localizan en toda la superficie de la hoja y en $A$. lecontei también en el margen; de tipo simple unicelular en A. graveolens y A. lecontei y pluricelular en A. fraxinifolium y A. graveolens.

Cristales y canales resiníferos. Se encuentran cristales prismáticos en las venas de $A$. conzattii y $A$. fraxinifolium y en el mesofilo de A. fraxinifolium, las otras dos especies carecen de ellos. En general no se presentan drusas, se observaron únicamente en las venas y mesofilo de $A$. lecontei. Se localizan canales resiníferos en las venas del primero al cuarto orden de A. lecontei.

6) Género: Blepharocarya F. Muell. (Fig. 7a-c).

Especie tipo: B. involucrigera F. Muell.

Ejemplares aclarados: B. depauperata Specht (Colección personal de la Dra. Terrazas).

Distribución: Australia.

Descripción: Organización macroscópica. Hojas compuestas paripinnadas de arreglo opuesto. Folíolos membranáceos, de forma obovada con base asimétrica, convexa en ambos lados, ápice retuso y margen entero; de tamaño micrófilo, la proporción largo/ancho es 1.82:1. Ángulo de la base de $77^{\circ}$ y el del ápice de $83^{\circ}$.

Venación. La venación primaria es pinnada. La secundaria, cladódroma I con 4 venas basales; el espacio entre las venas secundarias disminuye hacia la base y hacia el ápice y su ángulo con respecto a la vena primaria aumenta ligeramente 
hacia la base. No se presentan venas intersecundarias. La terciaria presenta un arreglo alterno percurrente, su curso es ramificado exmedialmente y el ángulo respecto a la vena primaria es obtuso que aumenta basalmente. La de cuarto orden presenta el patrón reticulado poligonal regular. Las venas de quinto orden son dicótomas. Las areolas están bien desarrolladas y las últimas venas libres son desde ausentes hasta ramificadas una vez. El orden más alto de venación es el quinto; el cuarto es el último que presenta ramificación excurrente. La venación marginal forma arcos. El grado de organización de la hoja es 3 r.

Características epidérmicas. Estomas de tipo policíticociclocítico localizados únicamente en el envés. Tricomas en cantidad moderada en toda la superficie del folíolo de tipo pluricelular.

Cristales y canales resiníferos. Cristales prismáticos al interior de las venas. Los canales resiníferos se encuentran en las venas del primero al cuarto orden.

7) Género: Bonetiella Rzed. (Fig. 7d-f).

Especie tipo: B.anomala (M. H. Johnston) Rzed.

Ejemplares aclarados: B. anomala (M. H. Johnston) Rzed. (MEXU-E. Carranza 2789, México).

Distribución: México.

Descripción: Organización macroscópica. Hojas simples con arreglo pseudoverticilado e inserción del pecíolo marginal, de textura cartácea, de forma oblonga simétrica con base decurrente, ápice convexo con una proyección de la vena media (mucrón) y margen entero. El tamaño es nanófilo, la proporción largo/ancho es de 4.98:1. El ángulo de la base es de $29^{\circ}$ y el del ápice de $36.5^{\circ}$.

Venación. La venación primaria es pinnada. La secundaria es cladódroma I con 3 venas basales, espaciadas irregularmente y el ángulo respecto a la vena primaria disminuye hacia la base. Las venas intersecundarias son débiles. La terciaria presenta arreglo dicótomo, su curso es ramificado exmedialmente y el ángulo respecto a la vena primaria es obtuso e inconsistente. La de cuarto orden es dicótoma, las areolas están moderadamente desarrolladas donde las últimas venas libres se ramifican una vez. El orden más alto de venación es el cuarto; el último que presenta ramificación excurrente, el tercero. La venación marginal forma arcos. El grado de organización de la hoja es $2 \mathrm{r}$.

Características epidérmicas. Estomas de tipo policíticoactinocítico ubicados tanto en el haz como en el envés. En toda la superficie de la hoja, se presentan tricomas escasos de tipo simple pluricelular y glandular.

Cristales y canales resiníferos. Se encuentran drusas tanto en el interior de las venas como en el mesofilo. Se localizan canales resiníferos en las venas de primero, segundo y tercer orden.

8) Género: Bouea Meissn (Fig. 7g-i).

Especie tipo: B. oppositifolia (Roxb.) Meissn.
Ejemplares aclarados: B. oppositifolia (Roxb.) Meissn (Colección personal de la Dra. Terrazas).

Ejemplares complementarios: B. oppositifolia (Roxb.) Meissn (K-E. Suzuki s/n, Brunei).

Distribución: Myanmar, Malasia, Sumatra, oeste de Java, Borneo, Islas Molucas.

Descripción: Organización macroscópica. Hojas simples con arreglo opuesto, pecioladas, de textura cartácea, elípticas, ligeramente asimétricas, con base convexa en un lado y cuneada en el otro, ápice acuminado y margen entero. El tamaño es notófilo, la proporción largo/ancho es 3.06:1. El ángulo de la base es de $58^{\circ}$ y el del ápice de $43^{\circ}$.

Venación. La venación primaria es pinnada. La secundaria, cladódroma I, con 5 venas basales, el espacio entre las secundarias disminuye hacia la base y el ápice; el ángulo, respecto a la vena primaria, es uniforme. No se presentan venas intersecundarias. La terciaria presenta el arreglo mixto (venas opuestas y alternas percurrentes), su curso es ramificado exmedialmente y el ángulo con respecto a la vena primaria es obtuso que aumenta basalmente. La venación de cuarto orden es dicótoma. Las venas de quinto orden también son dicótomas. Las areolas están moderadamente desarrolladas y las últimas venas libres son muy ramificadas (dos o más veces). El orden más alto de venación es el sexto y el último que presenta ramificación excurrente, el cuarto. La venación marginal forma arcos. El grado de organización de la hoja es $3 r$.

Características epidérmicas. Los estomas son de tipo policítico-anomocítico localizados únicamente en el envés. No se presentan tricomas.

Cristales y canales resiníferos. Los cristales prismáticos se encuentran al interior de las venas y en el mesofilo. Los canales resiníferos se presentan en las venas de primero, segundo y tercer orden.

9) Género: Buchanania Spreng. (Fig. 8a-d).

Especie tipo: B. lanzan Spreng.

Ejemplares aclarados: B. acuminata Turcz (DS-Toroes 2221, Sumatra), B. acuminatissima Merrill (US-M. Ramos y G. Edaño s/n, Filipinas), B. florida Schau (DS-Philip. For. Fl 13, Filipinas), B. palawensis Lauterb (DS-Herre 43, Islas Palau), B. reticulata Hance (Colección personal de la Dra. Terrazas).

Ejemplares complementarios: B. arborescens (Blume) Blume (MEXU-C. E. Ridsdale 1074, Filipinas), B. latifolia Roxb (MEXU-J. F. Maxwell 88-156, Tailandia), B. reticulata Elmer (NY-A. D. E. Elmer 12334, Filipinas, isotipo).

Distribución: India, China, Tailandia, Malasia, Java, Sumatra, Nueva Guinea, Australia, Micronesia, Melanesia, Islas Salomón, Polinesia.

Descripción: Organización macroscópica. Hojas simples con arreglo alterno, inserción del pecíolo marginal y textura cartácea (el arreglo es pseudoverticilado en B. arborescens* y B. latifolia*; la textura es membranácea en B. acuminatissima 
y coriácea en B. reticulata), forma elíptica, obovada u oblonga (elíptica en B. acuminata, B. arborescens*, B. florida, B. latifolia* y B. reticulata*, obovada en B. acuminatissima y $B$. palawensis y oblonga en B. latifolia*, B. palawensis y $B$. reticulata), son simétricas con base decurrente y ápice acuminado, de margen entero (asimétricas en la base en $B$. reticulata; base cóncavo-convexa en $B$. florida, y en $B$. reticulata convexa de un lado, cóncavo-convexa del otro; el ápice es retuso en $B$. palawensis y $B$. reticulata, y convexo en $B$. arborescens* y B. latifolia*), el tamaño es notófilo (mesofilo en B. palawensis), y la proporción largo/ancho es 2.115:1-(2.563:1)-3.32:1. Ángulo de la base de $49^{\circ}-\left(60.2^{\circ}\right)$ $71^{\circ}$ y el del ápice de $54^{\circ}-\left(68.7^{\circ}\right)-83.5^{\circ}$.

Venación. La venación primaria es pinnada. La secundaria cladódroma I, II o eucamptódroma con 3-5 o 9 venas basales (cladódroma I en $B$. reticulata, cladódroma II en B. acuminatissima y $B$. florida y eucamptódroma en $B$. acuminata y $B$. palawensis; 3 venas basales en $B$. florida, 4 en B. acuminatissima, 5 en B. acuminata y B. palawensis y 9 en $B$. reticulata). El espaciado de las venas es irregular en B. acuminatissima y B. palawensis, disminuye hacia la base en $B$. acuminata y disminuye hacia la base y hacia el ápice en $B$. florida, $B$. palawensis y $B$. reticulata. El ángulo de las venas secundarias con respecto a la vena primaria aumenta ligeramente hacia la base (abruptamente en B. acuminatissima y es uniforme en B. reticulata). No se presentan venas intersecundarias, excepto en B. acuminata donde son débiles y en $B$. reticulata donde son robustas. La venación terciaria presenta el arreglo alterno percurrente (mixto en B. florida), su curso es ramificado exmedialmente aunque en B. acuminatissima y $B$. florida es ramificado admedialmente y su ángulo con respecto a la vena primaria es principalmente obtuso aunque se pueden encontrar algunas con ángulo agudo en $B$. florida y $B$. reticulata y más raramente en B. palawensis. El ángulo de las venas terciarias con respecto a la vena primaria puede decrecer o aumentar exmedialmente (decrece en B. acuminata, B. palawensis y B. reticulata y aumenta en $B$. acuminatissima, $B$. florida y $B$. palawensis). La venación de cuarto orden es muy variable; presenta diferentes combinaciones en cada especie: en B. acuminata el arreglo es opuesto/alterno/dicótomo, en B. acuminatissima es dicótomo, en B. florida es opuesto/ dicótomo, en B. palawensis es mixto (opuesto/alterno) y en B. reticulata es reticulado poligonal regular. Las venas de quinto orden son dicótomas, las areolas están de poco a bien desarrolladas (poco en B. acuminatissima, moderadamente en $B$. acuminata y $B$. florida y están bien desarrolladas en $B$. palawensis y $B$. reticulata). Las últimas venas libres están ramificadas dos o más veces. Los órdenes más altos de venación son quinto a séptimo (quinto en B. acuminatissima, sexto en $B$. florida y $B$. palawensis, y séptimo en $B$. acuminata y $B$. reticulata), y los últimos que presentan ramificación excurrente, tercero a sexto (tercero en $B$. acuminatissima, cuarto en B. florida, quinto en B. acuminata y B. palawensis, y sexto en $B$. reticulata). La venación marginal forma arcos excepto en $B$. reticulata donde se presenta una vena fimbrial. El grado de organización de la hoja es $3 r$ (2r para $B$. acuminatissima y $4 \mathrm{r}$ para $B$. reticulata).

Características epidérmicas. Estomas de tipo policíticoanomocítico, ubicados únicamente en el envés (de tipo policítico-actinocítico en $B$. florida y se ubican en ambas superficies en B. acuminata). Buchanania acuminatissima carece de tricomas; en las demás especies son escasos y se localizan en toda la superficie de la hoja, como en $B$. florida y $B$. palawensis; únicamente en las venas, como en $B$. acuminata, o en las venas y el margen, como en B. reticulata; son de tipo simple pluricelular.

Cristales y canales resiníferos. Se encuentran cristales prismáticos al interior de las venas de todas las especies y en el mesofilo de $B$. florida, pueden estar ausentes en B. palawensis que además carece de drusas, pero éstas se presentan en las venas de las demás especies y en el mesofilo de B. acuminata, B. acuminatissima y B. reticulata. No se observan canales resiníferos.

10) Género: Campnosperma Thwaites (Fig. 8e-g).

Especie tipo: C. zeylanicum Thwaites.

Ejemplares aclarados: C. auriculata Hook. f. (US-Corner Singapore Field 26021, Singapur), C. montana Lauterb (USJ. Sinclair 5055, Singapur).

Ejemplares complementarios: C. auriculata Hook. f. (KSuzuki s/n, Brunei; K-Suzuki y Miyamoto s/n, Brunei), C. panamensis Standl (MEXU-G. Davidse y G. Herrera 31457, Costa Rica).

Distribución: Centroamérica, Colombia, Brasil, Madagascar, Sri Lanka, Malasia, Tailandia, Sumatra, Borneo, Islas Celebes, Islas Molucas, Nueva Guinea, Islas Seychelles, Micronesia, Melanesia.

Descripción: Organización macroscópica. Hojas simples con arreglo pseudoverticilado y unión del pecíolo marginal, de textura cartácea (C. montana) o coriácea (C. auriculata). Las hojas son de forma obovada (elíptica en C. auriculata), simétricas (C. montana) o ligeramente asimétricas ( $C$. auriculata) con base decurrente, ápice convexo ( $C$. panamensis*) o retuso que puede llegar a emarginado en C. auriculata y margen entero. De tamaño notófilo, la proporción largo/ancho es 3.18:1 (2.91:1 en C. auriculata y 3.45:1 en C. montana). Ángulo de la base de $45.5^{\circ}\left(52^{\circ}\right.$ en C. auriculata y $39^{\circ}$ en C. montana) y el del ápice de $57^{\circ}$ (C. montana).

Venación. La venación primaria es pinnada. La secundaria, eucamptódroma con 4 venas basales (C. auriculata). El espacio entre las venas secundarias disminuye hacia la base (C. auriculata) o hacia la base y el ápice (C. montana) y el ángulo respecto a la vena primaria aumenta ligeramente hacia la base. Las venas intersecundarias son débiles ( $C$. montana) o están ausentes (C. auriculata). La terciaria es alterna percurrente (C. auriculata) o mixta (C. montana), su 

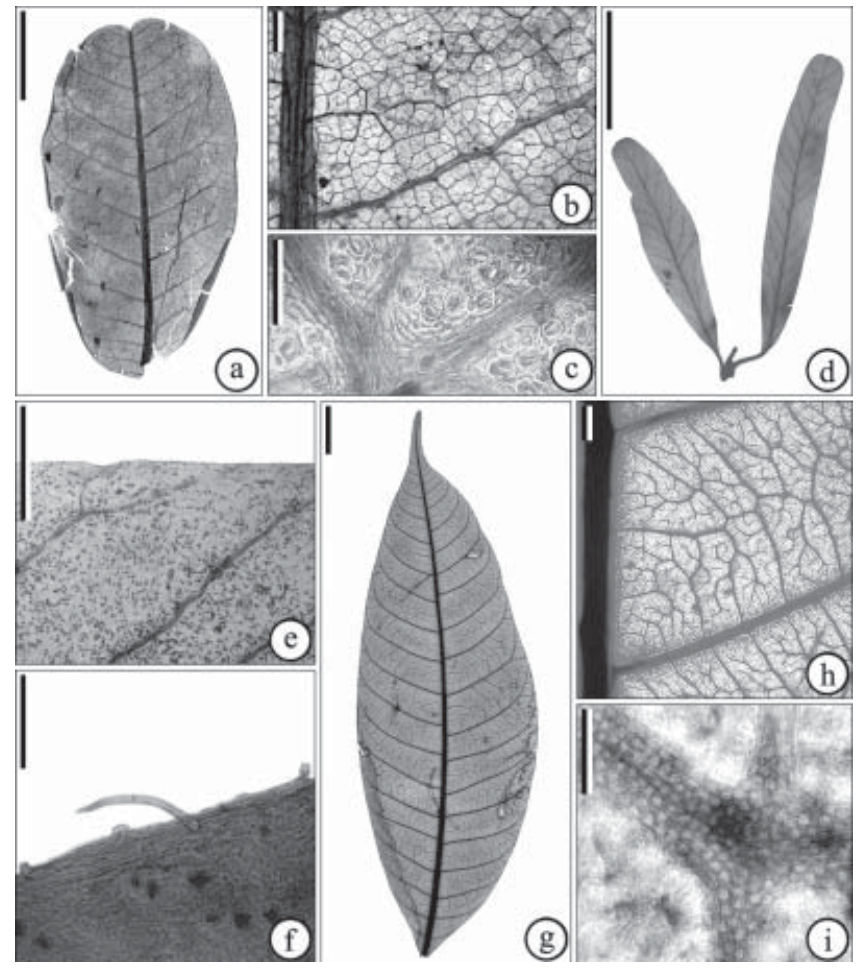

Figura 7. Blepharocarya, Bonetiella y Bouea. a-c, Blepharocarya. $a$, folíolo de $B$. depauperata (escala $=1 \mathrm{~cm}) ; b$, venación de tercer orden de $B$. depauperata (escala $=1 \mathrm{~mm}$ ); c, estomas de $B$. depauperata (escala=100 $\mu$ ). d-f, Bonetiella. d, hojas de B. anomala (escala $=1 \mathrm{~cm})$; e, canales resiníferos de B. anomala (escala $=1 \mathrm{~mm}$ ); $\mathrm{f}$, tricoma de B. anomala (escala=100 $\mu$ ). g-i, Bouea. g, hoja de B. oppositifolia (escala $=1 \mathrm{~cm}) ; \mathrm{h}$, venación de tercer orden de $B$. oppositifolia (escala $=1 \mathrm{~mm}) ; \mathrm{i}$, cristales prismáticos en las venas de B. oppositifolia (escala $=100 \mu)$.

curso es ramificado exmedialmente y el ángulo con respecto a la vena primaria es obtuso que aumenta basal (C. auriculata) o exmedialmente (C. montana). La venación de cuarto orden presenta el patrón reticulado poligonal regular. Las venas de quinto orden son dicótomas con areolas moderadamente desarrolladas donde las últimas venas libres van desde no ramificadas hasta muy ramificadas (dos o más veces) siendo esta última la condición predominante en C. auriculata. El orden más alto de venación es el sexto; el último que presenta ramificación excurrente, el quinto (C. auriculata) o el cuarto (C. montana). La venación marginal forma arcos. El grado de organización de la hoja es 3r.

Características epidérmicas. Estomas de tipo policíticoanomocítico, localizados únicamente en el envés. Tricomas en cantidad de moderada (C. auriculata) a abundante (C. montana) en toda la superficie de la hoja, son de tipo pluricelular.

Cristales y canales resiníferos. Se presentan cristales prismáticos únicamente al interior de las venas, las drusas se encuentran dentro de las venas y en el mesofilo. No se observan canales resiníferos.

11) Género: Cardenasiodendron F. A. Barkley (Fig. 8h-j). Especie tipo: C. brachypterum (Loes. ex Herzog) F. A. Barkley.

Ejemplares aclarados: C. brachypterum (Loes. ex Herzog) F. A. Barkley (NY-Heimbach 3873, Bolivia).

Distribución: Bolivia.

Descripción: Organización macroscópica. Hojas compuestas imparipinnadas de arreglo alterno con folíolos opuestos peciolulados de textura membranácea, de forma ovada ligeramente asimétrica con base convexa en ambos lados, ápice recto y margen serrado. El tamaño del folíolo es micrófilo, la proporción largo/ancho es 3.275:1. El ángulo de la base es $61^{\circ}$ y el del ápice es $31^{\circ}$.

Venación. La venación primaria es pinnada. La secundaria, craspedódroma, con 2 o 3 venas basales, ocasionalmente se presentan venas agróficas compuestas. El espaciado de las venas secundarias es irregular y el ángulo respecto a la vena primaria aumenta ligeramente hacia la base. Las venas intersecundarias son robustas. La terciaria presenta el arreglo mixto (venas opuestas y alternas percurrentes), su curso es sinuoso y recto y el ángulo con respecto a la vena primaria es obtuso que decrece exmedialmente. La venación de cuarto orden presenta el patrón reticulado poligonal regular. Las venas de quinto orden son dicótomas. Las areolas están bien desarrolladas y las últimas venas libres son desde ausentes hasta muy ramificadas (dos o más veces). El orden más alto de venación es el quinto, y el último que presenta ramificación excurrente el cuarto. La venación marginal forma arcos. El grado de organización de la hoja es $3 r$.

Dientes. Hay sólo un orden de dientes que se distribuyen regularmente, tres por centímetro a todo lo largo del margen. El lado apical del diente es flexo y el basal es convexo o flexo; el ápice del diente es espinoso y el seno, angular. La vena principal del diente es una rama proveniente de una dicotomía de una vena secundaria que puede ser la rama distal o la proximal.

Características epidérmicas. Estomas de tipo policíticoactinocítico, localizados únicamente en el envés. Tricomas de tipo pluricelular y glandular, en cantidad moderada, en toda la superficie de la lámina.

Cristales y canales resiníferos. Se presentan cristales prismáticos y drusas únicamente al interior de las venas, pero pueden estar ausentes. No se observan canales resiníferos.

12) Género: Choerospondias B. L. Burtt et A. W. Hill (Fig. 9a-c).

Especie tipo: C. axillaris (Roxb.) Burtt et A. W. Hill. Ejemplares aclarados: C. axillaris (Roxb.) Burtt et A. W. Hill (Colección personal de la Dra. Terrazas, Japón). Ejemplares complementarios: C. axillaris (Roxb.) Burtt et A. W. Hill (MEXU-K. L. Shi 13105, China), C. axillaris Roxb (MEXU-J. F. Maxwell 88-825, Tailandia). 
Distribución: China subtropical, Myanmar, Tailandia, Vietnam.

Descripción: Organización macroscópica. Hojas compuestas imparipinnadas con arreglo alterno y folíolos opuestos peciolulados de textura membranácea. Folíolos ovados simétricos con base cóncavo-convexa, ápice acuminado y margen entero. El tamaño de los folíolos es micrófilo, la proporción largo/ancho es 2.44:1. El ángulo de la base es de $72^{\circ}$ y el del ápice, de $37^{\circ}$.

Venación. La venación primaria es pinnada. La secundaria, eucamptódroma, con 5 venas basales, el espaciado de las secundarias es irregular y el ángulo respecto a la vena primaria es uniforme. Las venas intersecundarias son robustas. La terciaria presenta el arreglo mixto (venas opuestas y alternas percurrentes), su curso es recto y el ángulo con respecto a la vena primaria es obtuso que decrece exmedialmente. La venación de cuarto orden presenta el patrón reticulado poligonal regular. Las venas de quinto orden son dicótomas. Las areolas están bien desarrolladas y las últimas venas
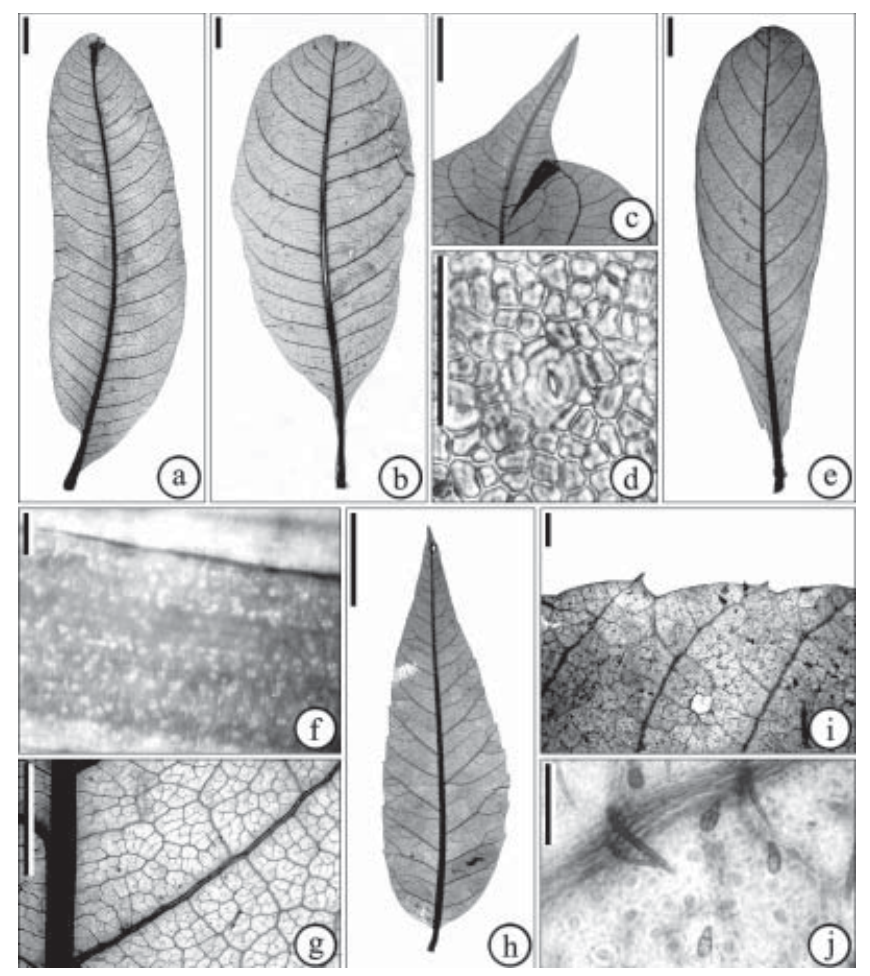

Figura 8. Buchanania, Campnosperma y Cardenasiodendron. a-d, Buchanania. a, hoja de $B$. reticulata $($ escala $=1 \mathrm{~cm})$; b, hoja de $B$. palawensis (escala $=1 \mathrm{~cm}$ ); c, ápice de $B$. acuminata (escala $=5 \mathrm{~mm}$ ); d, estoma de B. acuminata (escala $=100 \mu$ ). e-g, Campnosperma. e, hoja de $C$. montana (escala $=1 \mathrm{~cm})$; $\mathrm{f}$, cristales prismáticos en las venas de $C$. montana (escala $=100 \mu$ ); g, venación de tercer orden de C. montana (escala=5 mm). h-j, Cardenasiodendron. h, folíolo de $C$. brachypterum (escala $=1 \mathrm{~cm}$ ); i, dientes de $C$. brachypterum (escala $=1 \mathrm{~mm}) ; \mathrm{j}$, tricomas glandulares de $C$. brachypterum $($ escala $=100 \mu)$. libres son desde ausentes hasta muy ramificadas (dos o más veces). El orden más alto de venación es el sexto; el último que presenta ramificación excurrente, el cuarto. La venación marginal forma arcos. El grado de organización de la hoja es $3 r$.

Características epidérmicas. Los estomas son de tipo policítico-anomocítico localizados únicamente en el envés. Se presentan tricomas unicelulares escasos en toda la superficie y en el margen del folíolo; además, tricomas pluricelulares y glandulares en cantidad moderada sobre la superficie. Se presentan también los llamados domacios, que consisten únicamente de tricomas.

Cristales y canales resiníferos. No se presentan ni drusas ni cristales prismáticos, sin embargo, en el mesofilo se observa la presencia de arenas. Los canales resiníferos se localizan en las venas del primero al cuarto orden.

\section{3) Género: Comocladia P. Browne (Fig. 9d-i).} Especie tipo: C. pinnatifida L.
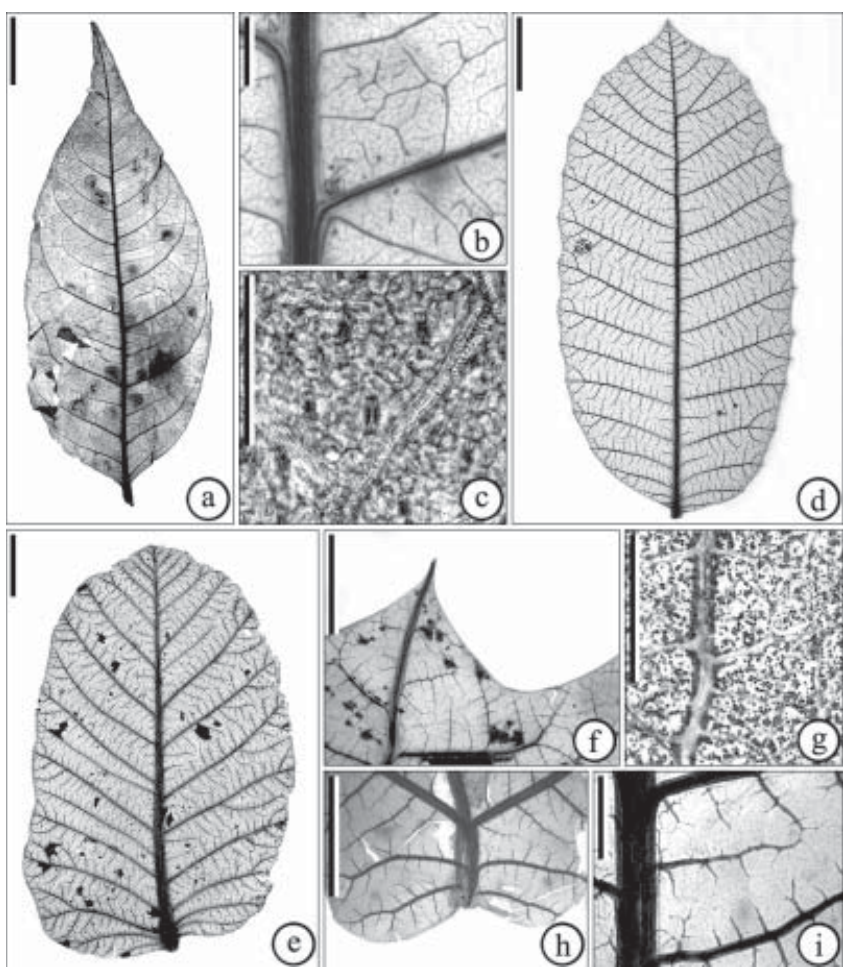

Figura 9. Choerospondias y Comocladia. a-c, Choerospondias. a, folíolo de C. axillaris (escala $=1 \mathrm{~cm}$ ); $\mathrm{b}$, domacio de C. axillaris (escala $=1 \mathrm{~mm}) ; \mathrm{c}$, estomas de C. axillaris (escala $=100 \mu)$. d-i, Comocladia. d, folíolo de C. mollissima (escala $=1 \mathrm{~cm}$ ); e, folíolo de $C$. guatemalensis (escala $=1 \mathrm{~cm}$ ); $\mathrm{f}$, dientes de $C$. platyphylla (escala $=5 \mathrm{~mm}$ ); g, drusas en el mesofilo y canales resiníferos de $C$. mollissima (escala=1 mm); h, base de C. ilicifolia (escala=5 mm); $\mathrm{i}$, venación de tercer orden y canales resiníferos de C. ilicifolia (escala $=1 \mathrm{~mm}$ ). 
Ejemplares aclarados: C. engleriana Loes. (FCME-LLP 1108, México; CAS-Mexia 1163, México), C. guatemalensis Donn. Sm. (DS-Breedlove 24473, México), C. ilicifolia Sw. (DS-Rickseker 374, St. Croix, Antillas, Estados Unidos), C. mollissima H. B. K. (FCME-COA 148, México; DS-Lathrop y Thorne 7339, México), C. palmeri Rose (FCME-AH 73, México), C. platyphylla A. Rich. ex Griseb. (DS-Jack 8484, Cuba).

Ejemplares complementarios: C. engleriana Loes. (MEXUL. Trejo 77, México), C. guatemalensis Donn. Sm. (MEXUA. Reyes García 1565, México), C. mollissima H. B. K. (MEXU-N. Riaño Ramírez 132, México), C. palmeri Rose (MEXU-U. Ramírez Cantú s/n, México), C. repanda S. F. Blake (MEXU-L. W. Boege 429, México).

Distribución: México, Antillas.

Descripción: Organización macroscópica. Hojas alternas o pseudoverticiladas compuestas imparipinnadas con folíolos opuestos peciolulados de textura cartácea (el arreglo es alterno en C. engleriana y C. palmeri y pseudoverticilado en C. guatemalensis y C. mollissima; la textura es membranácea en C. ilicifolia y C. platyphylla). Los folíolos son de forma oblonga, ovada o elíptica (oblonga en $C$. engleriana, C. guatemalensis, C. mollissima, C. platyphylla y C. repanda*, ovada en C. ilicifolia y C. mollissima y elíptica en C. engleriana y C. palmeri), son simétricos, o ligera/marcadamente asimétricos en la base (simétricos en C. engleriana, C. ilicifolia, C. mollissima y C. platyphylla, asimétricos en la base en $C$. guatemalensis y $C$. palmeri y ligeramente asimétricos en la base en $C$. engleriana y $C$. mollissima). La forma de la base es variable; cordada en $C$. engleriana, C. guatemalensis, C. ilicifolia y C. mollissima, cóncavo-convexa en $C$. engleriana, convexa en $C$. mollissima, C. platyphylla y C. repanda*, y convexa de un lado y cuneada del otro en C. palmeri. El ápice es acuminado; en $C$. ilicifolia y C. platyphylla, la vena media se proyecta más allá del margen formando una espina (ápice convexo en C. guatemalensis, C. platyphylla y C. repanda*). El margen es dentado excepto en $C$. palmeri donde es crenado y en algunos especimenes de C. engleriana donde es entero. El tamaño de los folíolos es notófilo (micrófilo en C. ilicifolia y a veces en $C$. mollissima, ocasionalmente mesófilo en $C$. engleriana), la proporción largo/ancho es 1.1:1-(1.573:1)1.87. El ángulo de la base es de $92^{\circ}-\left(104.979^{\circ}\right)-136^{\circ}$ y el del ápice de $69^{\circ}-\left(91.375^{\circ}\right)-106.5^{\circ}$.

Venación. La venación primaria es pinnada, excepto en $C$. ilicifolia donde es actinódroma suprabasal. La secundaria es craspedódroma, excepto en C. ilicifolia donde es cladódroma I. Las venas basales son 3 en C. engleriana y C. platyphylla, 4 en C. ilicifolia, C. mollissima y C. palmeri, 5 en C. engleriana, y 7 en C. guatemalensis y C. mollissima. El espaciado de las venas secundarias disminuye tanto hacia la base como hacia el ápice, excepto en C. ilicifolia y C. platyphylla donde es uniforme y en algunos ejemplares de $C$. engleriana que puede ser irregular. El ángulo con respecto a la vena primaria aumenta hacia la base ligera o abruptamente, o es uniforme (ligeramente en C. engleriana, C. guatemalensis, C. mollissima y C. palmeri; abruptamente en C. engleriana y C. ilicifolia, y es uniforme en C. platyphylla). Las venas intersecundarias son robustas (débiles en C. guatemalensis, C. ilicifolia y algunos ejemplares de C. engleriana y ausentes en C. platyphylla). La venación terciaria presenta típicamente el arreglo dicótomo, en ocasiones se presentan venas opuestas y alternas percurrentes dando un arreglo opuesto/ alterno/dicótomo; su curso es ramificado exmedialmente y el ángulo con respecto a la vena primaria es obtuso aunque en C. platyphylla se pueden presentar algunos agudos (el arreglo es opuesto/alterno/dicótomo en algunos ejemplares de $C$. engleriana y $C$. mollissima, y en C. palmeri). El ángulo varía sobre la lámina de diferentes formas, decrece exmedialmente en C. mollissima (algunos ejemplares) y C. palmeri, es inconsistente en C. mollissima (algunos ejemplares), aumenta exmedialmente en C. guatemalensis, C. ilicifolia y C. platyphylla, mientras que en C. engleriana puede ser uniforme o aumentar basalmente. La venación de cuarto orden es dicótoma. Las venas de quinto orden también son dicótomas (ocasionalmente pueden formar un retículo en $C$. engleriana). Las areolas están poco desarrolladas (completamente ausentes en C. palmeri y moderadamente desarrolladas en algunos ejemplares de $C$. engleriana); las últimas venas libres van desde ausentes hasta muy ramificadas (dos o más veces); esta condición es la más común en C. guatemalensis y C. ilicifolia, mientras que una sola ramificación lo es para C. platyphylla. El orden más alto de venación es el quinto (sexto en C. ilicifolia y C. platyphylla), y el último que presenta ramificación excurrente, el tercero (cuarto en C. platyphylla y en algunos ejemplares de $C$. engleriana y $C$. mollissima). La venación marginal forma arcos incompletos. El grado de organización de la hoja es $3 r$ ( $2 r$ en $C$. ilicifolia y algunos ejemplares de $C$. engleriana y C. mollissima).

Dientes. Hay sólo un orden de dientes, que se distribuyen regularmente, un diente por centímetro, a todo lo largo del margen. En C. engleriana hay dos órdenes de dientes distribuidos irregularmente; en C. palmeri se encuentran 2 dientes por centímetro, mientras que en $C$. mollissima hay de 1 a 2. El lado apical del diente es convexo en C. engleriana, C. guatemalensis y C. palmeri, recto en C. guatemalensis, C. mollissima y C. platyphylla y cóncavo en C. ilicifolia y C. platyphylla; el lado basal es convexo en C. engleriana, C. guatemalensis y $C$. palmeri, recto en $C$. engleriana, $C$. guatemalensis, C. mollissima y C. platyphylla y cóncavo en C. ilicifolia y C. platyphylla. El ápice del diente puede ser espinoso, mucronado, glandular o simple, el seno es redondo (el ápice es espinoso en C. ilicifolia y C. platyphylla, mucronado en C. engleriana y C. mollissima, glandular en $C$. palmeri, y simple en C. guatemalensis y C. mollissima). La vena principal del diente es típicamente una vena secundaria que no presenta dicotomías en su curso, pero en C. ilicifolia, 
las venas principales de los dientes son primarias.

Características epidérmicas. Estomas de tipo policíticoanomocítico; se localizan únicamente en el envés (policíticociclocítico en $C$. platyphylla y de ambos tipos en $C$. mollissima). Tricomas ausentes en C. platyphylla, pero en las demás especies de moderados hasta abundantes (moderados en C. ilicifolia, C. palmeri y algunos ejemplares de $C$. engleriana; abundantes en C. engleriana, C. guatemalensis y C. mollissima). Su distribución es muy variable pero típicamente se localizan en toda la superficie del folíolo (en C. palmeri sólo están en las venas, en C. ilicifolia y C. engleriana, las venas y la superficie y en C. ilicifolia están además en el margen). Son de tipo pluricelular (también hay unicelulares en C. engleriana y C. palmeri).

Cristales y canales resiníferos. En general no se presentan cristales prismáticos; sin embargo, en C. guatemalensis están en el mesofilo y en el interior de las venas, mientras que en $C$. platyphylla únicamente en las venas; en cuanto a las drusas, C. ilicifolia y C. palmeri carecen de ellas, C. platyphylla y algunos ejemplares de C. mollissima sólo las presentan en el interior de las venas mientras que $C$. engleriana, $C$. guatemalensis y C. mollissima las presentan en el mesofilo y en las venas. Los canales resiníferos se localizan en las venas del primero al cuarto orden; ocasionalmente, pueden no observarse en C. engleriana.

14) Género: Cotinus Mill (Fig. 10a-c).

Especie tipo: C. coggygria Scop.

Ejemplares aclarados: C. coggygria Scop. (US-R. de Soó s/n, Hungría).

Ejemplares complementarios: C. americanus Nutt (MEXUB. C. Tharp, et al. 17-176, Estados Unidos), C. carranzae J. Rzedowski et G. Calderón de Rzedowski (MEXU-E. Carranza y E. Pérez 5651, México), C. coggygria Scop. (MEXU-KEW0006931139 (loc 756), Reino Unido).

Distribución: Europa, Asia, Estados Unidos, México.

Descripción: Organización macroscópica. Hojas simples con arreglo alterno y unión marginal del pecíolo, de textura membranácea (cartácea en C. carranzae*), son elípticas, asimétricas en la base, cuya forma es convexa en ambos lados, con ápice convexo y margen entero (forma oblonga en C. carranzae*). Tamaño micrófilo; proporción largo/ancho 1.23:1. Ángulo de la base de $110^{\circ}$ y el del ápice de $106^{\circ}$.

Venación. La venación primaria es pinnada. La secundaria cladódroma I, con 5 venas basales y un par de venas agróficas. El espaciado de las venas secundarias disminuye hacia la base y el ápice y el ángulo con respecto a la vena primaria aumenta hacia la base ligeramente. No se presentan venas intersecundarias. La venación terciaria presenta el arreglo alterno percurrente, su curso es ramificado exmedialmente y el ángulo con respecto a la vena primaria es obtuso que decrece exmedialmente. La venación de cuarto orden presenta el patrón reticulado poligonal regular al igual que la de quinto orden. Las areolas están bien desarrolladas y las

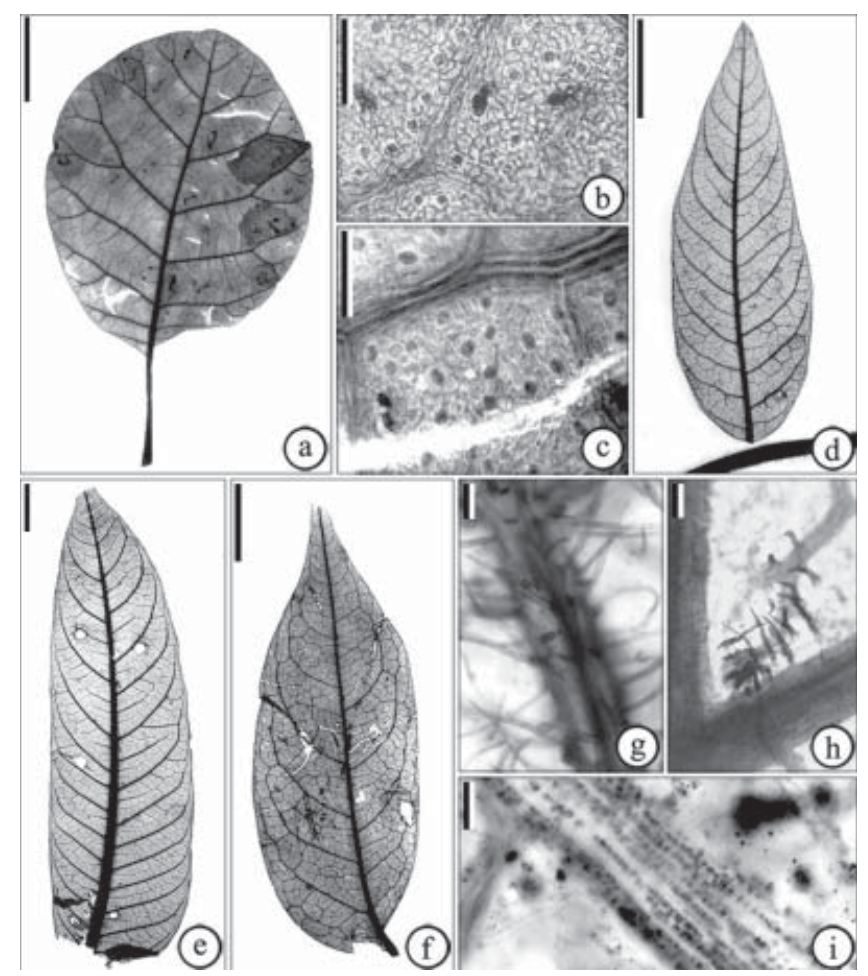

Figura 10. Cotinus, Cyrtocarpa y Dracontomelon. a-c, Cotinus. a, hoja de C. coggygria (escala $=1 \mathrm{~cm}$ ); $b$, tricomas glandulares de $C$. coggygria (escala $=100 \mu$ ); c, estomas de C. coggygria (escala $=100 \mu$ ). d-g, Cyrtocarpa. d, folíolo de C. procera (escala=1 $\mathrm{cm})$; g, tricomas pluricelulares y glandulares en las venas de $C$. procera (escala $=100 \mu$ ). e-f, h-i, Dracontomelon. e, folíolo de $D$. cumingianum (escala $=1 \mathrm{~cm}) ; \mathrm{f}$, folíolo de $D$. dao $($ escala $=1 \mathrm{~cm})$; h, domacio de $D$. dao (escala $=100 \mu$ ); i, cristales prismáticos en las venas de $D$. cumingianum (escala $=100 \mu$ ).

últimas venas libres, desde ausentes hasta muy ramificadas (dos o más veces). El orden más alto de venación es el sexto; el último que presenta ramificación excurrente, el quinto. La venación marginal forma arcos. El grado de organización de la hoja es 4 r.

Características epidérmicas. Estomas de tipo policíticoanomocítico, localizados únicamente en el envés. Tricomas de tipo glandular en cantidad moderada.

Cristales y canales resiníferos. No se presentan cristales prismáticos ni drusas. No se observan canales resiníferos.

15) Género: Cyrtocarpa Kunth. (Fig. 10d, g).

Especie tipo: C. procera H. B. K.

Ejemplares aclarados: C. procera H. B. K. (FCME-FL 3097, México).

Ejemplares complementarios: C. caatingae J. D. Mitchell et D. C. Daly (MEXU-A. M. de Carvalho et al. 3752, Brasil), C. edulis Standl (MEXU-J. H. Thomas 8467, México), C. procera H. B. K. (MEXU-R. Cedillo T. 1443 y R. Torres C, México).

Distribución: México (Baja California), Brasil. 
Descripción: Organización macroscópica. Hojas compuestas imparipinnadas con arreglo pseudoverticilado y folíolos opuestos sésiles, de textura cartácea y raquis alado. Folíolos de forma ovada, ligeramente asimétricos en la base que es convexa de ambos lados, el ápice es recto y presenta una proyección de la vena media (mucrón); el margen es entero (en C. edulis* el arreglo es alterno, la forma de los folíolos es elíptica, el ápice es convexo y no se presenta mucrón). El tamaño de los folíolos es micrófilo, la proporción largo/ ancho es 2.84:1. Ángulo de la base de $69.25^{\circ}$ y el del ápice, $47.875^{\circ}$.

Venación. La venación primaria es pinnada. La secundaria eucamptódroma, con 3 venas basales; el espaciado de las venas secundarias es uniforme al igual que su ángulo con respecto a la vena primaria. Las venas intersecundarias son robustas. La venación terciaria presenta el arreglo alterno percurrente, su curso es ramificado exmedialmente y el ángulo con respecto a la vena primaria es obtuso que decrece exmedialmente. La venación de cuarto orden presenta patrón reticulado poligonal regular, mientras que las venas de quinto orden son dicótomas. Las areolas están bien desarrolladas y las últimas venas libres no están ramificadas o están ausentes. El orden más alto de venación es el quinto; el último que presenta ramificación excurrente, el cuarto. La venación marginal forma arcos. El grado de organización de la hoja es $3 r$.

Características epidérmicas. Estomas de tipo policíticoanomocítico localizados únicamente en el envés. Tricomas de tipo pluricelular y glandular en cantidad abundante, distribuidos en toda la superficie.

Cristales y canales resiníferos. No se presentan cristales prismáticos ni drusas. No se observan canales resiníferos.

16) Género: Dracontomelon Blume (Fig. 10e-f, h-i).

Especie tipo: no designada.

Ejemplares aclarados: D. cumingianum Baill. (DS-Elmer 16235, Filipinas), D. dao Merrill et Rolfe (US-G. J. Labitag $s / n$, Filipinas).

Ejemplares complementarios: D. dao Merrill et Rolfe (KSuzuki y Miyamoto s/n, Brunei).

Distribución: Asia continental, India, China, Myanmar, Tailandia, Camboya, Malasia, Sumatra, Java, Filipinas, Islas Fiji, Nueva Guinea, Polinesia.

Descripción: Organización macroscópica. Hojas compuestas imparipinnadas de arreglo pseudoverticilado y folíolos opuestos peciolulados de textura cartácea. Los folíolos pueden ser de forma oblonga u ovada (oblonga en D. cumingianum y D. dao* y ovada en $D$. dao); son ligeramente asimétricos, con base convexa en ambos lados, ápice acuminado y margen entero, de tamaño notófilo (D. cumingianum) o micrófilo ( $D$. dao), la proporción largo/ancho es 3.005:1 (3.39:1 en $D$. cumingianum y 2.62:1 en $D$. dao), el ángulo de la base es de $64.25^{\circ}\left(61.5^{\circ}\right.$ en $D$. cumingianum y $67^{\circ}$ en $D$. dao) y el del ápice de $48.5^{\circ}$ ( $49^{\circ}$ en $D$. cumingianum y $48^{\circ}$ en $D$. dao).
Venación. La venación primaria es pinnada. La secundaria eucamptódroma con 4 venas basales en $D$. cumingianum y semicraspedódroma con 6 venas basales en $D$. dao. El espaciado de las venas secundarias disminuye hacia la base mientras que su ángulo con respecto a la vena primaria aumenta ligeramente hacia la base en D. cumingianum y es uniforme en $D$. dao. Las venas intersecundarias de $D$. cumingianum son débiles, mientras que en $D$. dao no se presentan. La venación terciaria presenta arreglo mixto (opuesto/alterno percurrente) en D. cumingianum y el reticulado poligonal regular en $D$. dao, su curso es ramificado exmedialmente y el ángulo con respecto a la vena primaria es obtuso; decrece exmedialmente en $D$. dao mientras que en $D$. cumingianum es inconsistente. La venación de cuarto orden presenta patrón reticulado poligonal regular en $D$. cumingianum mientras que en $D$. dao, es dicótomo. Las venas de quinto orden tienen patrón dicótomo en $D$. cumingianum y reticulado poligonal regular en $D$. dao. Las areolas están bien desarrolladas y las últimas venas libres están muy ramificadas (2 o más veces). El orden más alto de venación es el sexto; el último que presenta ramificación excurrente, el quinto. La venación marginal forma arcos en D. cumingianum y forma una vena fimbrial en D. dao. El grado de organización de la hoja es 3r.

Características epidérmicas. Estomas de tipo policíticoanomocítico en $D$. cumingianum y paracítico-braquiparacítico en $D$. dao, se encuentran únicamente en el envés. Tricomas escasos distribuidos en toda la superficie de tipo unicelular (D. dao) o pluricelular (D. cumingianum), además D. dao presenta domacios formados por tricomas.

Cristales y canales resiníferos. Se presentan cristales prismáticos en el interior de las venas. Hay drusas en el mesofilo de $D$. dao. No se observan canales resiníferos.

17) Género: Euroschinus Hook. f. (Fig. 11a-c).

Especie tipo: E. falcatus Hook. f.

Ejemplares aclarados: E. falcatus Hook. f. (US-S. F. Kajewski 1340, Australia).

Distribución: Nueva Guinea, Nueva Caledonia, Australia.

Descripción: Organización macroscópica. Hojas compuestas paripinnadas de arreglo pseudoverticilado y folíolos alternos, con inserción del peciólulo marginal y textura membranácea. La forma de los folíolos es elíptica asimétrica con base convexa en ambos lados, ápice acuminado y margen entero. El tamaño de los folíolos es notófilo, la proporción largo/ ancho es 2.15:1. El ángulo de la base es de $83^{\circ}$ y el del ápice de $64^{\circ}$.

Venación. La venación primaria es pinnada. La secundaria, cladódroma I con 4 venas basales, el espaciado de las venas secundarias disminuye hacia la base y el ápice y el ángulo con respecto a la vena primaria aumenta hacia la base abruptamente. Las venas intersecundarias son robustas. La venación terciaria presenta arreglo dicótomo, su curso es ramificado exmedialmente y el ángulo con respecto a la vena 
primaria es obtuso pero inconsistente. La venación de cuarto orden presenta el patrón reticulado poligonal regular. Las venas de quinto orden son dicótomas. Las areolas están bien desarrolladas y las últimas venas libres son ramificadas dos o más veces. El orden más alto de venación es el sexto; el último que presenta ramificación excurrente, el cuarto. La venación marginal forma arcos. El grado de organización de la hoja es 3r.

Características epidérmicas. Estomas de tipo policíticoanomocítico localizados únicamente en el envés. Se presentan tricomas en cantidad moderada, distribuidos en toda la superficie de la lámina, de tipo pluricelular y glandular; además, domacios formados únicamente por tricomas.

Cristales y canales resiníferos. Se presentan drusas en el mesofilo. No se observan canales resiníferos.

18) Género: Gluta L. (Fig. 11d, g).

Especie tipo: G. renghas L.

Ejemplares aclarados: G. tavoyana Hook. f. (L-Teysmann $s / n$, Sumatra).

Ejemplares complementarios: G. usitata (Wall.) Ding Hou (MEXU-J. F. Maxwell 91-151, Tailandia).

Distribución: India, Myanmar, Tailandia, Vietnam, Indochina, Malasia, Java, Sumatra, Borneo, Nueva Guinea, Madagascar.

Descripción: Organización macroscópica. Hojas simples con arreglo pseudoverticilado y unión del pecíolo marginal, de textura cartácea. Las hojas tienen forma elíptica, ligeramente asimétrica en la base que es decurrente, el ápice es convexo y el margen, entero (son oblongas con ápice acuminado y textura membranácea en G. usitata*). El tamaño de las hojas es notófilo, la proporción largo/ancho es 2.54:1, el ángulo de la base de $60^{\circ}$ y el del ápice de $62^{\circ}$.

Venación. La venación primaria es pinnada. La secundaria eucamptódroma con 3 venas basales, el espacio entre las venas secundarias disminuye hacia la base y el ápice; el ángulo con respecto a la vena primaria aumenta hacia la base ligeramente. Las venas intersecundarias son robustas. La venación terciaria es reticulada al azar, su curso es ramificado exmedialmente y el ángulo con respecto a la vena primaria es obtuso que decrece exmedialmente. La venación de cuarto orden presenta el patrón dicótomo. Las venas de quinto orden también son dicótomas, las areolas están bien desarrolladas y las últimas venas libres están ramificadas dos o más veces. El orden más alto de venación es el quinto, y el último que presenta ramificación excurrente, el cuarto. La venación marginal forma arcos. El grado de organización de la hoja es 3 r.

Características epidérmicas. Estomas de tipo policíticociclocítico localizados únicamente en el envés. Carece de tricomas.

Cristales y canales resiníferos. No se presentan cristales prismáticos ni drusas. No se observan canales resiníferos.

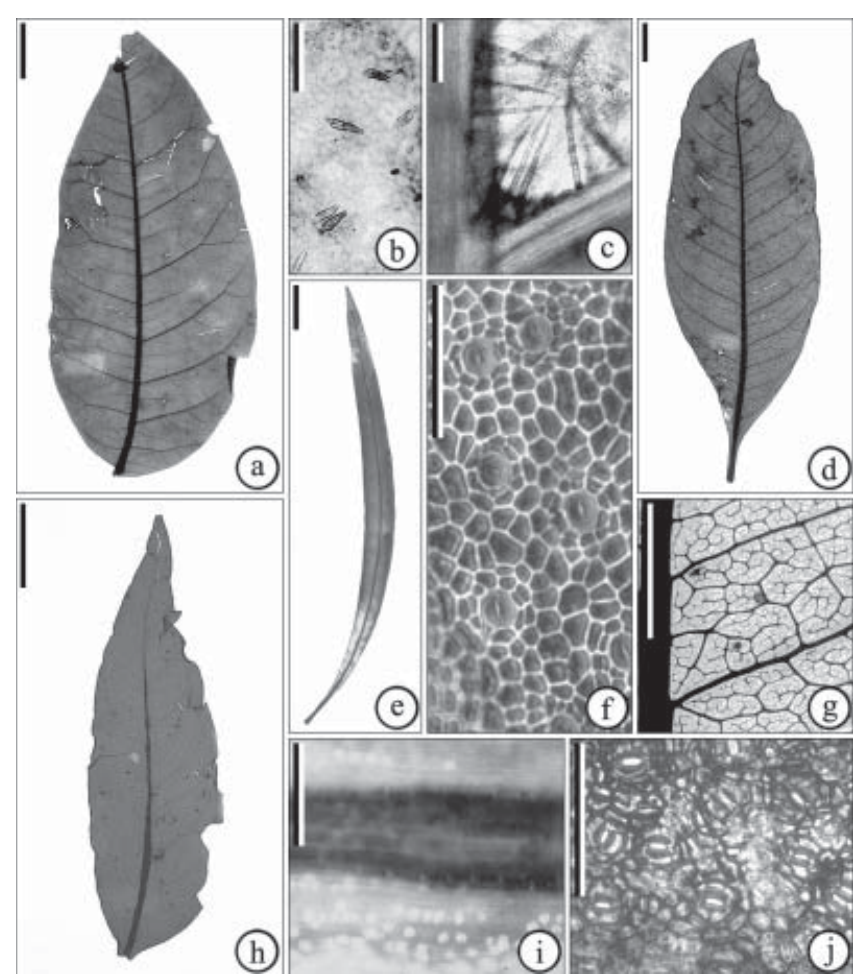

Figura 11. Euroschinus, Gluta, Haplorhus y Harpephyllum. a-c, Euroschinus. a, folíolo de E. falcatus (escala $=1 \mathrm{~cm}$ ); b, tricomas de E. falcatus (escala $=100 \mu$ ); c, domacio de E. falcatus (escala $=100$

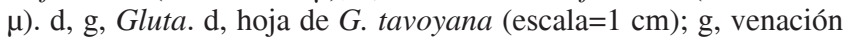
de tercer orden de G. tavoyana (escala=5 mm). e-f, Haplorhus. e, hoja de $H$. peruviana (escala $=1 \mathrm{~cm}$ ); f, estomas de $H$. peruviana (escala $=100 \mu$ ). h-j, Harpephyllum. h, folíolo de $H$. caffrum (escala $=1 \mathrm{~cm}$ ); i, drusas en las venas de $H$. caffrum (escala=100 $\mu$ ); j, estomas de $H$. caffrum (escala $=100 \mu$ ).

19) Género: Haplorhus Engl. (Fig. 11e-f).

Especie tipo: H. peruviana Engl.

Ejemplares aclarados: $H$. peruviana Engl. (Colección personal de la Dra. Terrazas).

Distribución: Perú, Chile.

Descripción: Organización macroscópica. Hojas simples pecioladas de textura cartácea, son oblongas, simétricas con base decurrente, ápice recto y margen entero, el tamaño es notófilo, la proporción largo/ancho es 17.3:1. Ángulo de la base de $12^{\circ}$ y el del ápice, $13.5^{\circ}$.

Venación. La venación primaria es pinnada. La secundaria cladódroma I con 3 venas basales, el espaciado de las venas secundarias es irregular y el ángulo con respecto a la vena primaria es uniforme. Las venas intersecundarias son débiles. La venación terciaria presenta el arreglo dicótomo, su curso es ramificado exmedialmente y el ángulo con respecto a la vena primaria es obtuso pero inconsistente. La venación de cuarto orden es dicótoma al igual que las venas de quinto orden. Las areolas están poco desarrolladas y las últimas venas libres son muy ramificadas (dos o más veces). El orden más alto de venación es el quinto; el último que presenta 
ramificación excurrente, el tercero. La venación marginal es libre (arcos incompletos). El grado de organización de la hoja es $1 r$.

Características epidérmicas. Estomas de tipo policíticoanficiclocítico y se localizan tanto en el haz como en el envés. No se presentan tricomas.

Cristales y canales resiníferos. No se presentan cristales prismáticos ni drusas. No se observan canales resiníferos.

20) Género: Harpephyllum Bernh. ex Krauss (Fig. 11h-j). Especie tipo: $H$. caffrum Bernh. ex Krauss.

Ejemplares aclarados: $H$. caffrum Bernh. ex Krauss (Colección personal de la Dra. Terrazas).

Distribución: Sudáfrica.

Descripción: Organización macroscópica. Hojas compuestas imparipinnadas de arreglo alterno y folíolos opuestos sésiles, de textura cartácea, con raquis alado, forma ovada, ligeramente asimétricos con base cóncavo-convexa en ambos lados, ápice recto y margen entero. El tamaño es micrófilo, la proporción largo/ancho 3.26:1, el ángulo de la base de $60^{\circ}$ y el del ápice, $31^{\circ}$.

Venación. La venación primaria es pinnada. La secundaria semicraspedódroma con 3 venas basales, el espaciado de las venas secundarias es irregular y el ángulo con respecto a la vena primaria aumenta hacia la base ligeramente. No se presentan venas intersecundarias. La venación terciaria presenta el arreglo mixto (hay venas opuestas y alternas percurrentes), su curso es ramificado exmedialmente y el ángulo con respecto a la vena primaria es obtuso que decrece exmedialmente. La venación de cuarto y quinto orden es dicótoma. Las areolas están moderadamente desarrolladas donde las últimas venas libres van desde ausentes hasta muy ramificadas (dos o más veces). El orden más alto de venación es el quinto y el último que presenta ramificación excurrente, el cuarto. La venación marginal forma arcos. El grado de organización de la hoja es 3r.

Características epidérmicas. Estomas de tipo policíticoanomocítico localizados únicamente en el envés. No se presentan tricomas.

Cristales y canales resiníferos. Se presentan drusas en el interior de las venas y en el mesofilo. No se observan canales resiníferos.

21) Género: Koordersiodendron Engl. (Fig. 12a-c).

Especie tipo: K. celebicum Engl.

Ejemplares aclarados: K. pinnatum Merrill (US-Castro, Borneo For. Dept. A-831, Borneo)

Ejemplares complementarios: K. pinnatum Merrill (MEXUC. E. Ridsdale 1131, Filipinas).

Distribución: Malasia, Borneo, Filipinas, Islas Celebes, Islas Molucas, Nueva Guinea.

Descripción: Organización macroscópica. Hojas compuestas imparipinnadas de arreglo pseudoverticilado, con folíolos alternos peciolulados de textura cartácea, ovados, ligeramente asimétricos en la base que es convexa en ambos lados, el ápice acuminado y el margen entero. El tamaño de los folíolos es notófilo, la proporción largo/ancho es 3.19:1. El ángulo de la base de $69^{\circ}$ y el del ápice, $47^{\circ}$.

Venación. La venación primaria es pinnada. La secundaria eucamptódroma, con 5 venas basales; el espaciado de las venas secundarias es irregular aunque su ángulo con respecto a la vena primaria es uniforme. Las venas intersecundarias son débiles. La venación terciaria presenta el arreglo reticulado al azar, su curso es ramificado admedialmente y el ángulo con respecto a la vena primaria es obtuso que decrece exmedialmente. La venación de cuarto orden es dicótoma al igual que la de quinto orden. Las areolas están moderadamente desarrolladas y las últimas venas libres son muy ramificadas (2 o más veces). El orden más alto de venación es el séptimo; el último que presenta ramificación excurrente, el quinto. La venación marginal forma una vena fimbrial. El grado de organización de la hoja es 2r.

Características epidérmicas. Los estomas son de tipo policítico-actinocítico localizados únicamente en el envés. Se presentan tricomas escasos de tipo pluricelular distribuidos sobre las venas; hay tricomas glandulares en toda la superficie.

Cristales y canales resiníferos. Se presentan cristales prismáticos al interior de las venas y drusas tanto al interior de las venas como en el mesofilo. No se observan canales resiníferos.

22) Género: Lannea A. Rich. (Fig. 12d-f).

Especie tipo: L. velutina A. Rich.

Ejemplares aclarados: L. grandis Engl. (Colección personal de la Dra. Terrazas, China).

Ejemplares complementarios: L. coromandelica (Houtt.) Merrill (MEXU-J. F. Maxwell 88-449, Tailandia).

Distribución: África tropical del este, Asia.

Descripción: Organización macroscópica. Hojas compuestas imparipinnadas de folíolos opuestos peciolulados y arreglo pseudoverticilado (L. coromandelica*). Los folíolos son de textura membranácea, forma ovada, asimétricos con base convexa de un lado y cordada del otro, ápice acuminado y margen entero (la forma es elíptica en L. coromandelica*). El tamaño de la lámina es notófilo, la proporción largo/ancho, 2.03:1. El ángulo de la base de $87^{\circ}$ y el del ápice, $64^{\circ}$.

Venación. La venación primaria es pinnada. La secundaria broquidódroma débil con 6 venas basales, el espaciado de las venas secundarias es uniforme y el ángulo con respecto a la vena primaria aumenta ligeramente hacia la base. Las venas intersecundarias son débiles. La venación terciaria presenta el arreglo mixto (opuesto/alterno percurrente), su curso es ramificado exmedialmente y el ángulo con respecto a la vena primaria es obtuso que decrece exmedialmente. La venación de cuarto orden es reticulada poligonal regular. Las venas de quinto orden son dicótomas, las areolas están bien desarrolladas y las últimas venas libres son muy ramificadas 
(2 o más veces). El orden más alto de venación es el sexto; el último que presenta ramificación excurrente, el cuarto. La venación marginal es libre, forma arcos incompletos. El grado de organización de la hoja es $3 r$.

Características epidérmicas. Estomas de tipo policíticoanomocítico, localizados únicamente en el envés. Los tricomas son moderados y se distribuyen por toda la superficie; son pluricelulares y estelares.

Cristales y canales resiníferos. No se presentan cristales prismáticos ni drusas. No se observan canales resiníferos.

23) Género: Laurophyllus Thunb. (Fig. 12g-i).

Especie tipo: L. capensis Thunb.

Ejemplares aclarados: L. capensis Thunb. (US-H-S. Gentry y A. C. Barclay, Sudáfrica).

Distribución: Sudáfrica.

Descripción: Organización macroscópica. Hojas simples de arreglo alterno e inserción del pecíolo marginal, de textura cartácea, forma oblonga simétrica con base cuneada, ápice convexo y margen serrado. El tamaño de las hojas es micrófilo, la proporción largo/ancho es 2.74:1. El ángulo de la base de $52^{\circ}$ y el del ápice $68^{\circ}$.

Venación. La venación primaria es pinnada. La secundaria craspedódroma con 5 venas basales, el espaciado de las venas secundarias es uniforme y el ángulo con respecto a la vena primaria aumenta ligeramente hacia la base. Las venas intersecundarias son débiles. La venación terciaria presenta el arreglo reticulado poligonal regular, su curso es ramificado exmedialmente y el ángulo con respecto a la vena primaria es obtuso e inconsistente. La venación de cuarto orden es reticulada poligonal regular. Las venas de quinto orden son dicótomas, las areolas están bien desarrolladas y las últimas venas libres van desde ausentes hasta muy ramificadas (2 o más veces). El orden más alto de venación es el quinto y el último que presenta ramificación excurrente, el cuarto. La venación marginal forma arcos. El grado de organización de la hoja es $4 r$.

Dientes. Hay dos órdenes de dientes distribuidos regularmente, 4 por centímetro a lo largo del margen. El lado apical del diente es recto mientras que el lado basal es recto o cóncavo, el ápice del diente es simple y el seno es angular. No hay una vena principal ya que la rama distal proveniente de la dicotomía de la vena secundaria llega al seno.

Características epidérmicas. Estomas de tipo policíticociclocítico localizados únicamente en el envés. Los tricomas son moderados, se distribuyen por toda la superficie y son pluricelulares.

Cristales y canales resiníferos. Se presentan drusas al interior de las venas. No se observan canales resiníferos.

24) Género: Lithraea Miers ex Hook. et Arn. (Fig. 13a-e). Especie tipo: L. caustica (Molina) Hook. et Arn.

Ejemplares aclarados: L. caustica Hook. et Arn. (DUKEMahu 1396-L, Chile; DS-Parsons 222, Chile), L. ternifolia

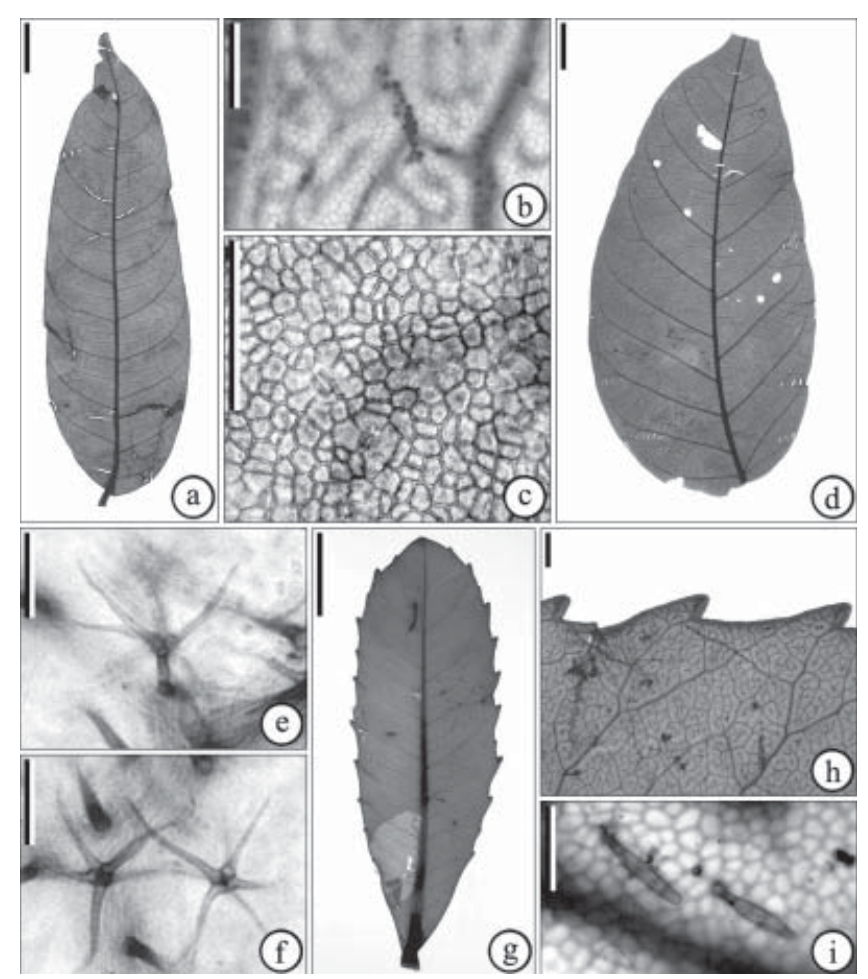

Figura 12. Koordersiodendron, Lannea y Laurophyllus. a-c, Koordersiodendron. a, folíolo de K. pinnatum (escala $=1 \mathrm{~cm}$ ); b, drusas al interior de las venas de $K$. pinnatum (escala $=100 \mu$ ); c, estomas de K. pinnatum (escala $=100 \mu$ ). d-f, Lannea. d, hoja de L. grandis (escala $=1 \mathrm{~cm}$ ); e, tricomas estelares en vista lateral de $L$. grandis (escala $=100 \mu$ ); f, tricomas estelares de L. grandis (escala $=100 \mu$ ). g-i, Laurophyllus. g, hoja de L. capensis (escala=1 $\mathrm{cm}$ ); h, dientes de $L$. capensis (escala=1 mm); i, tricomas de $L$. capensis (escala $=100 \mu$ ).

(Gillies ex Hook.) F. A. Barkley (CAS-Vervoost 8637, Argentina).

Ejemplares complementarios: L. brasiliensis March (MEXUJ. M. Silva y J. Cordeiro 2011, Brasil), L. molleoides Engl. (MEXU-A. Schinini y R. Vanni 15477, Argentina), L. ternifolia (Gillies ex Hook.) F. A. Barkley (MEXU-M. Nee 47703, Bolivia).

Distribución: Sur de Brasil, Paraguay, Bolivia, Uruguay, Chile y Argentina.

Descripción: Organización macroscópica. Hojas compuestas imparipinnadas de arreglo alterno, con folíolos opuestos peciolulados o sésiles, de textura coriácea o cartácea y con raquis alado (L. molleoides* y L. ternifolia), son simples, pecioladas con textura cartácea en $L$. brasiliensis*; en $L$. ternifolia imparipinnadas y en ocasiones trifoliadas; folíolos sésiles de textura coriácea; en $L$. molleoides* son sésiles de textura cartácea y en L. caustica* peciolulados y con textura coriácea; tienen forma elíptica, obovada u ovada, son simétricos o ligeramente asimétricos con base cuneada, ápice convexo, recto o acuminado y margen entero. En $L$. caustica son elípticos simétricos con ápice convexo y margen 


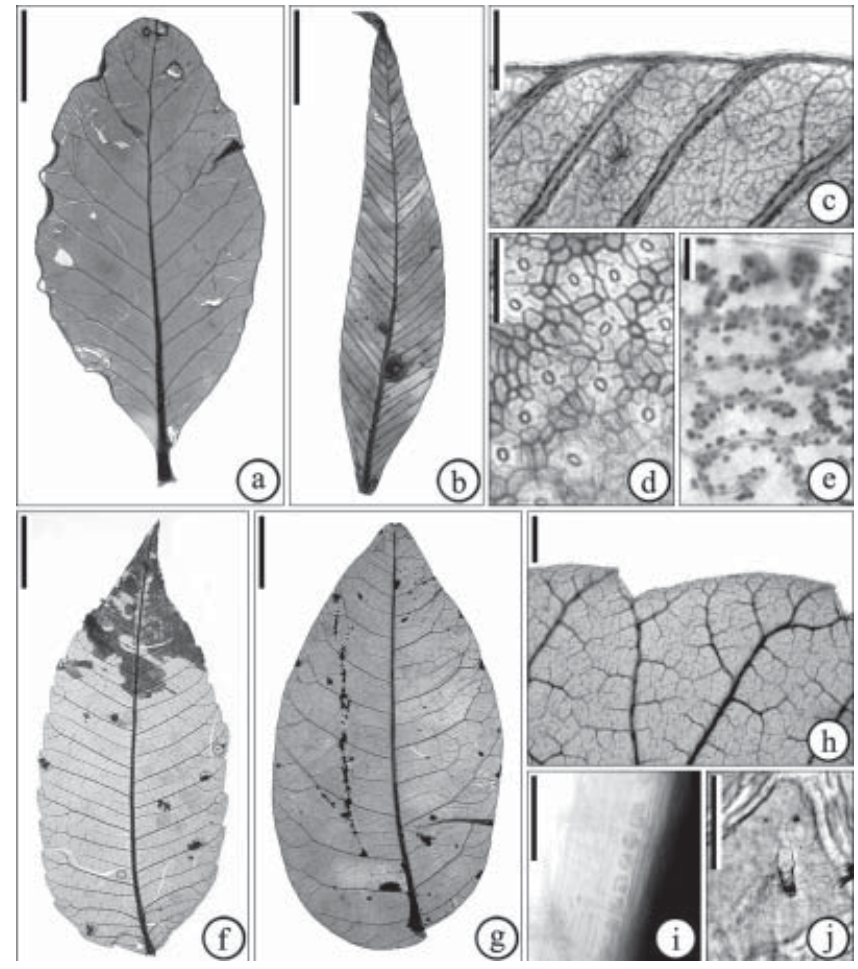

Figura 13. Lithraea y Loxopterygium. a-e, Lithraea. a, folíolo de $L$. caustica $($ escala $=1 \mathrm{~cm}) ; \mathrm{b}$, folíolo de $L$. ternifolia $($ escala $=1 \mathrm{~cm})$; c, venación marginal de L. ternifolia (escala $=1 \mathrm{~mm}$ ); d, estomas de $L$. caustica (escala $=100 \mu$ ); e, drusas al interior de las venas de L. ternifolia (escala $=100 \mu$ ). f-j, Loxopterygium. f, folíolo de $L$. grisebachii (escala $=1 \mathrm{~cm}) ; \mathrm{g}$, folíolo de L. sagottii (escala=1 cm); $\mathrm{h}$, dientes de L. grisebachii (escala=1 mm); i, cristales al interior de las venas de $L$. grisebachii (escala $=100 \mu$ ); j, tricomas glandulares de L. grisebachii (escala=100 $\mu$ ).

erosionado; en L. molleoides* elípticos y ápice acuminado; en L. brasiliensis* la forma es obovada y el ápice convexo, mientras que en $L$. ternifolia, la forma puede ser elíptica (L. ternifolia*) u ovada, ligeramente asimétricos, con ápice recto y base cuneada de un lado y cóncavo-convexa del otro. El tamaño de los folíolos es micrófilo, la proporción largo/ ancho es 3.3875:1 (1.865:1 en L. caustica y 4.91:1 en $L$. ternifolia). El ángulo de la base de $58^{\circ}\left(76.5^{\circ}\right.$ en $L$. caustica y $39.5^{\circ}$ en $L$. ternifolia) y el del ápice, $52.75^{\circ}\left(79.5^{\circ}\right.$ en $L$. caustica y $26^{\circ}$ en L. ternifolia).

Venación. La venación primaria es de tipo pinnada. La secundaria cladódroma I o intramarginal con 2, 3 o 4 venas basales, las venas están espaciadas uniformemente y el ángulo con respecto a la vena primaria es uniforme o aumenta hacia la base ya sea ligera o abruptamente. En L. caustica, la venación secundaria es cladódroma I, se encuentran 2 o 3 venas basales y las venas ocasionalmente pueden ser de espaciado irregular, su ángulo con respecto a la vena primaria aumenta hacia la base ligera o abruptamente; por otro lado, L. ternifolia tiene venación secundaria intramarginal con 4 venas basales y el ángulo con respecto a la vena primaria es uniforme. Las venas intersecundarias pueden estar ausentes, ser débiles (L. caustica) o robustas (L. ternifolia). La venación terciaria es dicótoma, su curso es ramificado admedialmente y el ángulo con respecto a la vena primaria es obtuso y agudo; decrece exmedialmente en L. caustica y es inconsistente en L. ternifolia y L. caustica (ocasionalmente se presentan venas opuestas percurrentes en la venación de tercer orden y ocasionalmente también estas venas presentan únicamente ángulo obtuso en $L$. caustica). La venación de cuarto orden presenta el arreglo dicótomo (en L. caustica, se presenta ocasionalmente el patrón reticulado poligonal regular). Las venas de quinto orden son dicótomas (L. caustica) con areolas poco (L. ternifolia) o de moderadamente a bien desarrolladas (L. caustica) donde las últimas venas libres pueden ser desde no ramificadas hasta ramificadas dos o más veces (en L. ternifolia son altamente ramificadas). El orden más alto de venación es el cuarto o el sexto (cuarto en L. ternifolia y sexto en L. caustica) y el último que presenta ramificación excurrente, el tercero (en $L$. ternifolia) o cuarto (en L. caustica). La venación marginal es libre (arcos incompletos) en L. ternifolia mientras que en $L$. caustica forma una vena fimbrial. El grado de organización de la hoja es $2 \mathrm{r}$ para L. ternifolia y $3 \mathrm{r}$ para L. caustica.

Características epidérmicas. Estomas de tipo policíticoactinocítico ( $L$. caustica) o policítico-ciclocítico ( $L$. ternifolia) ubicados únicamente en el envés. Se presentan tricomas escasos o abundantes únicamente en L caustica (L. ternifolia carece de tricomas), se localizan en toda la superficie de la hoja y son de tipo simple pluricelular.

Cristales y canales resiníferos. Se encuentran cristales prismáticos al interior de las venas (en L caustica, se presentan ocasionalmente también en el mesofilo), se presentan drusas en las venas y el mesofilo ( $L$. caustica carece de ellas). Se localizan canales resiníferos en las venas del primero, segundo y tercer orden de L. ternifolia, en $L$. caustica no se observan canales.

\section{5) Género: Loxopterygium Hook. f. (Fig. 13f-j).}

Especie tipo: L. sagotii Hook. f.

Ejemplares aclarados: L. grisebachii Hiern ex Griseb. (CASMeyer 17412, Argentina), L. sagotii Hook. f. (Colección personal de la Dra. Terrazas, Venezuela).

Ejemplares complementarios: L. grisebachii Hiern ex Griseb. (MEXU-M. Nee 48149, Bolivia), L. huasango Spruce ex Engl. (MEXU-C. Díaz y S. Balderón 2331, Perú), L. sagotii Hook. f. (MEXU-Stahel 81, México).

Distribución: Norte de Argentina, Sur de Bolivia.

Descripción: Organización macroscópica. Hojas compuestas imparipinnadas de arreglo alterno, con folíolos opuestos peciolulados de textura cartácea (membranácea en $L$. huasango*). Folíolos ovados asimétricos o asimétricos sólo en la base; la base es convexa en ambos lados en $L$. grisebachii y convexa de un lado y cordada del otro en $L$. 
sagotii, el ápice puede ser acuminado o retuso y el margen puede ser serrado, crenado o entero (los folíolos son elípticos en L. huasango*, son asimétricos en L. sagotii y asimétricos sólo en la base en L. grisebachii; el ápice es acuminado en $L$. huasango* y L. grisebachii y retuso en L. sagotii; el margen es serrado en L. grisebachii, crenado en L. huasango* y entero en L. sagotii). El tamaño de los folíolos es micrófilo, la proporción largo/ancho es 1.955:1 (2.08:1 en L. grisebachii y $1.83: 1$ en $L$. sagotii). Ángulo de la base de $87.75^{\circ}\left(85.5^{\circ}\right.$ en L. grisebachii y $90^{\circ}$ en $L$. sagotii), el del ápice, $65.75^{\circ}\left(56.5^{\circ}\right.$ en L. grisebachii y $75^{\circ}$ en L. sagotii).

Venación. La venación primaria es pinnada. La secundaria, craspedódroma o cladódroma I con 3 o 6 venas basales, un par de ellas son agróficas en L. sagotii (la venación es craspedódroma con 6 venas basales en L. grisebachii y cladódroma I con 3 venas basales en $L$. sagotii). El espaciado de las venas secundarias es irregular (L. sagotii) o uniforme (L. grisebachii) y su ángulo con respecto a la vena primaria puede ser uniforme (L. grisebachii) o aumentar ligeramente hacia la base (L. sagotii). Las venas intersecundarias en $L$. grisebachii son débiles y en $L$. sagotii, robustas. La venación terciaria presenta el arreglo dicótomo en L. grisebachii y una combinación de opuesto percurrente y reticulado al azar en L. sagotii. El curso de las venas terciarias es ramificado exmedialmente y el ángulo con respecto a la vena primaria es obtuso que decrece exmedialmente en $L$. sagotii mientras que en L. grisebachii es inconsistente. La venación de cuarto orden es reticulada poligonal regular en $L$. sagotii pero en $L$. grisebachii es dicótoma. Las venas de quinto orden presentan el patrón reticulado poligonal regular en L. grisebachii y son dicótomas en $L$. sagotii, las areolas son de moderada ( $L$. sagotii) a bien desarrolladas (L. grisebachii) y las últimas venas libres son muy ramificadas (2 o más veces). El orden más alto de venación es el sexto, y el último que presenta ramificación excurrente, el cuarto. La venación marginal es libre (arcos incompletos) en L. grisebachii y forma arcos en L. sagotii. El grado de organización de la hoja es 3r.

Dientes. En L. grisebachii hay sólo un orden de dientes distribuidos regularmente a todo lo largo del margen, encontrándose 2 dientes por centímetro. Tanto el lado apical como el basal del diente pueden ser de tipo convexo o flexo, el ápice es esferulado y el seno angular. La vena principal del diente es la rama distal de una dicotomía de una vena secundaria.

Características epidérmicas. Los estomas son de tipo policítico-anomocítico, localizados únicamente en el envés. L. sagotii carece de tricomas pero en L. grisebachii son abundantes, se distribuyen por toda la superficie y son de tipo pluricelular y glandular.

Cristales y canales resiníferos. Se presentan cristales prismáticos y drusas al interior de las venas de L. grisebachii; L. sagotii carece de ellos. Se presentan canales resiníferos en las venas de primero, segundo, tercero y cuarto orden.
26) Género: Loxostylis A. Spreng. ex Rchb. (Fig. 14a-b). Especie tipo: L. alata A. Spreng. ex Rchb.

Ejemplares aclarados: L. alata A. Spreng. ex Rchb. (US-R. D. A. Bayliss 5269, Sudáfrica).

Distribución: Sudáfrica.

Descripción: Organización macroscópica. Hojas compuestas imparipinnadas, alternas y folíolos opuestos sésiles, de textura coriácea y raquis alado. Los folíolos son de forma elíptica, ligeramente asimétricos en la base que es convexa de un lado y cuneada en el otro, el ápice es acuminado con una proyección de la vena media (mucrón) y el margen es entero. El tamaño de los folíolos es micrófilo, la proporción largo/ancho es 5.08:1. Ángulo de la base de $39^{\circ}$ y el del ápice de $30^{\circ}$.

Venación. La venación primaria es pinnada. La secundaria es cladódroma II, con 3 venas basales. El espaciado de las venas secundarias es uniforme, su ángulo con respecto a la vena primaria disminuye hacia la base. No se presentan venas intersecundarias. La venación terciaria es de tipo dicótomo cuyo curso es ramificado admedialmente y el ángulo con respecto a la vena primaria es tanto obtuso como agudo y

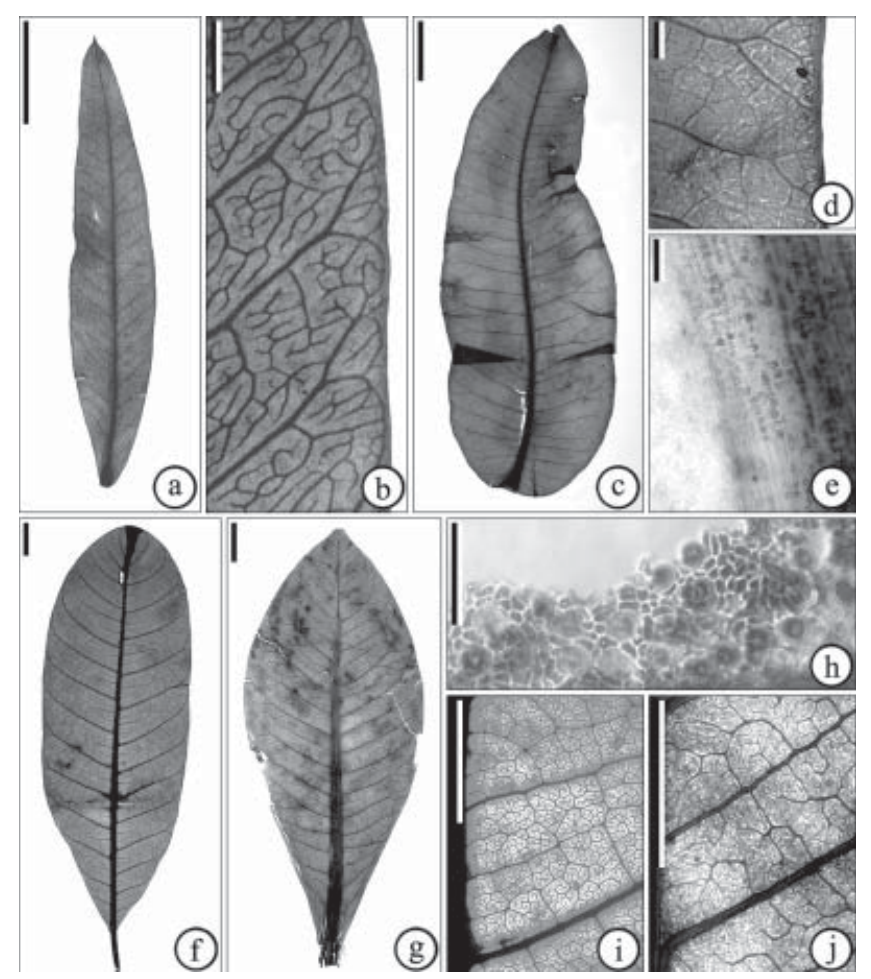

Figura 14. Loxostylis, Malosma y Mangifera. a-b, Loxostylis. a, folíolo de $L$. alata (escala $=1 \mathrm{~cm})$; b, venación secundaria de $L$. alata (escala=1 mm). c-e, Malosma. c, hoja de M. laurina (escala=1 $\mathrm{cm})$; , venación secundaria de M. laurina (escala=1 mm); e, cristales prismáticos y drusas al interior de las venas de $M$. laurina (escala $=100 \mu$ ). f-j, Mangifera. f, hoja de $M$. indica (escala=1 cm); g, hoja de $M$. verticillata (escala $=1 \mathrm{~cm}$ ); h, estomas de $M$. verticillata (escala $=100 \mu$ ); i, venación de tercer orden de $M$. indica (escala=5 $\mathrm{mm}$ ); j, venación de tercer orden de $M$. verticillata (escala=5 mm). 
decrece exmedialmente. Tanto la venación de cuarto como la de quinto orden son dicótomas. Las areolas están poco desarrolladas, las últimas venas libres pueden ser ausentes, no ramificadas o ramificadas una vez. El orden más alto de venación es el quinto y el último que presenta ramificación excurrente, el tercero. La venación marginal forma arcos incompletos. El grado de organización de la hoja es 2 r.

Características epidérmicas. Los estomas son de tipo policítico-ciclocítico, localizados únicamente en el envés. No se presentan tricomas.

Cristales y canales resiníferos. Se encuentran cristales prismáticos al interior de las venas. No se observan canales resiníferos.

27) Género: Malosma Engl. (Fig. 14c-e).

Especie tipo: M. laurina Engl.

Ejemplares aclarados: M. laurina Engl. (MEXU-Colecc. $H$. S. Gentry 4271, México).

Distribución: México (Baja California), Estados Unidos (Sur de California).

Descripción: Organización macroscópica. Hojas simples con arreglo alterno e inserción del pecíolo marginal, de textura coriácea. Las hojas son de forma elíptica, simétricas con base convexa, ápice acuminado y margen entero. El tamaño de las hojas es micrófilo, la proporción largo/ancho es 2.68:1. El ángulo de la base es de $77^{\circ}$ y el del ápice de $43^{\circ}$.

Venación. La venación primaria es pinnada. La secundaria cladódroma I con 6 venas basales, el espaciado de las venas secundarias disminuye hacia la base y hacia el ápice y el ángulo con respecto a la vena primaria aumenta ligeramente hacia la base. Las venas intersecundarias son débiles. La venación terciaria presenta el arreglo reticulado al azar, su curso es ramificado exmedialmente y el ángulo respecto a la vena primaria es obtuso y agudo e inconsistente. La venación de cuarto orden es reticulada poligonal regular al igual que las venas de quinto orden. Las areolas están bien desarrolladas y las últimas venas libres van desde ausentes hasta ramificadas una vez. El orden más alto de venación es el séptimo y el último que presenta ramificación excurrente, el quinto. La venación marginal forma arcos. El grado de organización de la hoja es 3 r.

Características epidérmicas. Estomas de tipo policíticoactinocítico, localizados únicamente en el envés. No se presentan tricomas.

Cristales y canales resiníferos. Los cristales prismáticos y las drusas se encuentran al interior de las venas. No se observan canales resiníferos.

28) Género: Mangifera L. (Fig. 14f-j).

Especie tipo: $M$. indica L.

Ejemplares aclarados: M. indica L. (US-F. R. Fosberg 31542, Islas Bonin, Japón), M. verticillata C. B. Robinson (DS-Elmer 13258, Filipinas).

Ejemplares complementarios: M. caloneura Kurz (MEXU-
J. F. Maxwell 88-130, Tailandia), M. indica L. (MEXUIrmtraud Wagenbreth 846, México; MEXU-L. M. Ortega T. 82, México), M. verticillata C. B. Robinson (NY-A. D. E. Elmer 13258, Filipinas, tipo).

Distribución: India, Sri Lanka, China, Myanmar, Tailandia, Indochina, Malasia, Indonesia, Islas Salomón, Nueva Guinea, Filipinas.

Descripción: Organización macroscópica. Hojas simples con arreglo pseudoverticilado ( $M$. indica) o verticilado (M. verticillata) e inserción del pecíolo marginal, de textura coriácea, pueden tener forma oblonga u obovada, son simétricas, presentan base cuneada, ápice convexo o acuminado y margen entero (obovadas en $M$. verticillata; el ápice es convexo en $M$. indica y acuminado en M. caloneura* y $M$. verticillata). Las hojas son de tamaño notófilo $(M$. verticillata) o mesófilo ( $M$. indica) de proporción largo/ancho 2.4275:1 (2.78:1 en $M$. indica y 2.075:1 en $M$. verticillata). El ángulo de la base es de $59.25^{\circ}\left(60^{\circ}\right.$ en $M$. indica y $58.5^{\circ}$ en $M$. verticillata) y el del del ápice de $75.75^{\circ}\left(71^{\circ}\right.$ en $M$. indica y $80.5^{\circ}$ en $M$. verticillata).

Venación. La venación primaria es pinnada. La secundaria, cladódroma I o II con 3 o 7 venas basales ( $M$. verticillata presenta venación secundaria tipo cladódroma I con 7 venas basales mientras que $M$. indica la tiene tipo cladódroma II con 3 venas basales). El espaciado de las venas secundarias es uniforme y el ángulo con respecto a la vena primaria es uniforme ( $M$. indica) o disminuye hacia la base $(M$. verticillata). Las venas intersecundarias son débiles o robustas (débiles en $M$. verticillata y robustas en $M$. indica). La venación terciaria es principalmente alterna percurrente aunque en $M$. verticillata pueden encontrarse también opuestas percurrentes dando un arreglo mixto. El curso de las venas terciarias es ramificado exmedialmente y el ángulo con respecto a la vena primaria es obtuso que decrece exmedialmente (en M. verticillata también hay algunas agudas). La venación de cuarto orden es reticulada poligonal regular. Las venas de quinto orden son dicótomas. Las areolas están poco (M. verticillata) o bien desarrolladas (M. indica) y las últimas venas libres son muy ramificadas (dos o más veces). El orden más alto de venación es el quinto o el séptimo (quinto para $M$. verticillata y séptimo para $M$. indica) y el último que presenta ramificación excurrente, el cuarto o quinto (cuarto para $M$. verticillata y quinto para $M$. indica). La venación marginal forma arcos en $M$. indica y arcos incompletos en $M$. verticillata. El grado de organización de la hoja es 4r ( $M$. indica) o 3r (M. verticillata).

Características epidérmicas. Estomas de tipo policíticociclocítico, localizados únicamente en el envés. No se presentan tricomas.

Cristales y canales resiníferos. Se presentan cristales prismáticos al interior de las venas (en $M$. indica también se encuentran en el mesofilo). No se observan canales resiníferos. 
29) Género: Mauria Kunth. (Fig. 15a-e).

Especie tipo: M. simplicifolia Kunth.

Ejemplares aclarados: M. aurantiodora Engl. (DSWeberbauer 6750, Perú), M. sessiliflora Standley (DSMatuda 5197, México), M. simplicifolia H. B. K. (USCuastrecasas 19167, Colombia; CAS-Asplund 13587, Perú).

Ejemplares complementarios: M. ferruginea Tul (MEXUD. N. Smith 6958, Perú), M. glauca Donn. Sm (MEXU-G. McPherson y M. Merello 8375, Panamá), M. heterophylla $\mathrm{H}$. B. K. (MEXU-P. M. Jorgensen et al. 611, Ecuador; MEXU-T. B. Croat 61574, Ecuador), M. sessiliflora Standley (MEXUC. Nelson y C. Soto 8154, Honduras; MEXU-V. Vázquez T. 551, México), M. simplicifolia H. B. K. (MEXU-M. Merello et al. 1071, Perú), M. suaveolens Poepp. et Endl. (MEXU-W. Palacios 3324, Ecuador).

Distribución: Centroamérica, Andes; Venezuela, Colombia, Ecuador, Perú, Argentina, Bolivia.

Descripción: Organización macroscópica. Hojas con arreglo alterno, compuestas imparipinnadas o simples con folíolos opuestos (en M. simplicifolia, las hojas son simples, en las demás especies son compuestas). La textura es coriácea o cartácea (coriácea en M. aurantiodora, M. glauca* y $M$. simplicifolia y cartácea en M. ferruginea*, M. heterophylla*, M. sessiliflora, M. simplicifolia y $M$. suaveolens*). La inserción del pecíolo/peciólulo es marginal, la forma de las hojas/folíolos es elíptica, aunque a veces puede ser oblonga u ovada, es simétrica (la forma es oblonga en algunos ejemplares de $M$. sessiliflora y $M$. simplicifolia y ovada en M. ferruginea*, M. glauca*, M. heterophylla* y $M$. suaveolens*; M. aurantiodora es asimétrica en la base). La forma de la base es variable, convexa de un lado y cóncavoconvexa del otro en $M$. aurantiodora, decurrente en $M$. sessiliflora y cuneada o convexa en $M$. simplicifolia. El ápice también es variable, acuminado en $M$. aurantiodora, $M$. glauca* y M. heterophylla*, recto o retuso en M. sessiliflora y convexo o retuso en $M$. simplicifolia. El margen es entero. Las hojas/folíolos son de tamaño notófilo (a veces micrófilo en $M$. sessiliflora). La proporción largo/ancho es 2.00:1(2.5766:1)-3.44:1, el ángulo de la base, de $53.5^{\circ}-\left(70.5^{\circ}\right)-86^{\circ}$ y el del ápice, $48^{\circ}-\left(67.666^{\circ}\right)-87^{\circ}$.

Venación. La venación primaria es pinnada. La secundaria cladódroma I con 4, 5 o 7 venas basales (es eucamptódroma en M. sessiliflora; en M. aurantiodora hay 4 venas basales, 5 en M. sessiliflora y M. simplicifolia y 7 en M. simplicifolia). El espaciado de las venas secundarias es irregular, sólo en M. simplicifolia decrece hacia la base; el ángulo respecto a la vena primaria es muy variable, es uniforme en $M$. sessiliflora, aumenta ligeramente hacia la base en $M$. aurantiodora y aumenta abruptamente o disminuye hacia la base en $M$. simplicifolia. Las venas intersecundarias pueden estar ausentes, ser débiles o robustas (están ausentes en $M$. simplicifolia, son débiles en $M$. aurantiodora y robustas en $M$. sessiliflora). La venación terciaria presenta principalmente el arreglo mixto (opuestas/alternas percurrentes) aunque puede ser reticulada al azar ( $M$. sessiliflora). El curso de las venas terciarias es ramificado exmedialmente (admedialmente en M. aurantiodora) y el ángulo respecto a la vena primaria es obtuso, y puede ser inconsistente, aumentar basalmente o decrecer exmedialmente (inconsistente en M. aurantiodora, aumenta basalmente en M. sessiliflora y M. simplicifolia y decrece exmedialmente en $M$. simplicifolia). La venación de cuarto orden es reticulada poligonal regular. Las venas de quinto orden pueden ser dicótomas como en M. sessiliflora y $M$. simplicifolia o tener el arreglo reticulado poligonal regular como en $M$. aurantiodora y M. simplicifolia. Las areolas están bien desarrolladas (a veces moderadamente en M. simplicifolia) y las últimas venas libres son desde no ramificadas hasta muy ramificadas (dos o más veces) siendo este último estado el más común en M. sessiliflora. El orden más alto de venación es el sexto (séptimo en M. aurantiodora) y el último que presenta ramificación excurrente es el cuarto o quinto (cuarto en M. sessiliflora y M. simplicifolia y quinto en M. aurantiodora y M. simplicifolia). La venación marginal forma $\operatorname{arcos}$ (en M. simplicifolia forma una vena fimbrial). El grado de organización de la hoja es $4 \mathrm{r}$ ( $3 \mathrm{r}$ en M. sessiliflora y algunos ejemplares de $M$. simplicifolia).

Características epidérmicas. Los estomas son de tipo policítico-anomocítico localizados únicamente en el envés (en M. simplicifolia también pueden encontrarse estomas de tipo policítico-actinocítico). Mauria aurantiodora y algunos ejemplares de M. simplicifolia carecen de tricomas, en los otros casos son escasos; son de tipo pluricelular y se distribuyen en toda la superficie.

Cristales y canales resiníferos. Se presentan cristales prismáticos al interior de las venas y en el mesofilo ( $M$. sessiliflora y algunos ejemplares de $M$. simplicifolia carecen de ellos). No se observan canales resiníferos excepto en M. sessiliflora donde se presentan en las venas de primero, segundo, tercero, cuarto y quinto orden.

30) Género: Melanochyla Hook. f. (Fig. 15f, h).

Especie tipo: M. auriculata Hook. f.

Ejemplares aclarados: M. auriculata Hook. f. (US-SFN 29364, Malasia).

Distribución: Malasia, Tailandia peninsular, Sumatra, Java y Borneo.

Descripción: Organización macroscópica. Hojas simples con arreglo pseudoverticilado e inserción del pecíolo marginal, de textura cartácea. Las hojas son elípticas simétricas con base cordada, ápice convexo y margen entero. El tamaño de las hojas es micrófilo, la proporción largo/ancho es 1.7:1. El ángulo de la base es $96^{\circ}$ y el del ápice, $95^{\circ}$.

Venación. La venación primaria es pinnada. La secundaria broquidódroma débil con 8 venas basales, el espaciado de las venas secundarias es uniforme y su ángulo aumenta abruptamente hacia la base. Las venas intersecundarias son robustas. La venación terciaria es mixta (venas opuestas y 
alternas percurrentes), su curso es recto y ángulo respecto a la vena primaria es obtuso que decrece exmedialmente. La venación de cuarto orden es reticulada poligonal regular mientras que las venas de quinto orden son dicótomas. Las areolas están moderadamente desarrolladas y las últimas venas libres van desde ausentes hasta ramificadas dos o más veces. El orden más alto de venación es el quinto; el último que presenta ramificación excurrente, el cuarto. La venación marginal forma arcos. El grado de organización de la hoja es $3 r$.

Características epidérmicas. Estomas de tipo policíticociclocítico, localizados únicamente en el envés. No se presentan tricomas.

Cristales y canales resiníferos. Los cristales prismáticos se presentan únicamente al interior de las venas. No se observan canales resiníferos.

31) Género: Metopium P. Browne (Fig. 15g, i).

Especie tipo: M. linnaei Engl.

Ejemplares aclarados: M. brownei Urb. (DS-Contreras 5766, Guatemala; MEXU-P. Moreno 597 y G. Gaos, México).

Ejemplares complementarios: $M$. brownei Urb. (MEXUM. Ventura 462, México); M. toxiferum (L.) Krug et Urb. (MEXU-M. Fishbein 821 V. Rans y B. Greenfeld s/n, Estados Unidos).

Distribución: Antillas, Estados Unidos (Florida), México, Centroamérica.

Descripción: Organización macroscópica. Hojas compuestas imparipinnadas de arreglo alterno, con folíolos opuestos peciolulados y textura cartácea o membranácea (cartácea en M. brownei y M. toxiferum*, membranácea en M. brownei). Los folíolos tienen forma elíptica u ovada, son asimétricos o asimétricos en la base, la cual es cóncavo-convexa o decurrente, el ápice es retuso-acuminado y el margen es entero ( $M$. brownei puede presentar forma elíptica u ovada, $M$. toxiferum* tiene forma ovada; el ápice de $M$. toxiferum* es recto). El tamaño de los folíolos es micrófilo o notófilo, la proporción largo/ancho es 1.605:1. El ángulo de la base es de $98.5^{\circ}$ y el del ápice de $82.5^{\circ}$.

Venación. La venación primaria es pinnada. La secundaria, cladódroma II con 6 venas basales; el espaciado de las venas secundarias disminuye hacia la base o es irregular y el ángulo aumenta ligeramente hacia la base. Las venas intersecundarias son débiles o están ausentes. La venación terciaria es mixta (con venas opuestas y alternas percurrentes), su curso es ramificado admedialmente y su ángulo con respecto a la vena primaria es obtuso que decrece exmedialmente o es inconsistente. La venación de cuarto orden es reticulada poligonal regular o dicótoma. Las venas de quinto orden son dicótomas. Las areolas están de moderadamente a bien desarrolladas y las últimas venas libres están ramificadas dos o más veces. El orden más alto de venación es el sexto; el último que presenta ramificación excurrente, el cuarto. La venación marginal forma arcos o una vena fimbrial. El grado

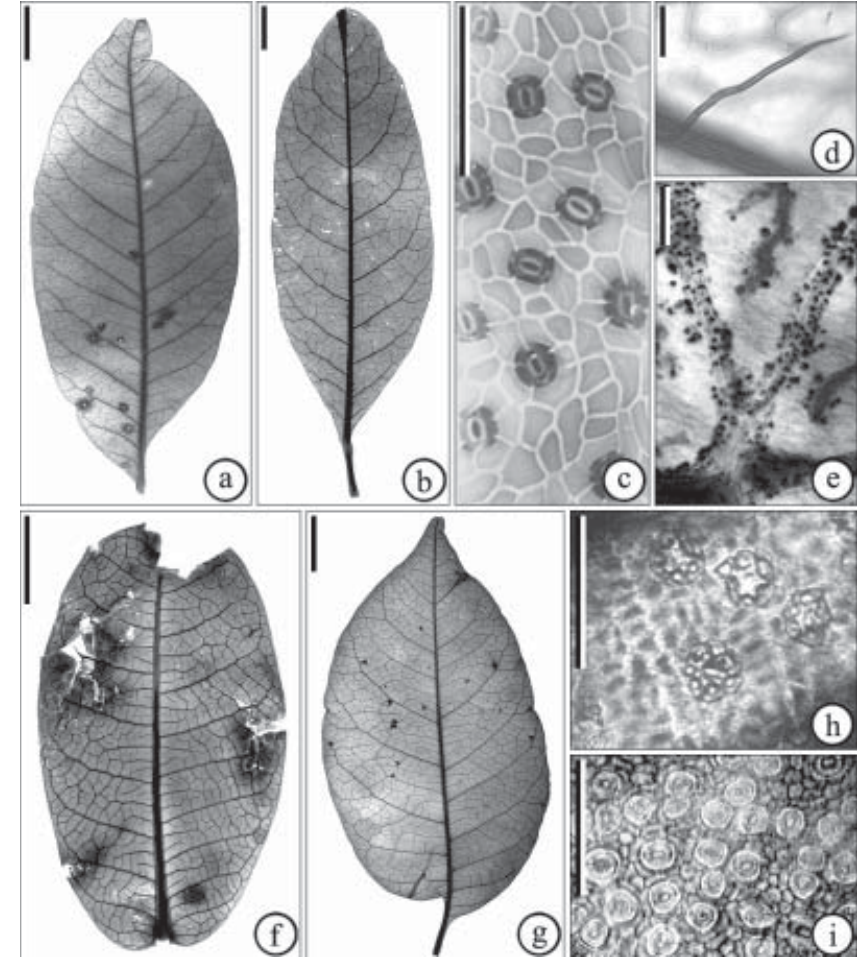

Figura 15. Mauria, Melanochyla y Metopium. a-e, Mauria. a, lámina de $M$. aurantiodora (escala $=1 \mathrm{~cm})$; b, hoja de $M$. simplicifolia (escala $=1 \mathrm{~cm}$ ); c, estomas de $M$. simplicifolia (escala $=100 \mu$ ); d, tricoma de $M$. sessiliflora (escala $=100 \mu$ ); e, cristales prismáticos en las venas de $M$. simplicifolia (escala=100 $\mu$ ). f, h, Melanochyla. $\mathrm{f}$, hoja de $M$. auriculata (escala $=1 \mathrm{~cm}$ ); h, estomas de $M$. auriculata (escala $=100 \mu$ ). g, i, Metopium. g, folíolo de M. brownei (escala=1 $\mathrm{cm})$; i, estomas de $M$. brownei. (escala $=100 \mu)$.

de organización de la hoja es 2 r o 3r.

Características epidérmicas. Estomas de tipo policíticoanomocítico o policítico-ciclocítico, localizados únicamente en el envés. No se presentan tricomas.

Cristales y canales resiníferos. Los cristales prismáticos se presentan únicamente al interior de las venas mientras que las drusas se presentan en el mesofilo aunque ambos tipos de cristal pueden estar ausentes. Los canales resiníferos se presentan en las venas de primero a cuarto y ocasionalmente en las de quinto orden.

32) Género: Mosquitoxylum Krug et Urb. (Fig. 16a-c).

Especie tipo: $M$. jamaicense Krug et Urb.

Ejemplares aclarados: M. jamaicense Krug et Urb. (DUKET. B. Croat 17409, Panamá).

Ejemplares complementarios: $M$. jamaicense Krug et Urb. (MEXU-H. Hernández G. 2331, México).

Distribución: Jamaica, México, Centroamérica, Noroeste de Ecuador.

Descripción: Organización macroscópica. Hojas compuestas paripinnadas de arreglo alterno y folíolos opuestos, inserción 
del peciólulo marginal y textura cartácea. Folíolos de forma obovada ligeramente asimétrica en la base que es cuneada, el ápice es acuminado y el margen, entero. El tamaño de los folíolos es micrófilo, la proporción largo/ancho es 2.59:1. El ángulo de la base es de $59^{\circ}$ y el del ápice de $68^{\circ}$.

Venación. La venación primaria es pinnada. La secundaria cladódroma I con 3 venas basales, incluyendo venas agróficas compuestas; el espaciado de las venas secundarias es irregular y su ángulo con respecto a la vena primaria, uniforme. Las venas intersecundarias son débiles. La venación terciaria es mixta/dicótoma (con venas opuestas, alternas percurrentes y dicótomas), su curso es ramificado exmedialmente y el ángulo con respecto a la vena primaria es obtuso y uniforme. La venación de cuarto y quinto orden es dicótoma. No se presentan areolas. El orden más alto de venación es el sexto y el último que presenta ramificación excurrente, el cuarto. La venación marginal forma arcos incompletos. El grado de organización de la hoja es 3 r.

Características epidérmicas. Estomas de tipo policíticoanomocítico localizados únicamente en el envés. Se presentan tricomas en una cantidad moderada y son de tipo glandular. Cristales y canales resiníferos. Se presentan drusas al interior de las venas. No se observan canales resiníferos.

\section{3) Género: Myracrodruon Allemão (Fig. 16d-g).}

Especie tipo: M. urundeuva Allemão et M. Allemão.

Ejemplares aclarados: M. balansae (Engl.) D. A. Santin (USH. M. Curran 55, Argentina), M. urundeuva Allemão et M. Allemão. (MEXU-I. G. Vargas C. 5285, Bolivia).

Ejemplares complementarios: $M$. urundeuva Allemão et M. Allemão. (MEXU-G. Hatschbach 64954 A. Schinini y J. M. Silva, Brasil).

Distribución: Cuba, Chaco de Argentina, Bolivia, Paraguay, Suroeste de Brasil.

Descripción: Organización macroscópica. Hojas compuestas imparipinnadas con arreglo alterno, de folíolos opuestos con inserción del peciólulo marginal y textura membranácea a cartácea. La forma de los folíolos es ovada, son asimétricos en la base ( $M$. urundeuva) o ligeramente asimétricos en la base ( $M$. balansae) que es cóncavo-convexa de un lado y convexa ( $M$. urundeuva) o cóncavo-convexa (M. balansae) del otro, el ápice es recto como en $M$. balansae o complejo con una proyección de la vena media (mucrón) como en $M$. urundeuva. El margen es serrado (M. balansae) o crenado (M. urundeuva). El tamaño de los folíolos es micrófilo, la proporción largo/ancho es 2.3:1 (2.41:1 en M. balansae y 2.19:1 en M. urundeuva). El ángulo de la base es de $76^{\circ}\left(73^{\circ}\right.$ en $M$. balansae y $79^{\circ}$ en $M$. urundeuva) y el del ápice, $55.5^{\circ}$ ( $55^{\circ}$ en $M$. balansae y $56^{\circ}$ en $M$. urundeuva).

Venación. La venación primaria es pinnada. La secundaria craspedódroma con 4 venas basales en $M$. balansae, y cladódroma I con 3 venas basales en $M$. urundeuva, el espaciado de las venas secundarias es uniforme en $M$. balansae y disminuye hacia la base y el ápice en $M$.

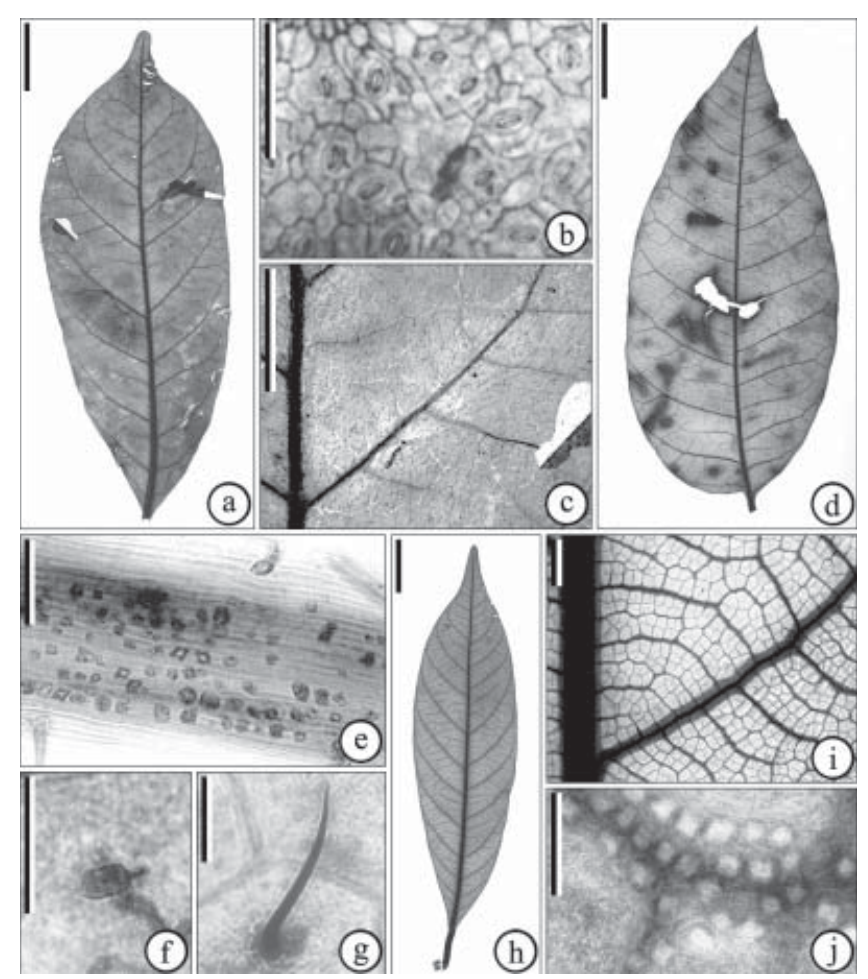

Figura 16. Mosquitoxylum, Myracrodruon y Nothopegia. a-c, Mosquitoxylum. a, folíolo de $M$. jamaicense (escala=1 cm); b, estomas de $M$. jamaicense (escala=100 $\mu$ ); c, venación de tercer orden de $M$. jamaicense (escala=5 mm). d-g, Myracrodruon. d, folíolo de $M$. urundeuva (escala=1 $\mathrm{cm}$ ); e, cristales prismáticos y drusas en las venas de $M$. urundeuva (escala $=100 \mu$ ); f, tricoma glandular de $M$. urundeuva (escala $=100 \mu$ ); g, tricoma pluricelular de $M$. urundeuva (escala=100 $\mu$ ). h-j, Nothopegia. h, lámina de $N$. beddomei (escala $=1 \mathrm{~cm}) ; \mathrm{i}$, venación de tercer orden de $N$. beddomei (escala $=1 \mathrm{~mm}$ ); $\mathrm{j}$, cristales prismáticos en las venas de $N$. beddomei (escala $=100 \mu$ ).

urundeuva y el ángulo aumenta ligeramente hacia la base. Las venas intersecundarias son robustas. La venación terciaria es dicótoma en $M$. balansae y mixta (venas opuestas/alternas percurrentes) en $M$. urundeuva, su curso es ramificado exmedialmente y el ángulo con respecto a la vena primaria es obtuso e inconsistente. La venación de cuarto orden es dicótoma en $M$. balansae y reticulada poligonal regular en M. urundeuva mientras que la de quinto orden es dicótoma. Las areolas están de poco ( $M$. balansae) a moderadamente desarrolladas (M. urundeuva), las últimas venas libres son ramificadas dos o más veces. El orden más alto de venación es el quinto ( $M$. balansae) o el séptimo (M. urundeuva) y el último que presenta ramificación excurrente, el tercero $(M$. balansae) o el quinto ( $M$. urundeuva). La venación marginal forma $\operatorname{arcos}$ en $M$. balansae y arcos incompletos en $M$. urundeuva. El grado de organización de la hoja es 3r para $M$. balansae y 2r para M. urundeuva.

Dientes. Hay un orden de dientes distribuidos regular $(M$. balansae) o irregularmente (M. urundeuva) a todo lo largo 
del margen, encontrándose 3 (M. balansae) o un solo diente por centímetro ( $M$. urundeuva). El lado apical del diente puede ser cóncavo ( $M$. balansae), convexo o recto ( $M$. urundeuva), el basal es convexo (ocasionalmente recto o retroflexo en $M$. balansae), el ápice del diente es simple y el seno, angular. La venación del diente en M. balansae carece de vena principal, la rama distal proveniente de la dicotomía de la vena secundaria llega al seno del diente mientras que en M. urundeuva, pequeñas venas entran al diente pero ninguna de ellas forma una vena principal.

Características epidérmicas. Los estomas son de tipo policítico-anomocítico localizados únicamente en el envés. En $M$. urundeuva, se presentan tricomas en cantidad moderada distribuidos en toda la superficie, son de tipo pluricelular y glandular, M. balansae carece de tricomas.

Cristales y canales resiníferos. Se presentan cristales prismáticos al interior de las venas y $M$. urundeuva también presenta drusas. No se observan canales resiníferos en $M$. urundeuva, pero en $M$. balansae se presentan en las venas de primero, segundo y tercer orden.

34) Género: Nothopegia Blume (Fig. 16h-j).

Especie tipo: N. colebrookiana (Wight) Blume.

Ejemplares aclarados: N. beddomei Gamble. (US-G. Davidse 8838, Sri Lanka).

Ejemplares complementarios: N. sp. (MEXU-C. E. Ridsdale 381, India). Número de especies: 12.

Distribución: India, Sri Lanka.

Descripción: Organización macroscópica. Hojas simples de arreglo alterno pecioladas $\left(N . \mathrm{sp} .^{*}\right)$ de textura cartácea. Las hojas son elípticas simétricas, de base cuneada (convexa en $N$. sp.*), ápice acuminado y margen entero. El tamaño de la lámina es micrófilo, la proporción largo/ancho es 6.19:1. El ángulo de la base es de $41^{\circ}$ y el del ápice de $47^{\circ}$.

Venación. La venación primaria es pinnada. La secundaria eucamptódroma con 5 venas basales, el espaciado de las venas secundarias disminuye hacia la base y el ápice y el ángulo aumenta ligeramente hacia la base. Las venas intersecundarias son débiles. La venación terciaria es mixta (venas opuestas/alternas percurrentes), su curso es recto y su ángulo con respecto a la vena primaria es obtuso que decrece exmedialmente. La de cuarto orden es reticulada poligonal regular al igual que la de quinto orden. Las areolas presentan un arreglo paxilado donde las últimas venas libres son no ramificadas o están ausentes. El orden más alto de venación es el sexto; el último que presenta ramificación excurrente, el quinto. La venación marginal forma una vena fimbrial. El grado de organización de la hoja es $4 \mathrm{r}$.

Características epidérmicas. Estomas de tipo policíticoanomocítico, localizados únicamente en el envés. No se presentan tricomas.

Cristales y canales resiníferos. Se presentan cristales prismáticos al interior de las venas. Los canales resiníferos se presentan en las venas de primero, segundo, tercero y cuarto orden.

35) Género: Ochoterenaea F. A. Barkley (Fig. 17a-c).

Especie tipo: O. colombiana F. A. Barkley.

Ejemplares aclarados: O. colombiana F. A. Barkley (NY-St. G. Beck 13622, Bolivia).

Ejemplares complementarios: O. colombiana F. A. Barkley (MEXU-J. A. Steyermark y R. Liesner 119105, Venezuela).

Distribución: Bolivia, Colombia, Venezuela.

Descripción: Organización macroscópica. Hojas compuestas imparipinnadas de arreglo alterno, con folíolos opuestos sésiles de textura membranácea. Folíolos de forma oblonga asimétrica; base convexa de un lado y cóncavo-convexa del otro, ápice acuminado y margen entero. El tamaño de los folíolos es micrófilo, la proporción largo/ancho es 3.05:1. El ángulo de la base es de $68^{\circ}$ y el del ápice, $57^{\circ}$.

Venación. La venación primaria es pinnada. La secundaria, broquidódroma débil con 7 venas basales; el espaciado de las venas secundarias es irregular y el ángulo aumenta ligeramente hacia la base. Las venas intersecundarias son débiles. La venación terciaria es mixta (venas opuestas/ alternas percurrentes), su curso es recto y el ángulo con respecto a la vena primaria es obtuso y uniforme. La venación de cuarto orden es mixta (opuestas y alternas percurrentes). La de quinto orden forma un retículo poligonal regular. Las areolas están moderadamente desarrolladas; las últimas venas libres son desde ausentes hasta altamente ramificadas. El orden más alto de venación es el sexto; el último que presenta ramificación excurrente, el cuarto. La venación marginal forma arcos. El grado de organización de la hoja es $3 r$.

Características epidérmicas. Estomas de tipo policíticoanomocítico, localizados únicamente en el envés. Los tricomas son moderados, de tipo pluricelular y glandular distribuidos en toda la superficie.

Cristales y canales resiníferos. No se presentan ni cristales prismáticos ni drusas. Los canales resiníferos no se observan.

36) Género: Operculicarya H. Perrier. (Fig. 17d-f).

Especie tipo: no designada.

Ejemplares aclarados: O. decaryi H. Perrier (MO-P. B. Phillipson 2890, Madagascar).

Distribución: Madagascar.

Descripción: Organización macroscópica. Hojas compuestas imparipinnadas de arreglo opuesto y folíolos opuestos sésiles de textura coriácea. Los folíolos tienen forma elíptica ligeramente asimétrica, la base es cuneada, el ápice emarginado y el margen entero. El tamaño de los folíolos es nanófilo, la proporción largo/ancho es 1.47:1. El ángulo de la base es de $90^{\circ}$ y el del ápice $115^{\circ}$.

Venación. La venación primaria es pinnada. La secundaria reticulódroma con 7 venas basales; el espaciado de las venas secundarias es irregular y el ángulo con respecto a la vena primaria, uniforme. No se presentan venas intersecundarias. 
La venación terciaria presenta el patrón reticulado al azar. El curso de las venas terciarias es ramificado admedialmente y el ángulo con respecto a la vena primaria es obtuso (a veces agudo) e inconsistente. La venación de cuarto orden tiene un patrón reticulado poligonal regular. La de quinto orden es dicótoma. Las areolas están poco desarrolladas y las últimas venas libres son altamente ramificadas (dos o más veces). El orden más alto de venación es el quinto; el último que presenta ramificación excurrente, el cuarto. La venación marginal forma arcos. El grado de organización de la hoja es $1 \mathrm{r}$.

Características epidérmicas. Estomas de tipo policíticoanomocítico localizados únicamente en el envés. Los tricomas son escasos, se localizan sobre las venas y son de tipo pluricelular.

Cristales y canales resiníferos. Los cristales prismáticos se encuentran en el interior de las venas y en el mesofilo. Los canales resiníferos no se observan.

37) Género: Ozoroa Delile (Fig. 17g-k).

Especie tipo: O. insignis Delile.

Ejemplares aclarados: O. paniculosa (Sond.) R. et A. Fernandes (MEXU-Lotsy y Goddijn s/n, Sudáfrica; NCU-G. Peeters et al. 194, Bophuthatswana).

Distribución: Este de África, Zaire, Sudáfrica, Madagascar. Descripción: Organización macroscópica. Hojas simples alternas, pecioladas de textura coriácea, son oblongas simétricas, la base y el ápice convexos; el ápice presenta una proyección de la vena media (mucrón), el margen es entero. El tamaño de las hojas es micrófilo, la proporción largo/ancho es de 3.49:1. El ángulo de la base es de $53^{\circ}$ y el del ápice de $47.5^{\circ}$.

Venación. La venación primaria es pinnada. La secundaria, intramarginal con 3 o 5 venas basales, el espaciado de las venas secundarias es uniforme al igual que su ángulo con respecto a la vena primaria. Las venas intersecundarias son débiles o robustas. La venación terciaria presenta el patrón mixto (opuestas/alternas) o el mixto/dicótomo (opuestas/ alternas/dicótomas). El curso de las venas terciarias es ramificado exmedialmente y sinuoso, su ángulo con respecto a la vena primaria es obtuso que puede decrecer exmedialmente o ser inconsistente. La venación de cuarto orden puede ser dicótoma o tener un patrón reticulado poligonal regular. La venación de quinto es dicótoma. Las areolas están moderadamente desarrolladas donde las últimas venas libres son altamente ramificadas (dos o más veces). El orden más alto de venación es el cuarto o quinto, y el último que presenta ramificación excurrente, el terceo o cuarto. La venación marginal forma arcos incompletos. El grado de organización de la hoja es 2 r o $3 r$.

Características epidérmicas. Estomas de tipo policíticoanomocítico localizados únicamente en el envés. Los tricomas son muy abundantes, se localizan en toda la superficie de la hoja y son de tipo unicelular, pluricelular y glandular.

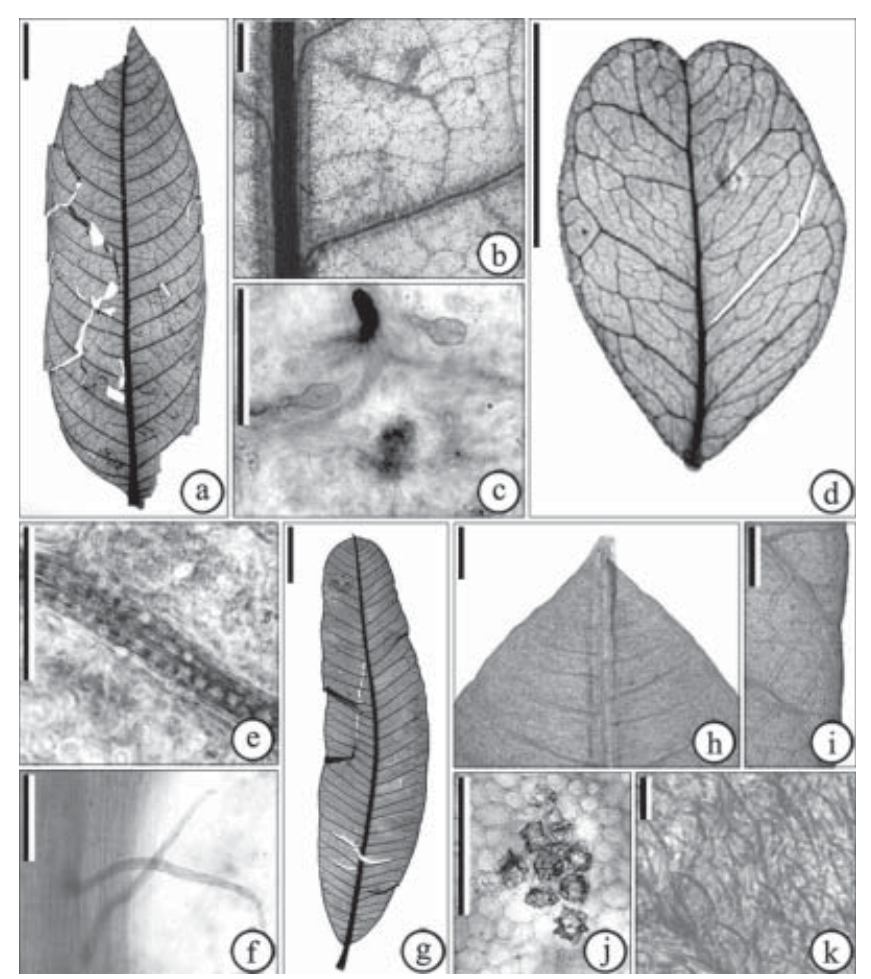

Figura 17. Ochoterenaea, Operculicarya y Ozoroa. a-c, Ochoterenaea. a, folíolo de O. colombiana (escala $=1 \mathrm{~cm}) ; \mathrm{b}$, venación de tercer orden de $O$. colombiana (escala $=1 \mathrm{~mm}$ ); c, tricomas glandulares de $O$. colombiana (escala $=100 \mu$ ). d-f, Operculicarya. d, folíolo de O. decaryi (escala $=5 \mathrm{~mm}$ ); e, cristales prismáticos en las venas de $O$. decaryi (escala $=100 \mu$ ); f, tricomas de O. decaryi (escala=100 $\mu$ ). g-k, Ozoroa. g, hoja de O. paniculosa (escala $=1 \mathrm{~cm}) ; \mathrm{h}$, ápice de $O$. paniculosa (escala $=1 \mathrm{~mm}) ;$ i, venación marginal de $O$. paniculosa (escala $=1 \mathrm{~mm}) ; \mathrm{j}$, drusas en el mesofilo de O. paniculosa (escala $=100 \mu)$; tricomas de O. paniculosa $($ escala $=100 \mu)$.

Cristales y canales resiníferos. Se presentan cristales prismáticos sólo en el interior de las venas mientras que las drusas están tanto al interior de las venas como en el mesofilo. No se observan canales resiníferos.

38) Género: Pachycormus Coville ex Standl. (Fig. 18a-c). Especie tipo: P. discolor (Benth.) Coville ex Standl.

Ejemplares aclarados: P. discolor (Benth.) Coville ex Standl. (MEXU-E. Guízar et al. BC5; México).

Ejemplares complementarios: P. discolor (Benth.) Coville ex Standl. (MEXU-H. Cota 7409, México).

Distribución: México (Baja California).

Descripción: Organización macroscópica. Hojas compuestas imparipinnadas de arreglo verticilado, con folíolos opuestos sésiles, de textura coriácea. Folíolos elípticos con base asimétrica de forma convexa al igual que el ápice y margen entero. El tamaño de los folíolos es leptófilo, la proporción largo/ancho es 1.32:1. El ángulo de la base es de $99^{\circ}$ y el del ápice de $107^{\circ}$. 


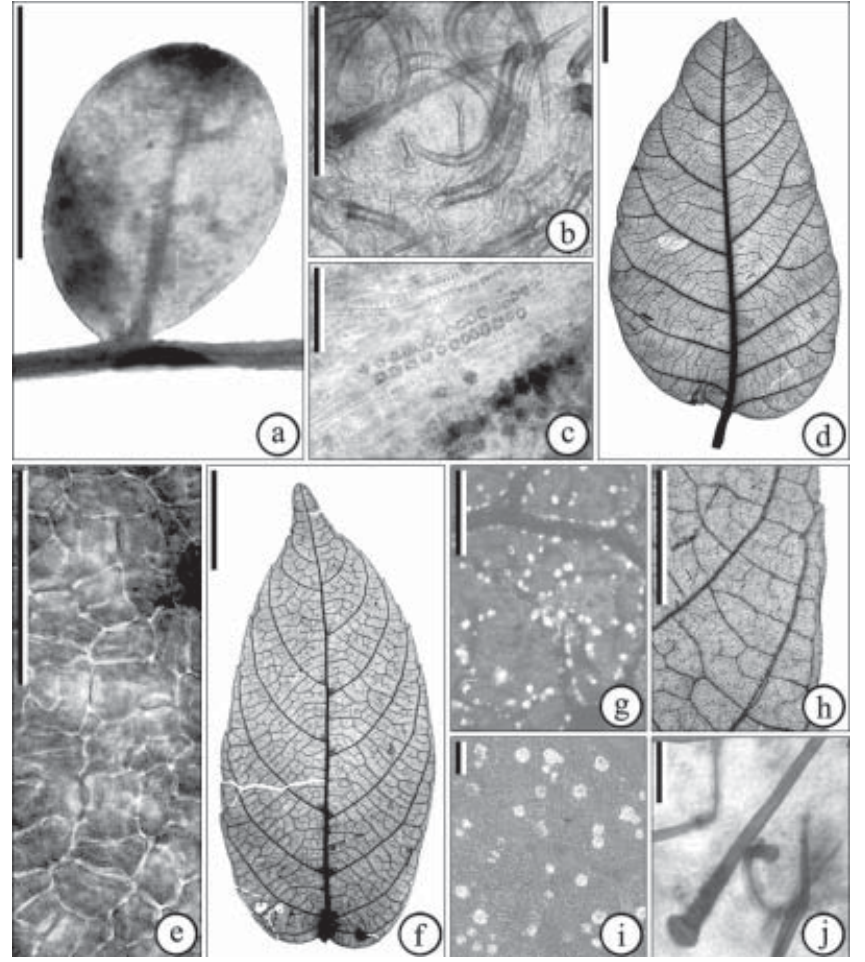

Figura 18. Pachycormus, Parishia y Pegia. a-c, Pachycormus. a, folíolo de $P$. discolor (escala $=5 \mathrm{~mm}$ ); $\mathrm{b}$, estoma y tricomas de $P$. discolor (escala $=100 \mu$ ); c, drusas al interior de las venas de $P$. discolor (escala=100 $\mu$ ). d-e, g, Parishia. d, folíolo de P. insignis (escala $=1 \mathrm{~cm}$ ); e, estomas de $P$. insignis (escala $=100 \mu$ ); g, cristales prismáticos al interior de las venas y drusas en el mesofilo de $P$. insignis (escala $=100 \mu$ ). f, h-j, Pegia. f. folíolo de P. nitida (escala=1 $\mathrm{cm}$ ); h, dientes de $P$. nitida (escala $=5 \mathrm{~mm}$ ); i, drusas en el mesofilo de $P$. nitida (escala $=100 \mu)$; , tricoma de $P$. nitida $($ escala $=100 \mu)$.

Venación. La venación primaria es pinnada. La secundaria, cladódroma II con 3 venas basales; el espaciado de las venas secundarias aumenta hacia la base mientras que el ángulo disminuye hacia la base. No se presentan venas intersecundarias. La venación terciaria presenta el patrón mixto y el dicótomo (opuestas/alternas/dicótomas). El curso de las venas terciarias es ramificado admedialmente, el ángulo con respecto a la vena primaria es obtuso e inconsistente. La venación de cuarto y quinto orden es dicótoma. Las areolas están poco desarrolladas donde las últimas venas libres son ramificadas dos o más veces. El orden más alto de venación es el quinto, y el último que presenta ramificación excurrente, el cuarto. La venación marginal forma arcos. El grado de organización de la hoja es 2 r.

Características epidérmicas. Estomas de tipo policíticoanomocítico localizados únicamente en el envés. Los tricomas son abundantes, se localizan en toda la superficie de la hoja y son de tipo unicelular y glandular.

Cristales y canales resiníferos. Se presentan cristales prismáticos y drusas en el interior de las venas y en el mesofilo. No se observan canales resiníferos.

39) Género: Parishia Hook. f. (Fig. 18d-e, g).

Especie tipo: $P$. insignis Hook. $\mathrm{f}$.

Ejemplares aclarados: P. insignis Hook. f. (BKF-Santisuk $s / n$; Tailandia).

Ejemplares complementarios: P. malabog Merrill (MEXUC. E. Ridsdale 1332, Filipinas).

Distribución: India, Sri Lanka, Myanmar, Tailandia, Malasia, Borneo, Filipinas, Islas Andaman.

Descripción: Organización macroscópica. Hojas compuestas imparipinnadas de arreglo pseudoverticilado, con folíolos alternos de inserción del peciólulo marginal y textura membranácea (folíolos opuestos, de textura coriácea en $P$. malabog*). Folíolos de forma ovada ligeramente asimétrica, la forma de la base es convexa de un lado y cordada del otro, el ápice es recto y margen entero (ápice acuminado en P. malabog*). El tamaño de los folíolos es notófilo, la proporción largo/ancho es 1.73:1. El ángulo de la base es de $100^{\circ}$ y el del ápice de $72^{\circ}$.

Venación. La venación primaria es pinnada. La secundaria cladódroma I con 4 venas basales y un par de venas agróficas, el espaciado de las venas secundarias disminuye hacia la base mientras que el ángulo aumenta ligeramente hacia la base. Las venas intersecundarias son débiles. La venación terciaria presenta el patrón mixto (opuestas/alternas percurrentes). El curso de las venas terciarias es sinuoso, el ángulo con respecto a la vena primaria es obtuso que aumenta basalmente. La venación de cuarto orden forma un retículo poligonal regular. La de quinto orden también es reticulada poligonal regular. Las areolas están bien desarrolladas, las últimas venas libres son desde no ramificadas hasta altamente ramificadas (dos o más veces). El orden más alto de venación es el sexto y el último que presenta ramificación excurrente, el cuarto. La venación marginal forma arcos. El grado de organización de la hoja es $4 r$.

Características epidérmicas. Estomas de tipo policíticoanomocítico localizados únicamente en el envés. Los tricomas son escasos, distribuidos en toda la superficie y son de tipo pluricelular y glandular.

Cristales y canales resiníferos. Se presentan cristales prismáticos al interior de las venas y drusas en el mesofilo. No se observan canales resiníferos.

40) Género: Pegia Colebr. (Fig. 18f, h-j).

Especie tipo: P. nitida Colebr.

Ejemplares aclarados: Pegia nitida Colebr. (Colección personal de la Dra. Terrazas-J. F. Rock 903; India).

Ejemplares complementarios: P. nitida Colebr. (MEXU-G. D. Tao 004881, China).

Distribución: India, Tibet, China, Myanmar, Tailandia, Laos, Vietnam, Malasia.

Descripción: Organización macroscópica. Hojas con arreglo alterno, de tipo compuesta imparipinnada con folíolos 
opuestos de inserción del peciólulo marginal, la textura es cartácea. Los folíolos son de forma ovada simétrica. La forma de la base es cordada, el ápice es acuminado y el margen, serrado. El tamaño de los folíolos es micrófilo, la proporción largo/ancho es 1.92:1. El ángulo de la base es de $90^{\circ}$ y el del ápice de $58^{\circ}$.

Venación. La venación primaria es pinnada. La secundaria eucamptódroma con 4 venas basales. El espaciado de las venas secundarias es uniforme al igual que el ángulo con respecto a la vena primaria. No se presentan venas intersecundarias. La venación terciaria presenta patrón mixto (opuestas/alternas percurrentes). El curso de las venas terciarias es recto, el ángulo con respecto a la vena primaria es obtuso que decrece exmedialmente. La venación de cuarto orden forma un retículo poligonal regular. La de quinto orden es dicótoma. Las areolas están moderadamente desarrolladas, las últimas venas libres son de ausentes a no ramificadas. El orden más alto de venación es el quinto y el último que presenta ramificación excurrente, el cuarto. La venación marginal forma arcos. El grado de organización de la hoja es $3 r$.

Dientes. Hay dos órdenes de dientes distribuidos regularmente a todo lo largo del margen, encontrándose 2 dientes por cm. El lado apical del diente puede ser recto o convexo mientras que el basal es recto o flexo, el ápice es simple y el seno angular. La vena principal del diente es una vena de cuarto orden.

Características epidérmicas. Estomas de tipo policíticoanomocítico localizados únicamente en el envés. Los tricomas son abundantes, se distribuyen en toda la superficie, de tipo pluricelular.

Cristales y canales resiníferos. Se presentan cristales prismáticos al interior de las venas y drusas en el mesofilo. No se observan canales resiníferos.

41) Género: Pentaspadon Hook. f. (Fig. 19a-c).

Especie tipo: P. motleyi Hook. f.

Ejemplares aclarados: P. motleyi Hook. f. (NY-Krukoff 4202; Sumatra).

Distribución: Tailandia, Vietnam, Malasia, Islas Salomón, Sumatra, Borneo, Nueva Guinea.

Descripción: Organización macroscópica. Hojas compuestas imparipinnadas de arreglo pseudoverticilado con folíolos opuestos de inserción del peciólulo marginal y textura membranácea. Folíolos ovados, ligeramente asimétricos, con base cóncavo-convexa, ápice acuminado y margen entero. El tamaño de los folíolos es notófilo, la proporción largo/ancho es 2.5:1. El ángulo de la base es de $67^{\circ}$ y el del ápice de $55^{\circ}$. Venación. La venación primaria es pinnada. La secundaria, broquidódroma débil con 5 venas basales, el espaciado de las venas secundarias es uniforme al igual que el ángulo. Las venas intersecundarias son robustas. La venación terciaria presenta el patrón mixto (opuestas/alternas percurrentes). El curso de las venas terciarias es convexo y el ángulo
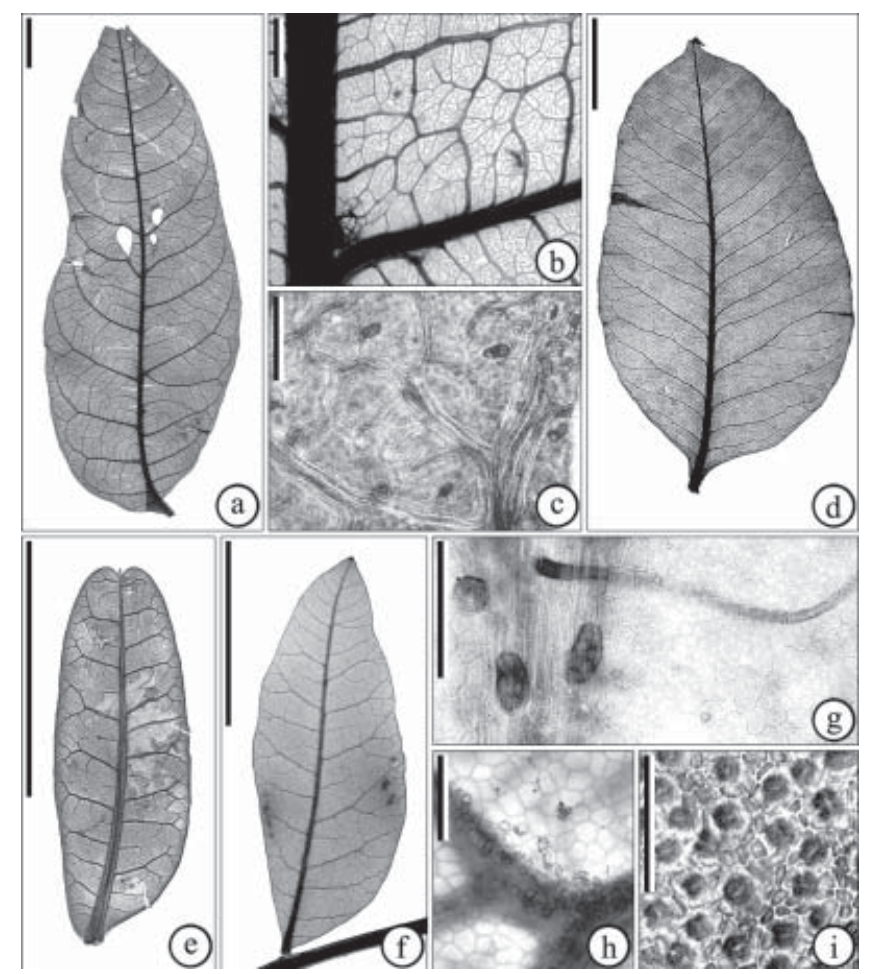

Figura 19. Pentaspadon y Pistacia. a-c, Pentaspadon. a, folíolo de $P$. motleyi (escala $=1 \mathrm{~cm}) ; \mathrm{b}$, venación de tercer orden y domacio de $P$. motleyi (escala $=1 \mathrm{~mm}$ ); c, tricomas glandulares de $P$. motleyi (escala $=100 \mu$ ). d-i, Pistacia. d, folíolo de P. khinjuk (escala=1 $\mathrm{cm})$; e, folíolo de $P$. weinmannifolia (escala $=1 \mathrm{~cm}) ; \mathrm{f}$, folíolo de $P$. mexicana (escala $=1 \mathrm{~cm})$. g. tricomas pluricelulares y glandulares de $P$. mexicana $($ escala $=100 \mu)$; h, cristales prismáticos en las venas y mesofilo de $P$. khinjuk (escala $=100 \mu$ ); i, estomas de $P$. weinmannifolia (escala $=100 \mu)$.

con respecto a la vena primaria es obtuso que decrece exmedialmente. La venación de cuarto y quinto orden forman un retículo poligonal regular. Las areolas están bien desarrolladas, las últimas venas libres son ramificadas dos o más veces. El orden más alto de venación es el séptimo y el último que presenta ramificación excurrente, el quinto. La venación marginal forma arcos. El grado de organización de la hoja es 4 r.

Características epidérmicas. Estomas de tipo policíticoanomocítico localizados únicamente en el envés. Los tricomas son abundantes, distribuidos en toda la superficie y de tipo pluricelular y glandular. Además se presentan domacios formados por una estructura en forma de cavidad (bolsa) y tricomas que crecen sobre ella.

Cristales y canales resiníferos. Se presentan cristales prismáticos al interior de las venas. No se observan canales resiníferos.

42) Género: Pistacia L. (Fig. 19d-i).

Especie tipo: P. vera L. 
Ejemplares aclarados: P. khinjuk Stocks (RSA-W. Thesiger 1670), P. mexicana H. B. K. (FCME-TH 46, México), $P$. weinmannifolia Poiss. ex Franch. (RSA-Qin Hai-ning et al., China).

Ejemplares complementarios: P. lentiscus L. (MEXU-J. Lewalle 13931, Marruecos; MEXU-E. Motte-Florac 237, Francia), P. mexicana H. B. K. (MEXU-A. Campos 3626 y R. Torres C., México), P. vera L. (MEXU-T. S. Elías 9876, Uzbekistán).

Distribución: México, Estados Unidos (Texas), Noreste de África, Mediterráneo; Grecia, Palestina, Etiopía, India, Islas Canarias, sureste y suroeste de Asia, Taiwan, Malasia, China, Islas Formosa, Filipinas.

Descripción: Organización macroscópica. Hojas compuestas imparipinnadas de arreglo pseudoverticilado, raquis alado en $P$. lentiscus* y folíolos alternos peciolulados, de textura cartácea (las hojas son trifoliadas en $P$. vera* y paripinnadas en $P$. lentiscus*, de arreglo alterno en ambas y folíolos sésiles en $P$. lentiscus*; la textura es membranácea en $P$. khinjuk). Folíolos de forma elíptica ligeramente asimétricos (forma oblonga en $P$. weinmannifolia). La forma de la base es variable, cóncavo-convexa en $P$. khinjuk, convexa de un lado y cuneada del otro en $P$. mexicana y convexa de un lado y cóncavo-convexa del otro en $P$. weinmannifolia. El ápice también es variable, acuminado en $P$. khinjuk, recto en $P$. mexicana, convexo en $P$. lentiscus* y retuso en $P$. vera* y $P$. weinmannifolia; generalmente se presenta una proyección de la vena media (mucrón), pero en $P$. khinjuk está ausente. El margen es entero. El tamaño de los folíolos es nanófilo (micrófilo en P. khinjuk), la proporción largo/ancho es 1.7:1(2.18:1)-2.57:1. El ángulo de la base es de 64.36 $-\left(77.286^{\circ}\right)$ $91^{\circ}$ y el del ápice, $61.44^{\circ}-\left(73.396^{\circ}\right)-84.5^{\circ}$.

Venación. La venación primaria es pinnada. La secundaria cladódroma I con 3,4 o 5 venas basales (3 en $P$. weinmannifolia, 4 en $P$. mexicana y 5 en $P$. khinjuk). El espaciado de las venas secundarias es uniforme y el ángulo con respecto a la vena primaria aumenta ligeramente hacia la base (el espaciado es irregular en P. mexicana y el ángulo es uniforme en $P$. weinmannifolia). Las venas intersecundarias son débiles (robustas en $P$. weinmannifolia). La venación terciaria es variable; reticulada poligonal regular en $P$. khinjuk, opuesta/alterna/dicótoma en P. mexicana y dicótoma en $P$. weinmannifolia. El curso de las venas terciarias es ramificado exmedialmente y el ángulo con respecto a la vena primaria es obtuso que puede ser inconsistente, uniforme o aumentar exmedialmente (el curso de las venas es ramificado admedialmente en $P$. weinmannifolia; el ángulo es inconsistente en P. khinjuk, uniforme en P. mexicana y aumenta exmedialmente en $P$. weinmannifolia). La venación de cuarto orden es dicótoma (el arreglo es reticulado poligonal regular en $P$. khinjuk). Las venas de quinto orden son dicótomas (en $P$. khinjuk, forman un retículo poligonal regular). Las areolas pueden ser desde ausentes hasta bien desarrolladas (ausentes en $P$. weinmannifolia, moderadamente desarrolladas en $P$. mexicana y bien desarrolladas en $P$. khinjuk). Las últimas venas libres son de ramificadas una vez hasta muy ramificadas (dos o más veces), siendo éste, el estado más común en $P$. khinjuk. El orden más alto de venación es el quinto (sexto en $P$. khinjuk); el último que presenta ramificación excurrente, el cuarto (quinto en $P$. khinjuk). La venación marginal forma arcos excepto en $P$. weinmannifolia donde es libre (arcos incompletos). El grado de organización de la hoja es $4 \mathrm{r}$ en $P$. khinjuk, $3 \mathrm{r}$ en $P$. mexicana y $2 \mathrm{r}$ en $P$. weinmannifolia.

Características epidérmicas. Estomas de tipo policíticoanomocítico localizados únicamente en el envés (en $P$. weinmannifolia son de tipo policítico-actinocítico). Los tricomas son escasos distribuidos en el margen (en toda la superficie en $P$. mexicana) y son de tipo pluricelular (además, hay tricomas glandulares en P. mexicana).

Cristales y canales resiníferos. Se presentan cristales prismáticos al interior de las venas y en el mesofilo (en $P$. weinmannifolia sólo están en las venas). Las drusas en general están ausentes pero se presentan en las venas y el mesofilo de $P$. mexicana. No se observan canales resiníferos.

43) Género: Pleiogynium Engl. (Fig. 20a-c).

Especie tipo: P. solandri (Benth.) Engl.

Ejemplares aclarados: P. solandri (Benth.) Engl. (CASMcClintock; Estados Unidos).

Distribución: Malasia, Borneo, Islas Molucas, Islas Celebes, Filipinas, Islas Salomón, Nueva Guinea, Australia, Fiji.

Descripción: Organización macroscópica. Hojas compuestas imparipinnadas de arreglo pseudoverticilado y folíolos con arreglo opuesto, la inserción del peciólulo es marginal, la textura es membranácea. Los folíolos son ovados asimétricos; la base es convexa de un lado y cuneada del otro, el ápice es recto y el margen, entero. El tamaño de los folíolos es micrófilo, la proporción largo/ancho es 2.53:1, el ángulo de la base es de $67.5^{\circ}$ y el del ápice de $57.5^{\circ}$.

Venación. La venación primaria es pinnada. La secundaria cladódroma I con 4 venas basales, el espaciado de las venas secundarias disminuye hacia la base y el ápice, el ángulo aumenta ligeramente hacia la base. Las venas intersecundarias son débiles. La venación terciaria presenta el patrón mixto (opuestas/alternas percurrentes), su curso es ramificado exmedialmente y el ángulo con respecto a la vena primaria es obtuso e inconsistente. La venación de cuarto orden es reticulada poligonal regular. Las venas de quinto orden son dicótomas. Las areolas están moderadamente desarrolladas, las últimas venas libres son muy ramificadas (dos o más veces). El orden más alto de venación es el séptimo; el último que presenta ramificación excurrente, el quinto. La venación marginal forma arcos incompletos. El grado de organización de la hoja es 2 r.

Características epidérmicas. Estomas de tipo policíticoanomocítico localizados únicamente en el envés. Los tricomas son escasos, distribuidos sobre las venas y en el margen, son de tipo pluricelular. Se presentan domacios 


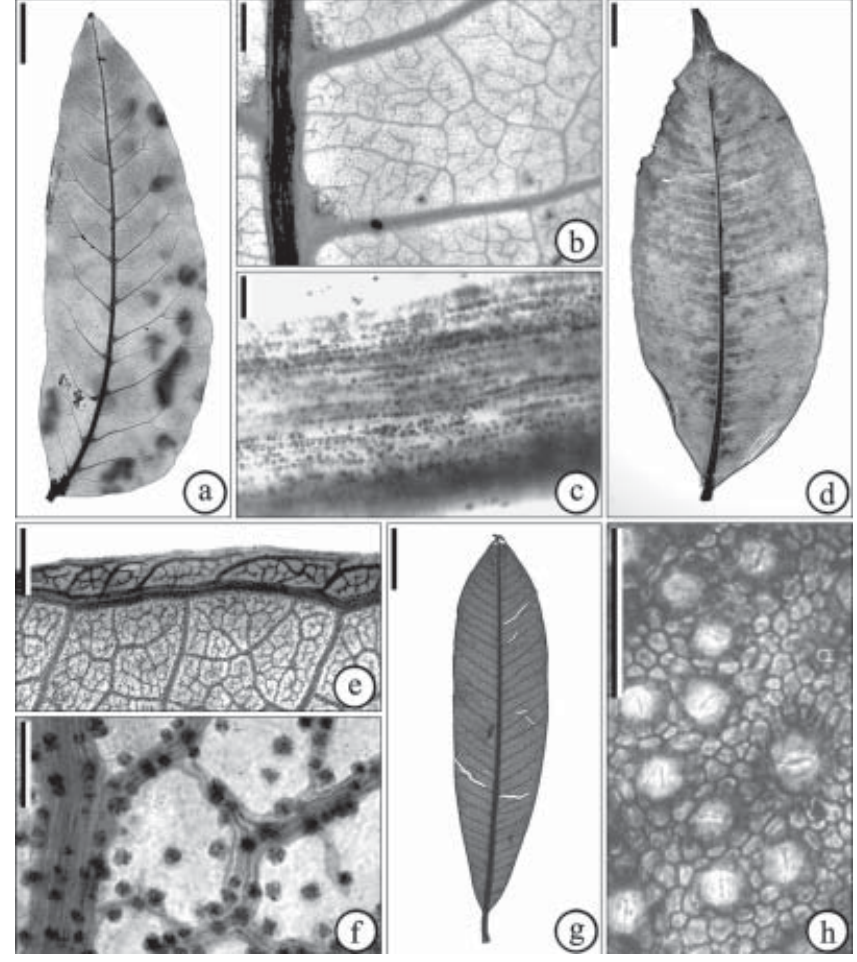

Figura 20. Pleiogynium, Poupartia y Protorhus. a-c, Pleiogynium. a, folíolo de $P$. solandri (escala $=1 \mathrm{~cm})$; b, venación de tercer orden y domacios de $P$. solandri (escala $=1 \mathrm{~mm}$ ); c, drusas al interior de las venas de $P$. solandri (escala $=100 \mu$ ). d-f, Poupartia. d, lámina de $P$. pinnata (escala $=1 \mathrm{~cm})$; e, venación secundaria intramarginal de $P$. pinnata (escala $=1 \mathrm{~mm}) ; \mathrm{f}$, drusas al interior de las venas y en el mesofilo de $P$. pinnata (escala $=100 \mu$ ). g-h, Protorhus. g, hoja de $P$. longifolia $($ escala $=1 \mathrm{~cm}) ; \mathrm{h}$, estomas de $P$. longifolia (escala $=100$ $\mu)$.

formados por una estructura en forma de cavidad (bolsas) y tricomas que crecen sobre ella.

Cristales y canales resiníferos. Se presentan drusas al interior de las venas y en el mesofilo. No se observan canales resiníferos.

44) Género: Poupartia Comm. ex Juss. (Fig. 20d-f). Especie tipo: P. borbonica J. F. Gmel.

Ejemplares aclarados: P. pinnata Blanco (CAS-Groff, Tailandia).

Ejemplares complementarios: $P$. gummifera Sprague (MEXU-F. R. Fosberg 49620, Asia).

Distribución: Madagascar.

Descripción: Organización macroscópica. Hojas compuestas imparipinnadas con arreglo alterno y folíolos alternos con inserción del peciólulo marginal ( $P$. gummifera*). Los folíolos son de textura membranácea, forma elíptica, ligeramente asimétrica; la base es convexa de un lado y cuneada o cóncavo-convexa del otro, el ápice es acuminado y el margen, entero (la textura es cartácea en P. gummifera*). El tamaño de la lámina es notófilo, la proporción largo/ancho es 2.47:1, el ángulo de la base es de $72.5^{\circ}$ y el del ápice de $53.5^{\circ}$.

Venación. La venación primaria es pinnada. La secundaria, intramarginal con 3 o 4 venas basales; el espaciado de las venas secundarias es uniforme, el ángulo aumenta ligeramente hacia la base o es uniforme. Las venas intersecundarias son débiles o están ausentes. La venación terciaria presenta el patrón mixto (opuestas/alternas percurrentes) o el reticulado al azar, su curso es ramificado admedialmente y el ángulo con respecto a la vena primaria es obtuso que varía inconsistentemente (en algunos ejemplares de P. pinnata se presentan algunas con ángulo agudo). La venación de cuarto orden es dicótoma al igual que la de quinto. Las areolas están de poco a moderadamente desarrolladas, las últimas venas libres son muy ramificadas (dos o más veces). El orden más alto de venación es el sexto o séptimo; el último que presenta ramificación excurrente, el cuarto o quinto. La venación marginal forma arcos incompletos. El grado de organización de la hoja es $3 r$.

Características epidérmicas. Estomas de tipo policíticoanomocítico localizados únicamente en el envés. No se presentan tricomas.

Cristales y canales resiníferos-Los cristales prismáticos pueden o no presentarse, si lo hacen se encuentran en el mesofilo. Hay drusas al interior de las venas y en el mesofilo. No se observan canales resiníferos.

\section{5) Género: Protorhus Engl. (Fig. 20g-h).}

Especie tipo: P. longifolia (Bernh. ex Krauss) Engl.

Ejemplares aclarados: P. longifolia (Bernh. ex Krauss) Engl. (Colección personal de la Dra. Terrazas-E. S. Kemp 930, Suazilandia).

Distribución: Madagascar, Sudáfrica.

Descripción: Organización macroscópica. Hojas simples de arreglo opuesto con inserción del pecíolo marginal y textura coriácea, forma oblonga simétrica, base cuneada, ápice retuso y margen entero. El tamaño de la hoja es micrófilo, la proporción largo/ancho es 3.84:1, el ángulo de la base es de $40^{\circ}$ y el del ápice de $50^{\circ}$.

Venación. La venación primaria es pinnada. La secundaria, intramarginal con 3 venas basales, el espaciado de las venas secundarias es uniforme, el ángulo también es uniforme. Las venas intersecundarias son robustas. La venación terciaria presenta patrón mixto (opuestas/alternas percurrentes), su curso es ramificado exmedialmente y el ángulo con respecto a la vena primaria es obtuso que aumenta basalmente. La venación de cuarto orden es reticulada poligonal regular. Las venas de quinto orden son dicótomas. Las areolas están bien desarrolladas, las últimas venas libres van desde ausentes hasta muy ramificadas (dos o más veces). El orden más alto de venación es el sexto; el último que presenta ramificación excurrente, el cuarto. La venación marginal forma arcos incompletos. El grado de organización de la hoja es 4r. Características epidérmicas. Estomas de tipo policítico- 
ciclocítico localizados únicamente en el envés. Se presentan tricomas escasos distribuidos en toda la superficie, son de tipo unicelular y glandular.

Cristales y canales resiníferos-No se presentan cristales prismáticos ni drusas. No se observan canales resiníferos.

46) Género: Pseudosmodingium Engl. (Fig. 21a-g).

Especie tipo: no designada.

Ejemplares aclarados: P. andrieuxii Engl. (FCME-JRS 140, México), P. barkleyi Miranda (FCME-RMF 2266, México), P. perniciosum Engl. (FCME-RMF 1687, México).

Ejemplares complementarios: P. andrieuxii Engl. (MEXURzed 19688, México), P. multifolium Rose (MEXU-R. Torres C. et al. 6943, México), P. perniciosum Engl. (MEXU-R. Palacios s/n, México), P. virletti (Baill.) Engl. (MEXU-S. Zamudio et al. 9655, México).

Distribución: México.

Descripción: Organización macroscópica. Hojas compuestas imparipinnadas con arreglo alterno, opuesto o verticilado (hojas paripinnadas en $P$. barkleyi; arreglo alterno en $P$. andrieuxii y opuesto o verticilado en $P$. perniciosum). Los folíolos son opuestos, sésiles de textura cartácea, el raquis puede ser simple o alado como en $P$. andrieuxii (folíolos alternos en $P$. multifolium* y $P$. virletti*, peciolulados en $P$. perniciosum, de textura membranácea en $P$. andrieuxii y $P$. multifolium*). Folíolos ovados, elípticos u obovados; simétricos, ligeramente asimétricos o asimétricos (ovados asimétricos en $P$. andrieuxii, ovados en $P$. multifolium*, elípticos ligeramente asimétricos en $P$. barkleyi, obovados simétricos en $P$. perniciosum y obovados en $P$. virletti*). Base decurrente excepto en $P$. barkleyi donde es cordada, ápice recto en $P$. andrieuxii y $P$. multifolium*, emarginado en $P$. barkleyi y complejo en $P$. perniciosum. El margen es entero, serrado o crenado (entero en P. barkleyi y P. virletti*, serrado en $P$. andrieuxii y $P$. multifolium* y crenado en $P$. perniciosum). El tamaño de los folíolos es micrófilo (notófilo en P. barkleyi), la proporción largo/ancho es 1.15:1-(3.233:1)$7.01: 1$, el ángulo de la base es de $29^{\circ}-\left(74.916^{\circ}\right)-122^{\circ}$ y el del ápice de $16.6^{\circ}-\left(82.783^{\circ}\right)-127.5^{\circ}$.

Venación. La venación primaria es pinnada. La secundaria, cladódroma I con 5 venas basales (craspedódroma en $P$. andrieuxii, se presentan 4 venas basales en $P$. perniciosum). El espaciado de las venas secundarias es uniforme, irregular o aumenta hacia la base, el ángulo con respecto a la vena primaria es uniforme (el espaciado de las venas secundarias es uniforme en $P$. andrieuxii, irregular en $P$. barkleyi y aumenta hacia la base en $P$. perniciosum; el ángulo aumenta ligeramente hacia la base en $P$. barkleyi). Las venas intersecundarias son débiles (robustas en P. andrieuxii). La venación terciaria presenta el arreglo dicótomo, su curso es ramificado exmedialmente y el ángulo con respecto a la vena primaria es obtuso, la variabilidad del ángulo puede decrecer exmedialmente, aumentar basalmente o ser inconsistente (el curso de las venas es ramificado admedialmente en

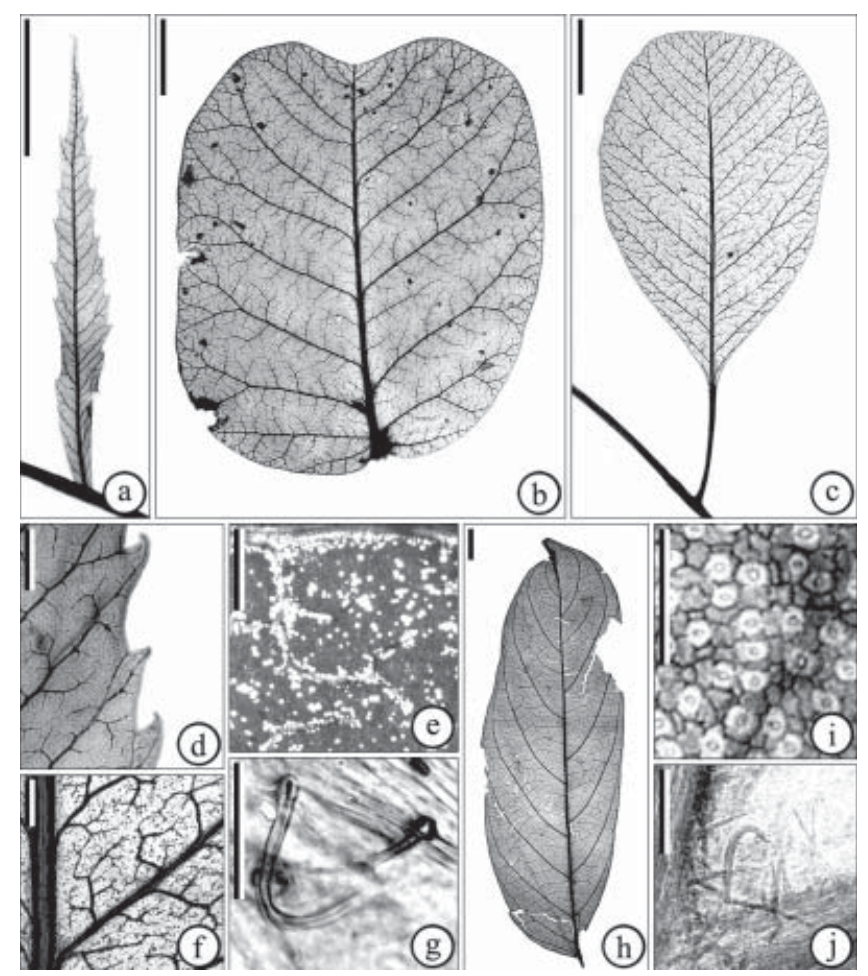

Figura 21. Pseudosmodingium y Pseudospondias. a-g, Pseudosmodingium. a, folíolo de $P$. andrieuxii (escala=1 cm); $\mathrm{b}$, folíolo de $P$. barkleyi (escala $=1 \mathrm{~cm}$ ); c, folíolo de $P$. perniciosum $($ escala $=1 \mathrm{~cm}) ; \mathrm{d}$, dientes de $P$. andrieuxii (escala=1 mm); e, drusas al interior de las venas y en el mesofilo de $P$. perniciosum (escala $=500 \mu$ ); f, venación de tercer orden y canales resiníferos de $P$. perniciosum (escala $=1 \mathrm{~mm}$ ); g, tricomas de P. barkleyi (escala=100 $\mu$ ). h-j, Pseudospondias. h, folíolo de P. microcarpa (escala $=1$ $\mathrm{cm}$ ); i, estomas de $P$. microcarpa (escala $=100 \mu$ ); j, tricomas en los domacios de $P$. microcarpa (escala $=100 \mu$ ).

$P$. andrieuxii; en $P$. perniciosum se pueden presentar algunas venas agudas; el ángulo decrece exmedialmente en $P$. andrieuxii, aumenta basalmente en $P$. barkleyi y es inconsistente en $P$. perniciosum). La venación de cuarto orden es dicótoma. Las venas de quinto orden también son dicótomas. Las areolas están en general ausentes pero en $P$. andrieuxii, se presentan algunas poco desarrolladas, las últimas venas libres van desde ausentes hasta muy ramificadas (dos o más veces). El orden más alto de venación es el quinto (cuarto en $P$. andrieuxii); el último que presenta ramificación excurrente, el tercero (cuarto en $P$. barkleyi). La venación marginal forma arcos incompletos (forma arcos en P. andrieuxii). El grado de organización de la hoja es 2r.

Dientes. En $P$. perniciosum hay un orden de dientes distribuidos de forma regular en los $2 / 5$ distales de la lámina, mientras que en $P$. andrieuxii hay dos órdenes distribuidos de forma irregular a todo lo largo del margen; se encuentran unos 4 dientes por centímetro. El lado apical del diente es cóncavo o retroflexo en $P$. andrieuxii y recto en $P$. perniciosum mientras que el lado basal es retroflexo en $P$. 
andrieuxii y recto en $P$. perniciosum, el ápice del diente es simple y el seno es angular. La vena principal del diente es una vena secundaria que nace directamente de la primaria en $P$. andrieuxii. En $P$. perniciosum no se presenta una vena principal, aunque hay pequeñas venas que entran al diente. Características epidérmicas. Estomas de tipo policíticoactinocítico y se encuentran en el envés (de tipo policíticoanomocítico en $P$. barkleyi, y en $P$. perniciosum se presentan en ambas superficies). En general no se presentan tricomas pero en $P$. barkleyi se presentan en cantidad moderada, distribuidos en toda la superficie y son de tipo unicelular.

Cristales y canales resiníferos. Se presentan cristales prismáticos y drusas en el interior de las venas y drusas en el mesofilo (excepto en $P$. andrieuxii que carece de ambos). Los canales resiníferos se encuentran en las venas de primero, segundo y tercer orden de $P$. andrieuxii y en las de primero, segundo, tercero y cuarto orden de $P$. barkleyi y $P$. perniciosum.

47) Género: Pseudospondias Engl. (Fig. 21h-j).

Especie tipo: P. microcarpa (A. Rich.) Engl.

Ejemplares aclarados: P. microcarpa Engl. (Colección personal de la Dra. Terrazas-P. Gille 251, Congo).

Ejemplares complementarios: P. microcarpa Engl. (MEXUK. McDonald 61, Gabón).

Distribución: oeste de África tropical, Congo.

Descripción: Organización macroscópica. Hojas compuestas paripinnadas con arreglo alterno y folíolos alternos, inserción del peciólulo marginal y textura coriácea. Los folíolos tienen forma oblonga asimétrica, la base es convexa de un lado y cuneada del otro, el ápice es retuso-acuminado y el margen, entero. El tamaño de los folíolos es mesófilo, la proporción largo/ancho es 3.06:1, el ángulo de la base es de $61^{\circ}$ y el del ápice de $64^{\circ}$.

Venación. La venación primaria es pinnada. La secundaria, eucamptódroma con 4 venas basales, el espaciado de las venas secundarias disminuye hacia la base y hacia el ápice, el ángulo con respecto a la vena primaria es uniforme. No se presentan venas intersecundarias. La venación terciaria presenta el patrón mixto (opuestas/alternas percurrentes), su curso es convexo y el ángulo con respecto a la vena primaria es obtuso que decrece exmedialmente. La venación de cuarto orden es reticulada poligonal regular. Las venas de quinto orden son dicótomas. Las areolas están bien desarrolladas, las últimas venas libres son muy ramificadas (dos o más veces). El orden más alto de venación es el sexto; el último que presenta ramificación excurrente, el cuarto. La venación marginal forma arcos. El grado de organización de la hoja es $4 \mathrm{r}$.

Características epidérmicas. Estomas de tipo policíticoanomocítico localizados únicamente en el envés. Se presentan tricomas escasos sobre las venas que son de tipo pluricelular, también se presentan tricomas de tipo glandular. Hay domacios formados sólo por tricomas.
Cristales y canales resiníferos-No se presentan cristales prismáticos ni drusas. No se observan canales resiníferos.

48) Género: Rhodosphaera Engl. (Fig. 22a-c).

Especie tipo: R. rhodanthema (F. Muell.) Engl.

Ejemplares aclarados: $R$. rhodanthema (F. Muell.) Engl. (Colección personal de la Dra. Terrazas-M. S. Clemens $s / n$, Australia).

Distribución: Australia (sureste de Queensland, noreste de Nueva Gales del Sur).

Descripción: Organización macroscópica. Hojas compuestas imparipinnadas con arreglo alterno y folíolos opuestos peciolulados de textura membranácea. Los folíolos son de forma oblonga asimétrica, con base decurrente, ápice acuminado y margen entero. El tamaño de los folíolos es micrófilo, la proporción largo/ancho es 2.34:1, el ángulo de la base es $66^{\circ}$ y el del ápice es $64^{\circ}$.

Venación. La venación primaria es pinnada. La secundaria cladódroma I con 6 venas basales, el espaciado de las venas secundarias aumenta hacia la base y el ángulo con respecto a la vena primaria es uniforme. Las venas intersecundarias son débiles. La venación terciaria presenta el patrón alterno percurrente, su curso es ramificado exmedialmente y el ángulo con respecto a la vena primaria es obtuso que decrece exmedialmente. La venación de cuarto orden es reticulada poligonal regular. Las venas de quinto orden son dicótomas. Las areolas están moderadamente desarrolladas, las últimas venas libres son muy ramificadas (dos o más veces). El orden más alto de venación es el sexto, y el último que presenta ramificación excurrente, el quinto. La venación marginal forma arcos. El grado de organización de la hoja es 3r.

Características epidérmicas. Estomas de tipo policíticoanomocítico localizados únicamente en el envés. Se presentan tricomas escasos, distribuidos en toda la superficie, de tipo pluricelular. También se presentan domacios formados sólo por tricomas.

Cristales y canales resiníferos-No se presentan cristales prismáticos ni drusas. No se observan canales resiníferos.

49) Género: Rhus L. (Fig. 22d-h).

Especie tipo: $R$. coriaria L.

Nota: La sección Baronia que comprende tres especies malgaches, muy probablemente representa un linaje independiente no relacionado al género Rhus (Randrianasolo, 1988; Pell, 2004). Sin embargo, debido a que estos estudios y la consecuente reinstitución del género Baronia no han sido válidamente publicados, siguiendo los lineamientos del Código Internacional de Nomenclatura Botánica, por el momento, las especies de esta sección serán tratadas bajo el género Rhus.

Ejemplares aclarados: R. galeottii Standl. (FCME-N 642, México), R. nelsonii F. A. Barkley (FCME-BAG 16, México), R. taratana (Baker) H. Perrier (=Baronia taratana Baker; K-Cours 2649, Madagascar), R. terebinthifolia Schlecht. et 

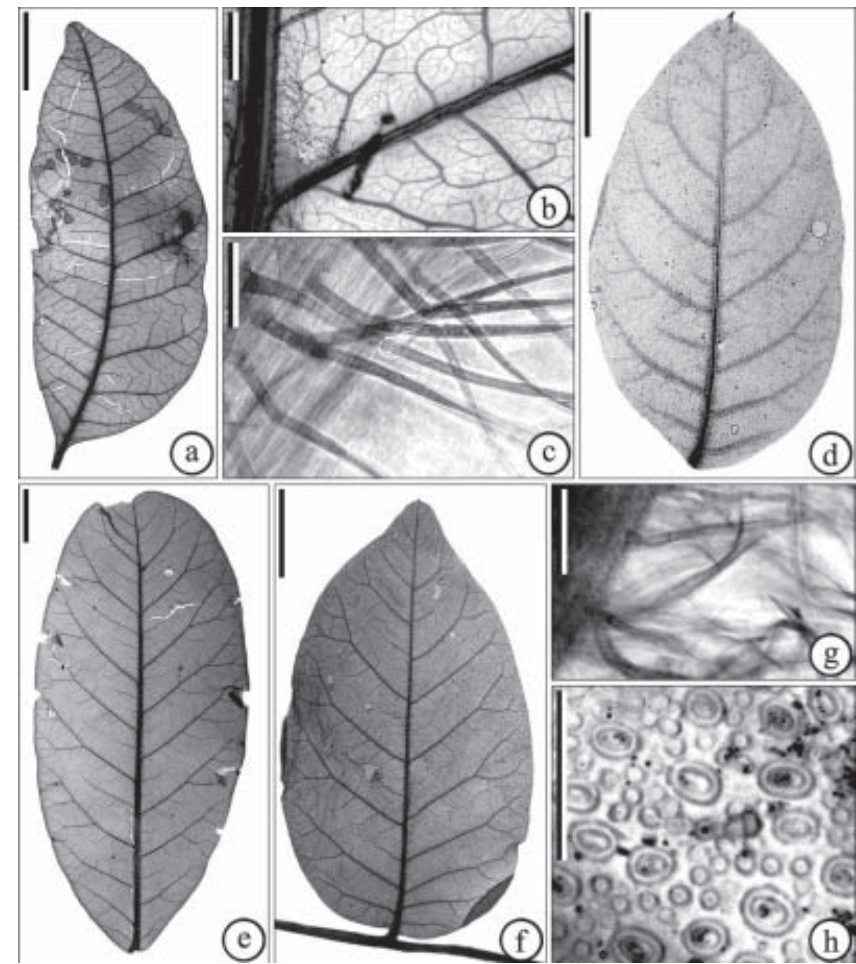

Figura 22. Rhodosphaera y Rhus. a-c, Rhodosphaera. a, folíolo de $R$. rhodanthema (escala $=1 \mathrm{~cm}) ; \mathrm{b}$, venación de tercer orden y domacio de $R$. rhodanthema (escala $=1 \mathrm{~mm}$ ); c, tricomas pluricelulares de $R$. rhodanthema (escala $=100 \mu$ ). d-h, Rhus. d, folíolo de $R$. galeottii (escala $=1 \mathrm{~cm}$ ); e, hoja de $R$. ("Baronia") taratana (escala=1 cm) $\mathrm{f}$, folíolo de $R$. terebinthifolia (escala $=1 \mathrm{~cm}$ ); $\mathrm{g}$, tricomas de $R$. galeottii (escala $=100 \mu)$, h, tricomas glandulares y estomas de $R$. ("Baronia") taratana (escala=100 $\mu$ ).

Cham. (FCME-GE 7, México).

Ejemplares complementarios: R. galeottii Standl. (MEXUI. Calzada y C. Toledo 16277, México), R. nelsonii F. A. Barkley (MEXU- C. R. Vilchis, R. M. Fonseca J., México), $R$. terebinthifolia Schlecht. et Cham. (MEXU-A. Ramírez Guadarrama 758, México).

Distribución: México, Centroamérica, Sudamérica tropical, China, Japón, Grecia, Irak, Norteamérica y Asia templadas, Sudáfrica, Madagascar, Malasia, Papúa, Australia.

Descripción: Organización macroscópica. Hojas con arreglo alterno, simples (R. taratana) o compuestas imparipinnadas con folíolos opuestos, inserción del pecíolo/peciólulo marginal y textura cartácea. Las hojas/folíolos son de forma elíptica u ovada, ligeramente asimétrica en la base (elíptica en $R$. galeottii y $R$. taratana y ovada en $R$. nelsonii y $R$. terebinthifolia; folíolos simétricos en $R$. terebinthifolia y asimétricos en $R$. nelsonii). La base puede ser convexa, cordada, convexa/cóncavo-convexa o convexa/cuneada (convexa en $R$. galeottii, $R$. nelsonii y $R$. terebinthifolia, cordada en $R$. terebinthifolia, convexa/cóncavo-convexa en $R$. galeottii y convexa/cuneada en $R$. nelsonii y $R$. taratana). El ápice puede ser recto, convexo, acuminado o retuso (recto en $R$. galeottii y $R$. nelsonii, convexo en $R$. galeottii, acuminado en $R$. nelsonii y $R$. terebinthifolia y retuso en $R$. taratana). Rhus galeottii y $R$. terebinthifolia presentan una proyección de la vena media (mucrón) mientras que las demás especies no la presentan. El margen es entero. El tamaño de las hojas/folíolos es micrófilo (es notófilo en $R$. taratana), la proporción largo/ancho es 1.57:1-(2.1175:1)$3.08: 1$, el ángulo de la base es de $75^{\circ}-\left(87.4375^{\circ}\right)-103.25^{\circ}$ y el del ápice de $58.5^{\circ}-\left(78.5625^{\circ}\right)-87^{\circ}$.

Venación. La venación primaria es pinnada. La secundaria, cladódroma I con 3 o 4 venas basales; en $R$. taratana se presentan venas agróficas compuestas (3 venas basales en $R$. galeottii y $R$. taratana y 4 en $R$. nelsonii y $R$. terebinthifolia). El espaciado de las venas secundarias es irregular y el ángulo con respecto a la vena primaria es uniforme o aumenta ligeramente hacia la base (el espaciado es uniforme en $R$. taratana; el ángulo es uniforme en $R$. nelsonii y $R$. taratana y aumenta ligeramente hacia la base en $R$. galeottii y $R$. terebinthifolia). Las venas intersecundarias son débiles (robustas en $R$. taratana y ausentes en $R$. nelsonii). La venación terciaria presenta el patrón opuesto/alterno/ dicótomo, su curso es ramificado exmedialmente y el ángulo con respecto a la vena primaria es obtuso que decrece exmedialmente (opuesto/alterno en $R$. nelsonii y alterno en $R$. galeottii; el ángulo aumenta basalmente en $R$. terebinthifolia y es inconsistente en $R$. taratana). La venación de cuarto orden es reticulada poligonal regular (alterna percurrente en $R$. terebinthifolia). Las venas de quinto orden presentan el arreglo reticulado poligonal regular en $R$. taratana y $R$. terebinthifolia y el dicótomo en $R$. galeottii y $R$. nelsonii. Las areolas están bien desarrolladas (son moderadas en $R$. nelsonii). Las últimas venas libres están ausentes en $R$. nelsonii, de ausentes a no ramificadas en $R$. taratana, de no ramificadas hasta muy ramificadas en $R$. galeottii y muy ramificadas en $R$. terebinthifolia. El orden más alto de venación es el quinto o el sexto; el último que presenta ramificación excurrente, el cuarto o el quinto (el orden más alto de venación es el quinto en $R$. galeottii y $R$. nelsonii y sexto en $R$. taratana y $R$. terebinthifolia, mientras que el último con ramificación excurrente es el cuarto en $R$. galeottii y $R$. nelsonii y el quinto en $R$. taratana y $R$. terebinthifolia). La venación marginal forma arcos. El grado de organización de la hoja es 3r para $R$. galeottii y $R$. nelsonii y $4 \mathrm{r}$ para $R$. taratana y $R$. terebinthifolia.

Características epidérmicas. Estomas de tipo policíticoanomocítico; se localizan únicamente en el envés (policíticoactinocítico en $R$. nelsonii y policítico-ciclocítico en $R$. taratana). Los tricomas son de escasos a abundantes (escasos en $R$. nelsonii, moderados en $R$. taratana y abundantes en $R$. galeottii y $R$. terebinthifolia). Se distribuyen en toda la superficie en $R$. galeottii y $R$. terebinthifolia y sobre las venas en $R$. nelsonii; son de tipo pluricelular, excepto en $R$. taratana donde sólo se encuentran tricomas glandulares y en $R$. terebinthifolia donde se encuentran ambos tipos. 
Cristales y canales resiníferos. Los cristales prismáticos y drusas están ausentes en $R$. nelsonii y $R$. terebinthifolia pero se encuentran al interior de las venas de R. galeottii. En las venas de $R$. taratana hay cristales prismáticos y drusas y en el mesofilo sólo drusas. En general no se observan canales resiníferos, únicamente se pudieron observar en las venas de primero, segundo, tercero y cuarto orden de R. taratana.

\section{0) Género: Schinopsis Engl. (Fig. 23a-d).}

Especie tipo: no designada.

Ejemplares aclarados: S. brasiliensis Engl. (Colección personal de la Dra. Terrazas-Krukoff 10036, Bolivia), S. lorentzii Engl. (CAS-Schulz 1300, Argentina).

Ejemplares complementarios: S. brasiliensis Engl. (MEXUAndrade et al. 11, Brasil), S. cornuta Loesener (MEXUM. Menacho y Z. López 101, Bolivia), S. haenkeana Engl. (MEXU-M. Nee y E. Chávez 48991, Bolivia), S. lorentzii Engl. (MEXU-G. E. Chaplin C. 659, Bolivia).

Distribución: Chaco de Argentina, Bolivia, Brasil, Paraguay.

Descripción: Organización macroscópica. Hojas compuestas imparipinnadas, paripinnadas o simples, de arreglo alterno o pseudoverticilado, con folíolos opuestos, a veces alternos, sésiles y de textura cartácea (hojas imparipinnadas en $S$. brasiliensis y S. haenkeana*, paripinnadas en S. lorentzii y simples en S. cornuta*; en esta misma especie, el arreglo es pseudoverticilado y el pecíolo, marginal; en S. haenkeana* los folíolos son alternos). El raquis es alado en $S$. lorentzii. Las hojas/folíolos son de forma oblonga, ovada o elíptica y son ligeramente asimétricos (forma oblonga en $S$. brasiliensis, ovada en $S$. cornuta* y $S$. lorentzii, y elíptica en S. haenkeana*). La base es convexa de un lado y cóncavoconvexa del otro en $S$. brasiliensis, convexa de un lado y cuneada del otro en S. haenkeana* y S. lorentzii, y convexa en $S$. cornuta*. El ápice es retuso, recto o convexo, se presenta una proyección de la vena media (mucrón) excepto en $S$. brasiliensis; el margen es entero (ápice retuso en $S$. brasiliensis, recto en $S$. lorentzii y convexo en $S$. cornuta* y S. haenkeana*). El tamaño de los folíolos es nanófilo, la proporción largo/ancho es 2.465:1 (2.00:1 en S. brasiliensis y 2.93:1 en $S$. lorentzii), el ángulo de la base es de $68.83^{\circ}\left(76^{\circ}\right.$ en $S$. brasiliensis y $61.66^{\circ}$ en $S$. lorentzii) y el del ápice de $67.015^{\circ}\left(91.7^{\circ}\right.$ en $S$. brasiliensis y $42.43^{\circ}$ en $S$. lorentzii).

Venación. La venación primaria es pinnada. La secundaria cladódroma I con 3 venas basales, el espaciado de las venas secundarias es uniforme como en $S$. brasiliensis o disminuye hacia la base como en $S$. lorentzii, el ángulo con respecto a la vena primaria es uniforme o aumenta ligeramente hacia la base (uniforme en S. brasiliensis y aumenta ligeramente hacia la base en $S$. lorentzii). Las venas intersecundarias son débiles en $S$. brasiliensis y robustas en S. lorentzii. La venación terciaria presenta el patrón reticulado al azar en S. brasiliensis y el mixto/dicótomo en S. lorentzii. El curso de las venas terciarias es ramificado admedialmente en $S$. brasiliensis y exmedialmente en S. lorentzii y el ángulo con respecto a la vena primaria es obtuso e inconsistente. La venación de cuarto orden es dicótoma (ocasionalmente se forman venas opuestas percurrentes en S. lorentzii). Las venas de quinto orden son dicótomas. Las areolas están de poco a moderadamente desarrolladas (poco desarrolladas en $S$. brasiliensis y moderadamente desarrolladas en $S$. lorentzii). Las últimas venas libres son muy ramificadas (dos o más veces). El orden más alto de venación es el quinto; el último que presenta ramificación excurrente, el tercero. La venación marginal forma arcos incompletos (libre). El grado de organización de la hoja es $2 \mathrm{r}$ para $S$. brasiliensis y $3 \mathrm{r}$ para S. lorentzii.

Características epidérmicas. Estomas de tipo policíticoanomocítico en $S$. brasiliensis y policítico-actinocítico en $S$. lorentzii, se localizan únicamente en el envés. Los tricomas son escasos (S. brasiliensis) o abundantes (S. lorentzii) y se distribuyen en toda la superficie, son de tipo unicelular en $S$. brasiliensis y pluricelular en S. lorentzii, en ambos se presenta también el tipo glandular.

Cristales y canales resiníferos. Se presentan cristales prismáticos en el interior de las venas. Las drusas están ausentes en $S$. brasiliensis pero se presentan al interior de las venas y en el mesofilo de $S$. lorentzii. Los canales resiníferos están presentes en las venas de primero, segundo y tercer orden.

51) Género: Schinus L. (Fig. 23e-j).

Especie tipo: S. molle L.

Ejemplares aclarados: S. dependens Orteg. (DS-MacDonald 750, Estados Unidos), S. latifolius Engl. (CAS-Jativa 2720, Estados Unidos), S. lentiscifolius March. (CAS-Broder 1344, Estados Unidos), S. meyeri F. A. Barkley (CAS-Schiavone et al. 11883C, Argentina), S. molle L. (FCME-RPG1, México), S. venturii F. A. Barkley (CAS-Vervoost 7625c, Argentina), S. weinmanniaefolius Engl. (DS-Rambo 39605, Brasil).

Ejemplares complementarios: S. dependens Orteg. (NYE. Hassler 11069, Paraguay, isotipo; NY-C. G. L. Bertero 230, Chile, sintipo; NY-G. Mandon 768, Bolivia, tipo), S. latifolius Engl. (NY-C. G. L. Bertero 964, Chile, isotipo), S. lentiscifolius March. (NY-E. Hassler 7909, Paraguay, isotipo; NY-E. Hassler 5422, Paraguay, isolectotipo; NY-E. Hassler 5959, Paraguay, isotipo), S. molle L. (MEXU-V. Sánchez T. 0346, México), S. terebinthifolius Raddi (MEXU-T. Wendt y K. Collins 7071, Estados Unidos), S. weinmanniaefolius Engl. (MEXU-O. Ahumada et al. 3435, Argentina).

Distribución: Sudamérica subtropical, Chile, Argentina, Brasil, Uruguay, Florida.

Descripción: Organización macroscópica. Hojas de arreglo alterno, simples, compuestas imparipinnadas o paripinnadas; los folíolos tienen arreglo alterno u opuesto, la inserción del pecíolo/peciólulo es marginal (las hojas son simples en $S$. dependens y $S$. latifolius, compuestas imparipinnadas con folíolos opuestos en $S$. lentiscifolius, S. terebinthifolius* y $S$. 
weinmanniaefolius y paripinnadas con folíolos alternos en $S$. molle; la inserción es marginal en S. dependens, S. latifolius, S. meyeri y $S$. venturii y sésil en S. lentiscifolius, S. molle, $S$. terebinthifolius* y S. weinmanniaefolius). Cuando las hojas son compuestas, el raquis es alado. La textura es cartácea excepto en $S$. meyeri donde es membranácea. Las hojas/ folíolos son de forma elíptica, ovada, obovada u oblonga, pueden ser simétricos, ligeramente asimétricos o ligeramente asimétricos en la base (forma elíptica en S. latifolius y $S$. venturii, ovada en S. meyeri, S. molle y S. terebinthifolius*, obovada en $S$. dependens y $S$. weinmanniaefolius y oblonga en S. lentiscifolius; son simétricos en S. dependens, ligeramente asimétricos en $S$. lentiscifolius, $S$. meyeri y $S$. venturii y ligeramente asimétricos en la base en $S$. latifolius, $S$. molle y $S$. weinmanniaefolius). La base es de forma variable; convexa en S. latifolius y $S$. molle, decurrente en $S$. dependens y $S$. venturii, convexa de un lado y cuneada del otro en S. lentiscifolius y $S$. weinmanniaefolius y convexa de un lado y cóncavo-convexa del otro en $S$. meyeri. El ápice es convexo, recto o acuminado, presenta una proyección de la vena media (mucrón) únicamente en S. lentiscifolius y $S$. molle (es convexo en $S$. dependens, S. latifolius, $S$. meyeri, S. terebinthifolius* y $S$. weinmanniaefolius, recto en $S$. dependens, S. lentiscifolius y $S$. molle y acuminado en $S$. venturii). El margen es entero en $S$. dependens y $S$. venturii, dentado en $S$. latifolius, serrado en $S$. molle y $S$. weinmanniaefolius y crenado en $S$. lentiscifolius, $S$. meyeri y S. terebinthifolius*. El tamaño de las hojas/folíolos es micrófilo, la proporción largo/ancho es 1.61:1-(3.5178:1)6.595:1, el ángulo de la base es de $24.875^{\circ}-\left(57.42^{\circ}\right)-90.5^{\circ}$ y el del ápice, $20.4575^{\circ}-\left(54.51^{\circ}\right)-88^{\circ}$.

Venación. La venación primaria es pinnada. La secundaria cladódroma I, el número de venas basales es de 2 a 5 (es craspedódroma en $S$. latifolius y $S$. weinmanniaefolius y cladódroma I/II en $S$. dependens; hay 2 venas basales en $S$. molle y $S$. weinmanniaefolius, 3 en S. dependens, S. latifolius y $S$. venturii, 4 en $S$. lentiscifolius, S. meyeri y S. molle y 5 en $S$. dependens). El espaciado es uniforme, irregular o disminuye hacia la base y el ángulo con respecto a la vena primaria es principalmente uniforme (uniforme en $S$. dependens y $S$. molle, irregular en S. latifolius, S. lentiscifolius y $S$. venturii y disminuye hacia la base en $S$. meyeri y $S$. weinmanniaefolius, el ángulo en $S$. dependens puede ser uniforme o disminuir hacia la base, en $S$. latifolius aumenta abruptamente hacia la base y ligeramente en $S$. meyeri y $S$. weinmanniaefolius). Las venas intersecundarias son débiles (robustas en $S$. dependens y en algunos ejemplares de $S$. molle). La venación terciaria es dicótoma, su curso es ramificado admedialmente excepto en S. molle donde es ramificado exmedialmente; su ángulo con respecto a la vena primaria es obtuso y agudo, su variación en la lámina es inconsistente (en algunos ejemplares de S. dependens se presenta únicamente ángulo agudo y éste puede ocasionalmente aumentar exmedialmente). La venación de cuarto orden es dicótoma. Las venas de quinto

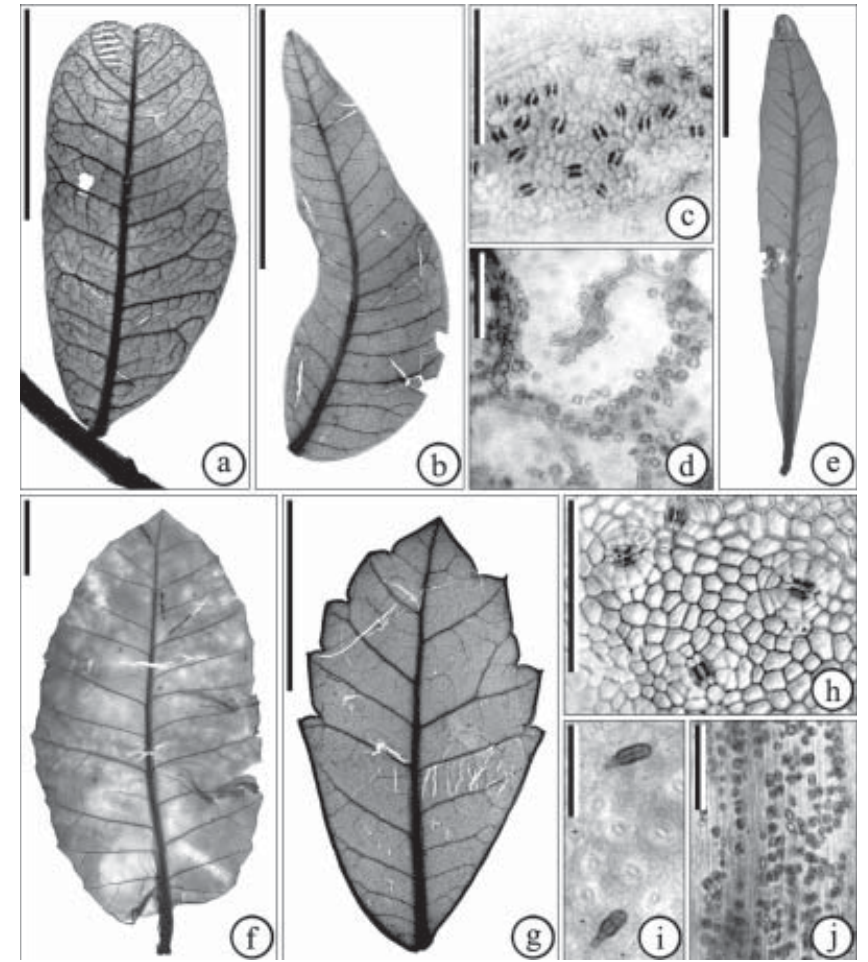

Figura 23. Schinopsis y Schinus. a-d, Schinopsis. a, folíolo de $S$. brasiliensis (escala $=1 \mathrm{~cm})$; $\mathrm{b}$, folíolo de $S$. lorentzii (escala=1 cm); c, estomas de $S$. brasiliensis (escala $=100 \mu$ ); d, drusas al interior de las venas de $S$. lorentzii (escala $=100 \mu$ ). e-j, Schinus. e, folíolo de $S$. dependens (escala $=1 \mathrm{~cm}) ; \mathrm{f}$, folíolo de $S$. latifolius (escala=1 cm); $\mathrm{g}$, folíolo de $S$. weinmanniaefolius (escala $=1 \mathrm{~cm}$ ); h, estomas de $S$. lentiscifolius (escala $=100 \mu$ ); $\mathrm{i}$, tricomas glandulares de $S$. meyeri (escala $=100 \mu) ; \mathrm{j}$, cristales prismáticos y drusas al interior de las venas de $S$. molle $($ escala $=100 \mu)$.

orden también son dicótomas (forman un retículo poligonal regular en $S$. meyeri y en $S$. molle puede presentar ambos estados). Las areolas están moderadamente desarrolladas (poco desarrolladas en $S$. latifolius y algunos ejemplares de $S$. dependens y $S$. molle y ausentes en S. lentiscifolius y $S$. weinmanniaefolius). Las últimas venas libres van desde ausentes hasta muy ramificadas (dos o más veces); en $S$. latifolius, este último es el estado más común mientras que en $S$. dependens, van de ausentes a ramificadas sólo una vez. El orden más alto de venación es el sexto (quinto en $S$. lentiscifolius y $S$. molle), y el último que presenta ramificación excurrente, el cuarto (tercero en $S$. weinmanniaefolius y $S$. lentiscifolius). La venación marginal forma arcos incompletos (forma arcos en S. meyeri y ocasionalmente en S. molle). El grado de organización de la hoja es $2 \mathrm{r}$ excepto en $S$. meyeri y $S$. venturii donde es $3 r$.

Dientes. Hay un orden de dientes distribuidos de forma irregular, 1 a 3 dientes por centímetro, a todo lo largo del margen (en $S$. weinmanniaefolius hay dos órdenes de dientes distribuidos de forma regular en los 2/5 distales de la lámina; 
en S. latifolius también están distribuidos de forma regular y en $S$. molle se distribuyen en los 2/5 distales del margen; se encuentra 1 diente por centímetro en $S$. lentiscifolius, $S$. meyeri y $S$. molle, 2 en $S$. molle y 3 en $S$. latifolius y $S$. weinmanniaefolius). El lado apical del diente es recto en $S$. latifolius y S. molle, convexo en S. lentiscifolius, S. meyeri, S. molle y $S$. weinmanniaefolius, cóncavo en $S$. molle y flexo en $S$. weinmanniaefolius; el lado basal es convexo en S. lentiscifolius, S. meyeri, S. molle y S. weinmanniaefolius, recto en $S$. latifolius, $S$. lentiscifolius, $S$. meyeri y $S$. weinmanniaefolius y retroflexo en $S$. molle. El ápice del diente es simple y el seno es angular (el ápice es simple o glandular en S. latifolius, simple o espinoso en S. molle y mucronado en $S$. weinmanniaefolius; el seno es redondo en S. latifolius y $S$. lentiscifolius). La vena principal del diente es una secundaria que nace directamente de la primaria (en S. weinmanniaefolius puede ser también la rama proximal de una dicotomía de la vena secundaria; en $S$. meyeri, no se presenta una vena principal sino que hay pequeñas venas que entran al diente y en $S$. lentiscifolius no hay venas en el diente).

Características epidérmicas. Estomas de tipo policíticociclocítico en S. dependens, S. latifolius, S. meyeri y S. molle, policítico-actinocítico en $S$. dependens, S. lentiscifolius y $S$. venturii y policítico-anomocítico en $S$. molle y $S$. weinmanniaefolius; se ubican tanto en el haz como en el envés en $S$. dependens, S. lentiscifolius y $S$. molle, y únicamente en el envés en S. latifolius, S. meyeri, S. venturii y $S$. weinmanniaefolius. Los tricomas son generalmente escasos; en $S$. meyeri moderados y en $S$. weinmanniaefolius abundantes; se ubican principalmente en el margen, aunque en $S$. molle y $S$. weinmanniaefolius están en toda la superficie; son de tipo unicelular, pluricelular y glandular (unicelulares en S. dependens, S. lentiscifolius, S. meyeri, S. molle y $S$. weinmanniaefolius, pluricelulares en $S$. latifolius, $S$. lentiscifolius y $S$. molle y glandulares en $S$. meyeri, $S$. venturii, $S$. weinmanniaefolius y en algunos ejemplares de S. molle).

Cristales y canales resiníferos. Schinus meyeri y $S$. weinmanniaefolius carecen de cristales prismáticos y de drusas, se presentan cristales prismáticos en el interior de las venas de las demás especies y además en el mesofilo de S. latifolius y S. molle. Se presentan drusas en el mesofilo de las mismas especies y además en el interior de las venas de S. latifolius, S. molle, S. venturii y algunos ejemplares de $S$. dependens. No se observan canales resiníferos excepto en algunos ejemplares de $S$. dependens, en las venas de primero, segundo y tercer orden, y en S. meyeri, donde están en las del primero al cuarto orden.

52) Género: Sclerocarya Hochst. (Fig. 24a-c). Especie tipo: S. birrea (A. Rich.) Hochst. Ejemplares aclarados: S. birrea (A. Rich.) Hochst. (Colección personal de la Dra. Terrazas-J. Viegas da Graca $s / n$, Guinea).

Distribución: África, Madagascar, Sudán.

Descripción: Organización macroscópica. Hojas compuestas imparipinnadas con arreglo pseudoverticilado y folíolos opuestos de inserción del peciólulo marginal y textura cartácea. Folíolos de forma elíptica, ligeramente asimétricos con base cóncavo-convexa, ápice acuminado con una proyección de la vena media (mucrón) y margen entero. El tamaño de los folíolos es nanófilo, la proporción largo/ancho es 1.82:1, el ángulo de la base es de $81^{\circ}$ y también el del ápice.

Venación. La venación primaria es pinnada. La secundaria cladódroma I con 3 venas basales, el espaciado de las venas secundarias disminuye hacia la base y hacia el ápice y el ángulo con respecto a la vena primaria es uniforme. Las venas intersecundarias son débiles. La venación terciaria presenta el patrón mixto (opuesto/alterno percurrente), su curso es sinuoso y el ángulo con respecto a la vena primaria es obtuso que se mantiene uniforme. La venación de cuarto orden presenta el patrón opuesto percurrente. Las venas de quinto orden son dicótomas. Las areolas están moderadamente desarrolladas, las últimas venas libres, desde ausentes hasta ramificadas una vez. El orden más alto de venación es el quinto, y el último que presenta ramificación excurrente, el cuarto. La venación marginal forma arcos. El grado de organización de la hoja es $2 \mathrm{r}$.

Características epidérmicas. Estomas de tipo policíticoanomocítico localizados únicamente en el envés. No se presentan tricomas.

Cristales y canales resiníferos-Las drusas se encuentran al interior de las venas y en el mesofilo. No se observan canales resiníferos.

53) Género: Semecarpus L. f. (Fig. 24d-f).

Especie tipo: S. anacardium L. f.

Ejemplares aclarados: S. curtisii King (BKF-Bunnak 769, Tailandia), S. venenosa Volk. (DS-Fehlmann, Islas Palau). Ejemplares complementarios: S. cochinchinensis Engl (MEXU-J. F. Maxwell 91-119, Tailandia), S. forstenii Blume (MEXU-F. A. W. Schram BW10640, Nueva Guinea).

Distribución: India, Sri Lanka, Myanmar, Tailandia, Malasia, Filipinas, Australia, Nueva Caledonia, Islas Salomón, Micronesia, Fiji.

Descripción: Organización macroscópica. Hojas simples con arreglo pseudoverticilado o alterno, inserción del pecíolo marginal y textura cartácea o coriácea (en S. curtisii el arreglo es pseudoverticilado mientras que en S. cochinchinensis* y S. forstenii* es alterno; en estas dos especies la textura es coriácea mientras que en $S$. curtisii y $S$. venenosa es cartácea). Las hojas son de forma obovada, ligeramente asimétricas o simétricas, de base decurrente o convexa, ápice recto o acuminado y margen entero (las hojas de S. curtisii son ligeramente asimétricas con base convexa, ápice acuminado y margen entero; las de $S$. venenosa, simétricas con base 
decurrente, ápice recto y margen erosionado mientras que las de S. cochinchinensis* y S. forstenii* tienen base decurrente, ápice acuminado y margen entero). El tamaño de las hojas es mesófilo, la proporción largo/ancho es 4.395:1 (3.54:1 en $S$. curtisii y 5.25:1 en $S$. venenosa), el ángulo de la base es de $30^{\circ}\left(45^{\circ}\right.$ en $S$. curtisii y $15^{\circ}$ en $S$. venenosa) y el del ápice de $39.5^{\circ}\left(50^{\circ}\right.$ en $S$. curtisii y $29^{\circ}$ en $S$. venenosa).

Venación. La venación primaria es pinnada. La secundaria broquidódroma débil en $S$. curtisii y eucamptódroma en $S$. venenosa, con 3 venas basales, el espaciado de las venas secundarias disminuye hacia la base y hacia el ápice en S. curtisii y es uniforme en $S$. venenosa, y el ángulo con respecto a la vena primaria es uniforme. No se presentan venas intersecundarias. La venación terciaria presenta el patrón alterno percurrente aunque en $S$. venenosa también se presentan algunas opuestas dando así, el patrón mixto. El curso de las venas terciarias es ramificado exmedialmente en $S$. curtisii y recto en $S$. venenosa y el ángulo con respecto a la vena primaria es obtuso que en $S$. venenosa se mantiene uniforme mientras que en $S$. curtisii decrece exmedialmente. La venación de cuarto y quinto orden presenta el patrón reticulado poligonal regular. Las areolas están bien desarrolladas, las últimas venas libres son muy ramificadas (dos o más veces). El orden más alto de venación es el séptimo, el último que presenta ramificación excurrente, el quinto. La venación marginal forma arcos en $S$. venenosa y en S. curtisii forma una vena fimbrial. El grado de organización de la hoja es $4 r$.

Características epidérmicas. Estomas de tipo policíticoanomocítico, localizados únicamente en el envés. En $S$. curtisii no se presentan tricomas; en $S$. venenosa se presentan en cantidad moderada y se distribuyen en toda la superficie de la hoja; son de tipo pluricelular.

Cristales y canales resiníferos. Se presentan cristales prismáticos al interior de las venas y además, en S. curtisii también están en el mesofilo. Se encuentran drusas en el mesofilo, y en $S$. venenosa, también se presentan al interior de las venas. Hay canales resiníferos en las venas del primero al quinto orden de $S$. curtisii, pero en $S$. venenosa no se observan.

54) Género: Smodingium E. Mey. ex Sond. (Fig. 24g-i). Especie tipo: S. argutum E. Mey. ex Sond.

Ejemplares aclarados: S. argutum E. Mey. ex Sond. (Colección personal de la Dra. Terrazas, Sudáfrica).

Distribución: Sudáfrica.

Descripción: Organización macroscópica. Hojas trifoliadas de arreglo alterno con folíolos sésiles de textura cartácea, ovados, simétricos, con base decurrente, ápice recto y margen serrado. El tamaño del folíolo es micrófilo, la proporción largo/ancho es 4.71:1, el ángulo de la base es de $36^{\circ}$ y el del ápice de $31^{\circ}$.

Venación. La venación primaria es pinnada. La secundaria craspedódroma con 3 venas basales, el espaciado de las venas secundarias es uniforme al igual que el ángulo. Las venas intersecundarias son robustas. La venación terciaria es dicótoma, su curso es ramificado exmedialmente y el ángulo con respecto a la vena primaria es obtuso que decrece exmedialmente. La venación de cuarto orden presenta el patrón reticulado poligonal regular. La de quinto orden es dicótoma. Las areolas están bien desarrolladas, las últimas venas libres no están ramificadas o están ausentes. El orden más alto de venación es el quinto; el último que presenta ramificación excurrente, el cuarto. La venación marginal forma arcos. El grado de organización de la hoja es 3r.

Dientes. Hay dos órdenes de dientes distribuidos irregularmente a todo lo largo del margen, encontrándose unos 3 dientes por centímetro. El lado apical del diente es flexo, el basal también es flexo, el ápice del diente es esferulado y el seno, angular. La vena principal del diente es la rama distal, proveniente de una dicotomía de la vena secundaria.

Características epidérmicas. Estomas de tipo policíticoanomocítico, localizados únicamente en el envés. Los tricomas son escasos, distribuidos sobre las venas y en el

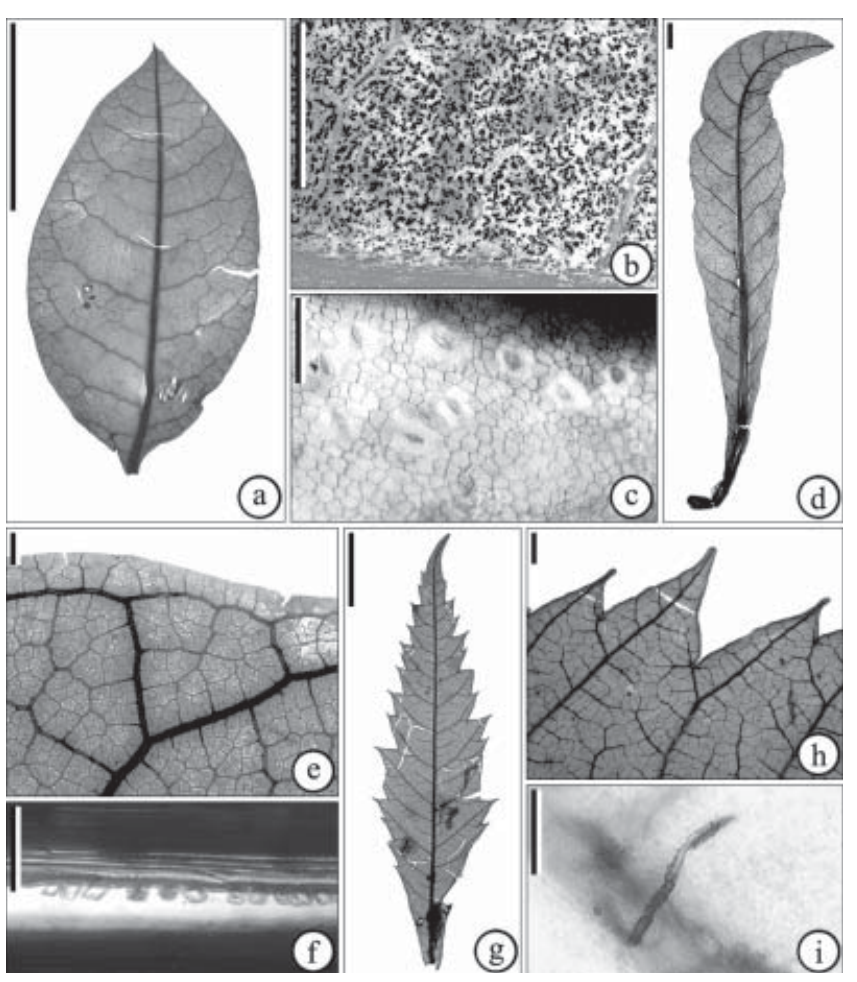

Figura 24. Sclerocarya, Semecarpus y Smodingium. a-c, Sclerocarya. a, folíolo de $S$. birrea (escala $=1 \mathrm{~cm}$ ); b, drusas al interior de las venas y en el mesofilo de $S$. birrea (escala=1 $\mathrm{mm}$ ); c, estomas de $S$. birrea (escala $=100 \mu$ ). d-f, Semecarpus. d, hoja de $S$. venenosa $($ escala $=1 \mathrm{~cm})$; e, venación broquidódroma débil de S. curtisii (escala $=1 \mathrm{~mm}) ; \mathrm{f}$, cristales prismáticos al interior de las venas de $S$. venenosa (escala $=100 \mu$ ). g-i, Smodingium. g, folíolo de $S$. $\operatorname{argutum}($ escala $=1 \mathrm{~cm}) ; \mathrm{h}$, dientes de $S$. $\operatorname{argutum}($ escala $=1 \mathrm{~mm})$; i, tricoma de $S$. argutum (escala $=100 \mu$ ). 
margen, de tipo pluricelular.

Cristales y canales resiníferos. Se presentan cristales prismáticos y drusas al interior de las venas. Los canales resiníferos se encuentran en las venas del primero al cuarto orden.

\section{5) Género: Sorindeia Thouars (Fig. 25a-b).}

Especie tipo: S. madagascariensis DC.

Ejemplares aclarados: S. madagascariensis DC. (US-R. B. Faden et. al s/n, Kenia).

Ejemplares complementarios: S. madagascariensis DC. (FTG-K. Bradley 556, Estados Unidos).

Distribución: África tropical, Centroáfrica, Tanzania, Madagascar.

Descripción: Organización macroscópica. Hojas compuestas imparipinnadas de arreglo alterno con folíolos alternos peciolulados de textura coriácea. Los folíolos tienen forma ovada, son ligeramente asimétricos con base convexa, ápice acuminado y margen entero. El tamaño de los folíolos es notófilo, la proporción largo/ancho es 1.52:1, el ángulo de la base es de $104^{\circ}$ y el del ápice de $83^{\circ}$.

Venación. La venación primaria es pinnada. La secundaria cladódroma II con 5 venas basales, el espaciado de las venas secundarias es irregular, el ángulo aumenta ligeramente hacia la base. No hay venas intersecundarias. La venación terciaria es reticulada poligonal regular, su curso es ramificado exmedialmente y el ángulo con respecto a la vena primaria es obtuso que decrece exmedialmente. La venación de cuarto orden presenta el patrón reticulado poligonal regular. La venación de quinto orden es dicótoma. Las areolas están bien desarrolladas, las últimas venas libres son desde ausentes hasta muy ramificadas (dos o más veces). El orden más alto de venación es el sexto, y el cuarto es el último que presenta ramificación excurrente. La venación marginal forma una vena fimbrial. El grado de organización de la hoja es 4r.

Características epidérmicas. Estomas de tipo policíticoactinocítico localizados únicamente en el envés. No se presentan tricomas.

Cristales y canales resiníferos-No hay cristales prismáticos ni drusas. No se observan canales resiníferos.

56) Género: Spondias L. (Fig. 25c-i).

Especie tipo: S. mombin L.

Ejemplares aclarados: S. lutea L. (DS-Ferris 5425, México), S. mombin L. (CAS-Holmgren 3, Ecuador), S. nigrescens Pittier (DS-Foster 2317, Panamá), S. philippinensis (Elmer) Airy Shaw et Forman (DS-Elmer 17913, Filipinas), S. purpurea L. (FCME-RMFJ 1475, México; DS-Wiggins 18510, Islas Galápagos), S. radlkoferi Donn. Sm. (FCMERMF 2054, México).

Ejemplares complementarios: S. cytherea Sonner (MEXUC. E. Ridsdale et al. s/n, Filipinas), S. lutea L. (MEXU-M. G. Zola B 00544, México), S. mombin L. (MEXU-M. Sousa y M. Peña de Sousa 50, México), S. nigrescens Pittier (MO-
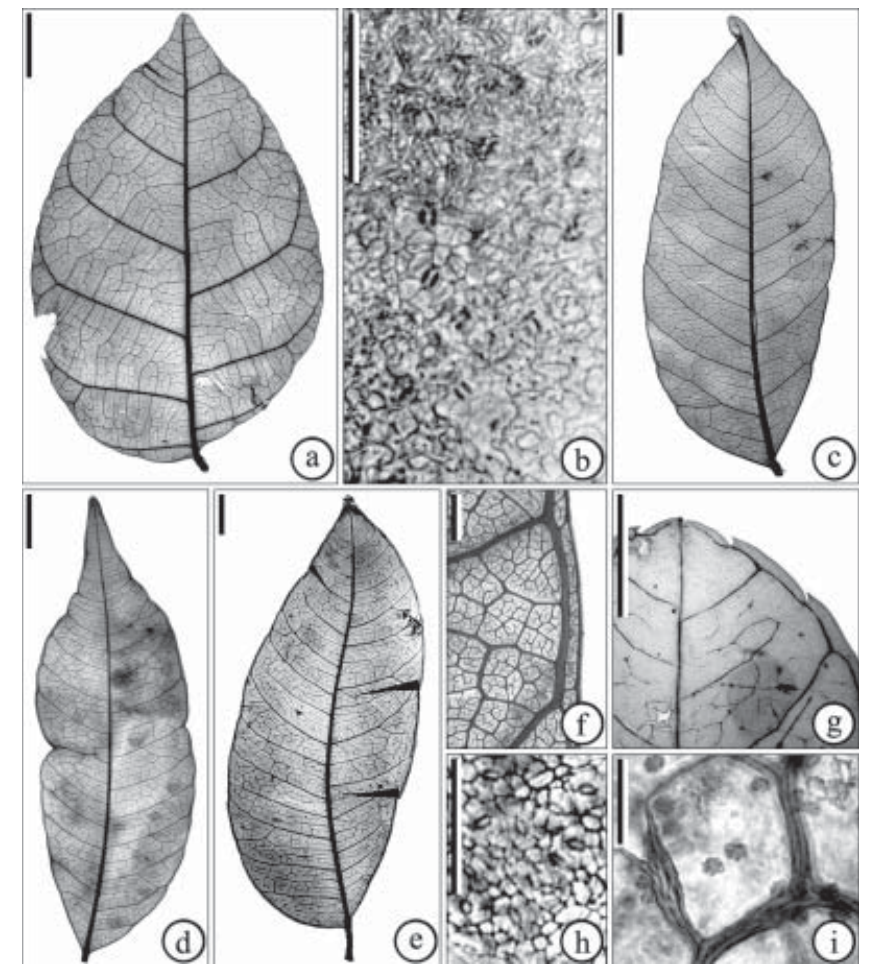

Figura 25. Sorindeia y Spondias. a-b, Sorindeia. a, folíolo de $S$. madagascariensis (escala $=1 \mathrm{~cm})$; $\mathrm{b}$, estomas de $S$. madagascariensis $($ escala $=100 \mu$ ). c-i, Spondias. c, folíolo de $S$. nigrescens (escala=1 $\mathrm{cm}$ ); d, folíolo de $S$. mombin (escala=1 $\mathrm{cm}$ ); e, folíolo de $S$. radlkoferi (escala $=1 \mathrm{~cm})$; f, venación secundaria intramarginal y vena fimbrial de $S$. lutea (escala=1 mm); $\mathrm{g}$, ápice y dientes de $S$. purpurea (escala $=5 \mathrm{~mm})$; h, estomas de $S$. mombin (escala=100 $\mu$ ); $\mathrm{i}$, drusas en el mesofilo de $S$. lutea $($ escala $=100 \mu)$.

A. Tonduz 13925, Costa Rica, protólogo), S. philippinensis (Elmer) Airy Shaw et Forman (NY-A. D. E. Elmer 13467, Filipinas, tipo), S. purpurea L. (MEXU-M. Martínez $s / n$, México), S. radlkoferi Donn. Sm. (MEXU-G. Castillo C. y L. Tapia 492, México).

Distribución: México, Costa Rica, Panamá, Colombia, Surinam, Ecuador, Brasil, China, Myanmar, Sumatra, Nueva Guinea, Nueva Caledonia, Filipinas.

Descripción: Organización macroscópica. Hojas compuestas imparipinnadas de arreglo alterno o pseudoverticilado (en $S$. purpurea y $S$. radlkoferi el arreglo es alterno, mientras que en S. lutea, S. mombin y S. philippinensis es pseudoverticilado), con folíolos opuestos o alternos peciolulados, de textura membranácea (son alternos en S. lutea y S. purpurea, opuestos en las demás especies observadas). Los folíolos son de forma elíptica, aunque en algunas especies pueden ser oblongos, ovados u obovados; son generalmente asimétricos, pero a veces ligeramente asimétricos o ligeramente asimétricos en la base (oblongos en S. mombin, ovados en S. cytherea* y obovados en $S$. purpurea; son ligeramente asimétricos en $S$. lutea y $S$. mombin y ligeramente asimétricos en la base 
en S. philippinensis y S. purpurea). La base es convexa en un lado y cuneada en el otro (convexa en ambos lados en S. lutea y S. philippinensis, ocasionalmente cuneada en $S$. purpurea). El ápice es acuminado (recto en $S$. radlkoferi y ocasionalmente convexo en $S$. purpurea). El margen es entero (crenado en $S$. cytherea* y $S$. mombin y serrado en S. axillaris* y S. purpurea). El tamaño de los folíolos es micrófilo (S. lutea, S. mombin y S. purpurea) o notófilo ( $S$. nigrescens, $S$. philippinensis y $S$. radlkoferi), la proporción largo/ancho es 2.02:1-(2.476:1)-2.91:1, el ángulo de la base es de $61^{\circ}-\left(70.324^{\circ}\right)-81^{\circ}$ y el del ápice, $43^{\circ}-\left(60.458^{\circ}\right)-74.75^{\circ}$. Venación. La venación primaria es pinnada. La secundaria intramarginal, excepto en $S$. philippinensis donde es eucamptódroma; hay 3 venas basales (4 en S. nigrescens y 6 en S. philippinensis y S. radlkoferi). El espaciado de las venas secundarias es irregular y el ángulo aumenta ligeramente hacia la base (el espaciado es uniforme en S. nigrescens y ocasionalmente aumenta hacia la base en $S$. purpurea; el ángulo es uniforme en S. mombin y S. purpurea). Las venas intersecundarias son débiles (robustas en $S$. nigrescens y $S$. radlkoferi). La venación terciaria puede ser reticulada al azar como en S. lutea, S. philippinensis y S. radlkoferi, puede tener el arreglo opuesto/alterno como en S. mombin, S. nigrescens y algunos ejemplares de $S$. purpurea o puede tener el arreglo opuesto/alterno/dicótomo como en S. purpurea; su curso es ramificado exmedialmente (ramificado admedialmente en S. philippinensis y convexo en $S$. nigrescens) y el ángulo con respecto a la vena primaria es obtuso que decrece exmedialmente (es inconsistente en S. lutea). La venación de cuarto orden presenta el patrón reticulado poligonal regular (es dicótomo en $S$. philippinensis y ocasionalmente en $S$. purpurea). La venación de quinto orden puede presentar el patrón reticulado poligonal regular (S. lutea, S. mombin y S. nigrescens) o el dicótomo (S. philippinensis, S. purpurea y S. radlkoferi). Las areolas están generalmente bien desarrolladas, pero están moderadamente desarrolladas en $S$. radlkoferi y poco desarrolladas en S. philippinensis y algunos ejemplares de $S$. purpurea. Las últimas venas libres son muy ramificadas (dos o más veces). El orden más alto de venación es el sexto, y el último que presenta ramificación excurrente, el cuarto (el último orden de venación es el séptimo en $S$. lutea y $S$. nigrescens y quinto en algunos ejemplares de S. purpurea mientras que el último orden con venación excurrente es el quinto en $S$. lutea y $S$. nigrescens y el tercero en $S$. philippinensis y algunos ejemplares de $S$. purpurea). La venación marginal forma una vena fimbrial excepto en S. philippinensis y S. purpurea donde forma arcos. El grado de organización de la hoja es 3r (2r para S. philippinensis y algunos ejemplares de $S$. purpurea).

Dientes. Hay un solo orden de dientes distribuidos de forma irregular únicamente en los 2/5 distales del folíolo (ocasionalmente son regulares en $S$. purpurea). Se encuentran 1,2 o 4 dientes por centímetro ( 1 en $S$. mombin y 2 o 4 en S. purpurea). El lado apical del diente es convexo en $S$. mombin, mientras que en $S$. purpurea, puede ser cóncavo, flexo o retroflexo, el lado basal es convexo en S. mombin y en $S$. purpurea es convexo o recto. El ápice es simple en $S$. mombin y esferulado o espinoso en $S$. purpurea, y el seno es angular. El diente de $S$. mombin presenta pequeñas venas pero ninguna principal, mientras que en $S$. purpurea, los dientes son muy pequeños y carecen de venas.

Características epidérmicas. Estomas de tipo policíticoanomocítico ubicados únicamente en el envés (policíticoactinocítico en $S$. nigrescens). Los tricomas son moderados en $S$. lutea, S. mombin y $S$. nigrescens, escasos en $S$. purpurea y $S$. radlkoferi y ausentes en $S$. philippinensis y $S$. purpurea; se distribuyen en toda la superficie en $S$. mombin y S. nigrescens, sobre las venas en S. lutea, S. purpurea y $S$. radlkoferi y en el margen en S. purpurea y S. radlkoferi. Los tricomas son de tipo pluricelular (ocasionalmente unicelular en S. radlkoferi y únicamente unicelulares en S. mombin).

Cristales y canales resiníferos-En general no se presentan cristales prismáticos; únicamente se observaron en las venas de $S$. mombin y $S$. philippinensis. Se presentan drusas en el mesofilo y además en las venas de $S$. lutea y $S$. mombin, en algunos ejemplares de $S$. purpurea y en $S$. philippinensis están ausentes. Los canales resiníferos se encuentran en las venas de primero, segundo y tercer orden excepto en $S$. nigrescens, S. philippinensis y en algunos ejemplares de $S$. purpurea donde no se observan.

57) Género: Swintonia Griff. (Fig. 26a-c).

Especie tipo: S. floribunda Griff.

Ejemplares aclarados: S. floribunda Griff. (Colección personal de la Dra. Terrazas).

Ejemplares complementarios: S. foxworthyi Elmer (MEXUC. E. Ridsdale (SMHI1565), Filipinas).

Distribución: Myanmar, Tailandia, Camboya, Laos, Vietnam, Malasia, Sumatra, Borneo, Islas Andaman, Filipinas.

Descripción: Organización macroscópica. Hojas simples de arreglo pseudoverticilado o alterno, pecioladas de textura coriácea (el arreglo es pseudoverticilado en $S$. floribunda y alterno en $S$. foxworthyi*). Las hojas son oblongas, simétricas, de base cóncavo-convexa, ápice acuminado y margen entero. El tamaño de las hojas es mesófilo, la proporción largo/ancho es 2.42:1, el ángulo de la base es de $72^{\circ}$ y el del ápice de $73^{\circ}$.

Venación. La venación primaria es pinnada. La secundaria eucamptódroma con 5 venas basales, el espaciado de las venas secundarias es irregular, el ángulo aumenta ligeramente hacia la base. Las venas intersecundarias son robustas. La venación terciaria es mixta (opuesto/alterno percurrente), su curso es recto o sinuoso y el ángulo con respecto a la vena primaria es obtuso e inconsistente. La venación de cuarto orden presenta el patrón reticulado poligonal regular. La de quinto orden es dicótoma. Las areolas están bien desarrolladas, las últimas venas libres son muy ramificadas (dos o más veces). El orden más alto de venación es el sexto; 

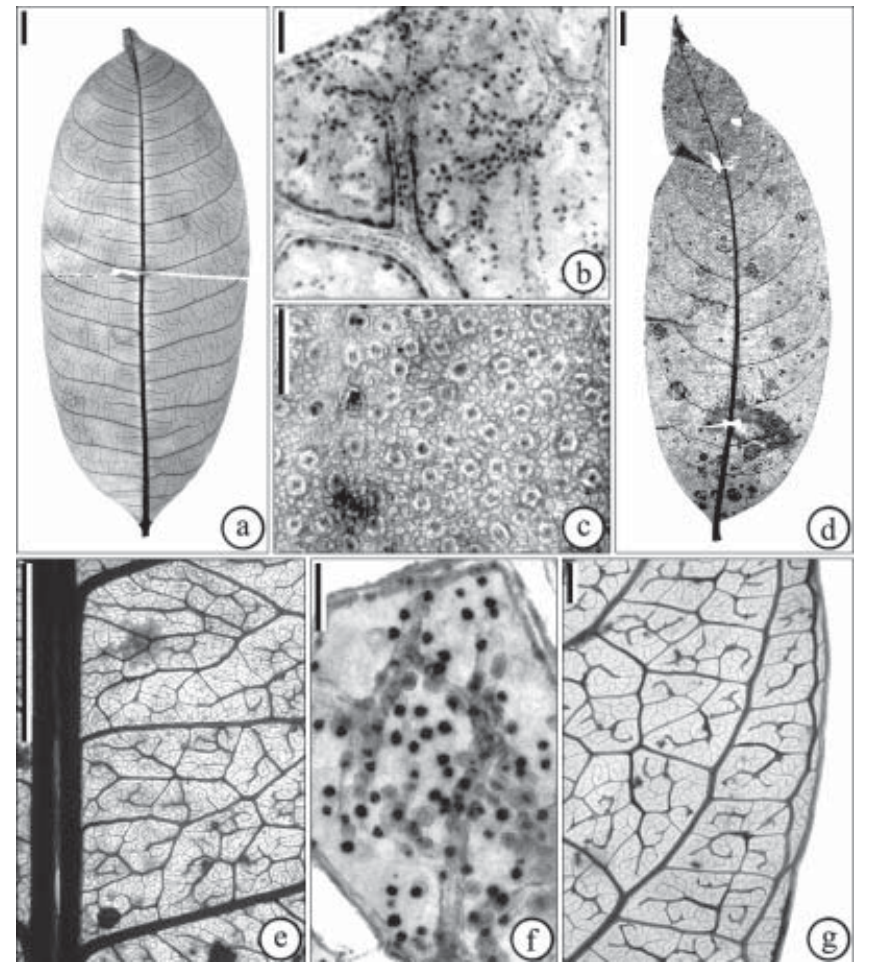

Figura 26. Swintonia y Tapirira. a-c, Swintonia. a, hoja de S. floribunda (escala $=1 \mathrm{~cm}) ; \mathrm{b}$, cristales prismáticos al interior de las venas y en el mesofilo de $S$. floribunda (escala=100 $\mu$ ); c, estomas de $S$. floribunda (escala $=100 \mu$ ). d-g, Tapirira. d, folíolo de $T$. mexicana (escala $=1 \mathrm{~cm})$; e, venación de tercer orden de $T$. mexicana (escala $=5 \mathrm{~mm}$ ); f, drusas en el mesofilo de T. mexicana $($ escala $=100 \mu) ; g$, venación eucamptódroma y canales resiníferos de $T$. mexicana (escala $=1 \mathrm{~mm})$.

el último que presenta ramificación excurrente, el quinto. La venación marginal forma arcos. El grado de organización de la hoja es $3 r$.

Características epidérmicas. Estomas de tipo policíticoanomocítico localizados únicamente en el envés. No se presentan tricomas.

Cristales y canales resiníferos-Los cristales prismáticos se ubican en el interior de las venas y en el mesofilo al igual que las drusas. No se observan canales resiníferos.

58) Género: Tapirira Aubl. (Fig. 26d-g).

Especie tipo: T. guianensis Aubl.

Ejemplares aclarados: T. mexicana March. (DS-F. Miranda 7159, México).

Ejemplares complementarios: T. chimalapana T. Wendt et J. D. Mitchell (MEXU-T. Wendt et al. 5268, México), T. mexicana March. (MEXU-M. Sousa 2142, México), T. mexicana March. (MEXU-T. Wendt et al. 5315, México). Distribución: México, Centroamérica, Colombia, Venezuela, Guyana, Surinam, Brasil.

Descripción: Organización macroscópica. Hojas compuestas imparipinnadas de arreglo pseudoverticilado o alterno con folíolos opuestos peciolulados y textura coriácea (de tipo compuesta paripinnada en T. chimalapana*; arreglo pseudoverticilado en T. mexicana y alterno en T. chimalapana* y T. mexicana*; textura cartácea en T. chimalapana*). Los folíolos son de forma ovada, simétrica de base convexa, ápice acuminado y margen entero (ocasionalmente la base es cóncavo-convexa en T. mexicana). El tamaño de los folíolos es notófilo o mesófilo, la proporción largo/ancho es 2.805:1, el ángulo de la base es de $67^{\circ}$ y el del ápice de $42.5^{\circ}$.

Venación. La venación primaria es pinnada. La secundaria eucamptódroma con 5 venas basales, el espaciado de las venas secundarias es irregular, el ángulo aumenta ligeramente hacia la base o es uniforme. Las venas intersecundarias son débiles o están ausentes. La venación terciaria es alterna percurrente o mixta (opuesto/alterno percurrente), su curso es ramificado exmedialmente o sinuoso y el ángulo con respecto a la vena primaria es obtuso que decrece exmedialmente o es inconsistente. La venación de cuarto orden presenta el patrón reticulado poligonal regular. La venación de quinto orden es dicótoma. Las areolas están de moderadamente a bien desarrolladas, las últimas venas libres son muy ramificadas (dos o más veces). El orden más alto de venación es el sexto o séptimo; el último que presenta ramificación excurrente, el quinto. La venación marginal forma arcos. El grado de organización de la hoja es 2 r o 3r.

Características epidérmicas. Estomas de tipo policíticoanomocítico y policítico-actinocítico, se localizan únicamente en el envés. Los tricomas son escasos, se distribuyen en toda la superficie y en el margen y son de tipo pluricelular.

Cristales y canales resiníferos-Los cristales prismáticos se encuentran al interior de las venas y ocasionalmente en el mesofilo mientras que las drusas sólo están en el mesofilo. Los canales resiníferos se encuentran en las venas del primero al cuarto orden, ocasionalmente también en las de quinto orden.

59) Género: Thyrsodium Salzm. ex Benth. (Fig. 27a-c).

Especie tipo: no designada.

Ejemplares aclarados: T. paraense Huber (US-A. Ducke 11384, Brasil).

Ejemplares complementarios: T. herrerense F. Encarnación (MEXU-R. Vázquez y N. Jaramillo 6312, Perú), T. paraense Huber (MEXU-G. T. Prance et al. 22860, Brasil), T. schomburgkianum Benth (MEXU-R. Liesner y A. González 10386, Venezuela).

Distribución: Brasil, Venezuela, Guyana, Surinam.

Descripción: Organización macroscópica. Hojas compuestas paripinnadas o imparipinnadas de arreglo alterno, con folíolos alternos peciolulados y textura coriácea (hojas paripinnadas en T. paraense e imparipinnadas en T. schomburgkianum*). Folíolos oblongos, ligeramente asimétricos de base cuneada o convexa, ápice acuminado y margen entero (la forma de la base es cuneada en T. paraense y convexa en T. herrerense* y 
T. schomburgkianum*). El tamaño de los folíolos es notófilo, la proporción largo/ancho es 2.52:1, el ángulo de la base es de $64^{\circ}$ y el del ápice de $68^{\circ}$.

Venación. La venación primaria es pinnada. La secundaria eucamptódroma con 5 venas basales, el espaciado de las venas secundarias disminuye hacia la base y hacia el ápice y el ángulo aumenta ligeramente hacia la base. Las venas intersecundarias son débiles. La terciaria es mixta (opuesto/alterno percurrente), su curso es sinuoso y el ángulo con respecto a la vena primaria es obtuso que decrece exmedialmente. La venación de cuarto orden presenta el patrón reticulado poligonal regular. La de quinto orden es dicótoma. Las areolas están bien desarrolladas, las últimas venas libres son muy ramificadas (dos o más veces). El orden más alto de venación es el sexto; el último que presenta ramificación excurrente, el cuarto. La venación marginal forma arcos. El grado de organización de la hoja es 3r. Características epidérmicas. Estomas de tipo tetracíticoestaurocítico y se localizan únicamente en el envés. Los tricomas son escasos, se distribuyen sobre las venas y son

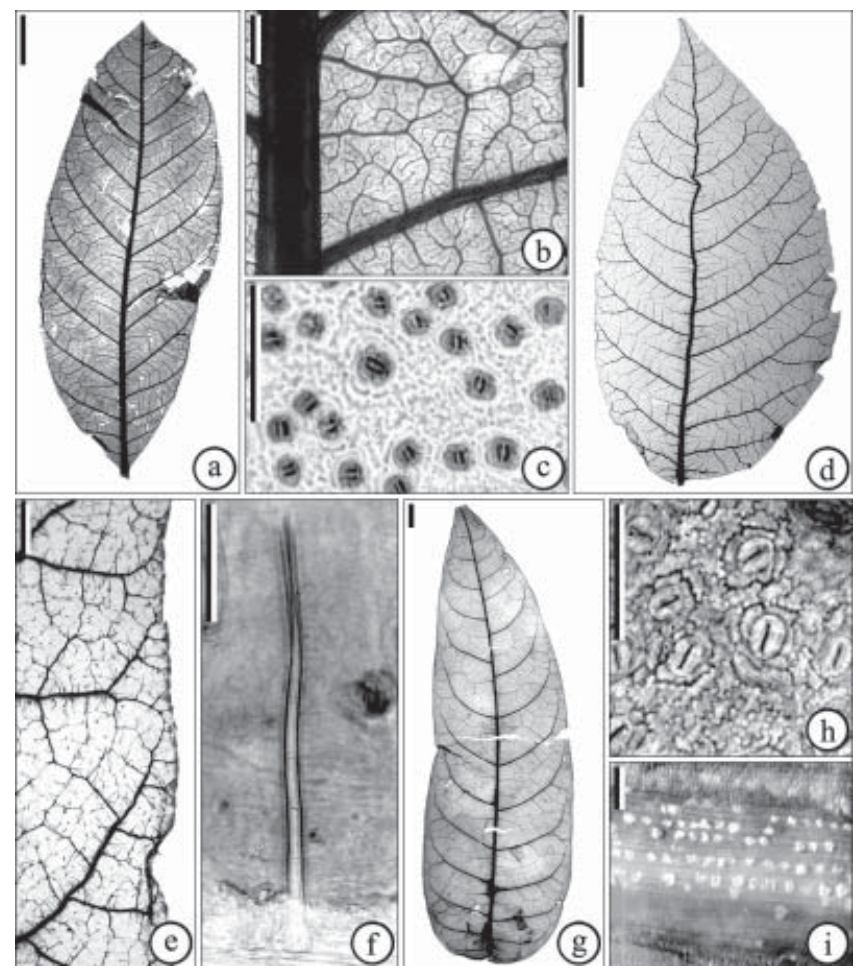

Figura 27. Thyrsodium, Toxicodendron y Trichoscypha. a-c, Thyrsodium. a, folíolo de $T$. paraense (escala $=1 \mathrm{~cm}$ ); $\mathrm{b}$, venación de tercer orden de $T$. paraense (escala $=1 \mathrm{~mm}$ ); $\mathrm{c}$, estomas tetracíticos de $T$. paraense (escala $=100 \mu)$. d-f, Toxicodendron. $\mathrm{d}$, folíolo de $T$. radicans (escala $=1 \mathrm{~cm}$ ); e, margen y glándulas marginales de $T$. radicans (escala $=1 \mathrm{~mm}$ ); $\mathrm{f}$, tricoma pluricelular de $T$. radicans (escala $=100 \mu$ ). g-i, Trichoscypha. g, folíolo de $T$. acuminata (escala $=1 \mathrm{~cm}) ; \mathrm{h}$, estomas de $T$. acuminata (escala $=100$ $\mu$ ); i, cristales prismáticos al interior de las venas de T. acuminata (escala $=100 \mu)$. de tipo pluricelular, también hay tricomas glandulares distribuidos sobre la lámina.

Cristales y canales resiníferos-No se presentan cristales prismáticos ni drusas. Los canales resiníferos se encuentran en las venas del primero al cuarto orden.

60) Género: Toxicodendron Mill. (Fig. 27d-f).

Especie tipo: T. pubescens Mill.

Ejemplares aclarados: T. radicans (L.) Kuntze (FCME-RMF 462, México).

Ejemplares complementarios: T. delavayi (Franch.) F. A. Barkley (MEXU-B. Bartholomew y D. E. Boufford 1992, China), T. radicans (L.) Kuntze (MEXU-F. H. Utech 82230, Estados Unidos), T. striata Kuntze (MEXU-Leg y Matuda 41817, México), T. succedaneum Kuntze (MEXUD. E. Boufford y B. Bartholomew 24643 et al., China), T. verniciferum (DC.) E. D. et F. A. Barkley (MEXU-D. E. Boufford y B. Bartholomew 24355 et al., China).

Distribución: trópico y subtrópico, Norteamérica y Eurasia templadas; Estados Unidos, México, Antillas, Centroamérica, Colombia, Venezuela, China, Japón, Tailandia.

Descripción: Organización macroscópica. Hojas compuestas trifoliadas, imparipinnadas o paripinnadas de arreglo alterno y folíolos opuestos peciolulados de textura membranácea (trifoliadas en $T$. radicans, imparipinnadas en T. delavayi*, T. striata* y T. succedaneum* y paripinnadas en T. verniciferum*; el arreglo es pseudoverticilado en $T$. succedaneum* y T. verniciferum*; la textura es cartácea en T. succedaneum* y T. verniciferum*). Los folíolos son ovados asimétricos, de base redonda, ápice acuminado y margen entero con glándulas (son elípticos en T. striata*). El tamaño de los folíolos es micrófilo, la proporción largo/ ancho es 1.87:1, el ángulo de la base es de $89^{\circ}$ y el del ápice de $62.5^{\circ}$.

Venación. La venación primaria es pinnada. La secundaria cladódroma I con 5 venas basales, el espaciado de las venas secundarias es irregular y el ángulo aumenta abruptamente hacia la base. Las venas intersecundarias son débiles. La terciaria es mixta (opuesto/alterno percurrente), su curso es ramificado exmedialmente y el ángulo con respecto a la vena primaria es obtuso que se mantiene uniforme. La venación de cuarto orden es reticulada poligonal regular. La de quinto orden también es reticulada poligonal regular. Las areolas están bien desarrolladas, las últimas venas libres son desde no ramificadas hasta ramificadas dos o más veces. El orden más alto de venación es el quinto y el último que presenta ramificación excurrente, el cuarto. La venación marginal forma arcos. El grado de organización de la hoja es 4r.

Características epidérmicas. Estomas de tipo policíticoanomocítico, se localizan únicamente en el envés. Los tricomas son moderados, se distribuyen sobre las venas y son de tipo pluricelular.

Cristales y canales resiníferos-No se presentan cristales prismáticos ni drusas. Los canales resiníferos se encuentran 
en las venas del primero al cuarto orden.

61) Género: Trichoscypha Hook. f. (Fig. 27g-i). Especie tipo: T. mannii Hook. f.

Ejemplares aclarados: T. acuminata Engl. (NY-Dubois 741, Congo).

Distribución: oeste de África tropical, Uganda, Gabón.

Descripción: Organización macroscópica. Hojas con arreglo pseudoverticilado, de tipo compuesta imparipinnada, de textura coriácea. El folíolo es de forma ovada, simétrica, con base cordada, ápice recto y margen entero. El tamaño del folíolo es mesófilo, la proporción largo/ancho es 3.09:1, el ángulo de la base es de $66^{\circ}$ y el del ápice de $47^{\circ}$.

Venación. La venación primaria es pinnada. La secundaria broquidódroma débil con 5 venas basales, el espaciado de las venas secundarias disminuye hacia el ápice y la base, el ángulo aumenta ligeramente hacia la base. Las venas intersecundarias son débiles. La venación terciaria es mixta (opuesto/alterno percurrente), su curso es ramificado exmedialmente y el ángulo con respecto a la vena primaria es obtuso que decrece exmedialmente. La venación de cuarto orden es reticulada poligonal regular. La de quinto orden también es reticulada poligonal regular. Las areolas están bien desarrolladas, las últimas venas libres son no ramificadas o ramificadas una vez. El orden más alto de venación es el sexto y el cuarto es el último que presenta ramificación excurrente. La venación marginal forma arcos. El grado de organización de la hoja es 3r.

Características epidérmicas. Estomas de tipo policíticociclocítico, se localizan únicamente en el envés. Los tricomas son abundantes, distribuidos por toda la superficie y de tipo pluricelular.

Cristales y canales resiníferos. Los cristales prismáticos se encuentran al interior de las venas, mientras que las drusas, están tanto al interior como en el mesofilo. No se observan canales resiníferos.

\section{Conclusiones}

La arquitectura foliar de la familia Anacardiaceae es diversa, no hay un solo carácter que sea constante en todos los géneros ni tampoco una combinación de caracteres que distinga inequívocamente a la familia. Sin embargo, hay ciertos patrones que caracterizan algunos grupos. Por ejemplo, cuando Engler $(1883,1896)$ dividió la familia en 5 tribus, utilizó algunos de los caracteres foliares para la caracterización de éstas; Anacardieae, Semecarpeae y Dobineeae tendrían hojas simples, mientras que Rhoeae y Spondiadeae tenderían a tenerlas compuestas. Aunque a simple vista parezca que las hojas simples son más comunes en la familia, debido al número de tribus en que se presentan, las dos tribus con hojas compuestas comprenden la mayor parte de los géneros y especies de la familia, haciendo que las hojas compuestas, en general, sean más comunes. En este estudio, esta tendencia se corrobora, ya que de los 61 géneros estudiados, 44 tienen hojas compuestas, aunque 5 de ellos también incluyen especies con hojas simples (Cuadro 6).

Otro de los caracteres foliares que se ha asociado con Anacardiaceae es la venación secundaria de tipo cladódroma que ayuda a distinguirla de su grupo hermano, la familia Burseraceae, la cual tiende a presentar venación secundaria broquidódroma. Tendencia que se corrobora en este estudio, ya que la venación cladódroma resultó ser común para la familia (Cuadro 7); tanto, que incluso se detectaron subtipos, los cuales se definieron como cladódroma I y II (Fig. 1f). Considerando únicamente la categoría cladódroma (incluyendo I y II), el número de géneros que presentan exclusivamente este tipo de venación secundaria es de 21 (16 presentan cladódroma I, 4 cladódroma II y 1 presenta ambas); pero si se agregan los géneros que pueden presentar venación cladódroma, así como otros tipos de venación, el número asciende a 31 (Cuadro 7). Este número está muy por encima del número de géneros que presentan el segundo tipo de venación secundaria más común, la eucamptódroma, que es de 11 si sólo se considera ese tipo de venación, y de 18 si se consideran los géneros que pueden presentar otros tipos de venación además de la eucamptódroma (Cuadro 7). Es interesante notar que aunque ocasionalmente se puede encontrar en Anacardiaceae un patrón de venación que podría llamarse broquidódromo, no es exactamente del mismo tipo que en Burseraceae. En Burseraceae se presenta la venación broquidódroma "típica" mientras que en Anacardiaceae es broquidódroma débil, siguiendo las definiciones del Leaf Architecture Working Group (1999); además, esta condición no es muy común, se presenta sólo en 6 géneros, y de éstos, uno, Semecarpus también puede presentar venación eucamptódroma (Cuadro 7).

Algunas anacardiáceas presentan dientes, márgenes ya sea dentados, crenados o serrados, mientras que otras no los presentan; es decir, los márgenes son enteros o erosionados. El hecho de que algunas anacardiáceas comunes en México tienen márgenes con dientes llevó a examinar la distribución de este carácter en la familia (Cuadro 8). El resultado es que la gran mayoría de los géneros presenta márgenes sin dientes (48 de los 61 géneros estudiados); 7 géneros siempre presentan dientes y 6 tienen especies que los presentan y especies que no (Cuadro 8), lo que indica que la presencia de dientes no sería una característica particularmente útil para identificar una anacardiácea en el campo; no es una característica común en la familia aunque algunos géneros bien conocidos la presentan.

Por último se examinó la distribución de la presencia de tricomas glandulares (Cuadro 9). Los tricomas glandulares de las anacardiáceas generalmente están formados por un pedúnculo y una cabeza. El pedúnculo puede ser unicelular o pluricelular y la cabeza es generalmente pluricelular y multiseriada, cónica, ovoide o cilíndrica (Fig. 4a; Ding 
Cuadro 6. Géneros de Anacardiaceae incluidos en este estudio según el tipo de hoja que presentan.

\begin{tabular}{|c|c|c|c|c|}
\hline \multicolumn{5}{|l|}{ Simple } \\
\hline Anacardium & Campnosperma & Laurophyllus & Melanochyla & Protorhus \\
\hline Bonetiella & Cotinus & Malosma & Nothopegia & Semecarpus \\
\hline Bouea & Gluta & Mangifera & Ozoroa & Swintonia \\
\hline Buchanania & Haplorhus & & & \\
\hline \multicolumn{5}{|c|}{ Compuesta paripinnada } \\
\hline Antrocaryon & Blepharocarya & Mosquitoxylum & Pseudosmodingium* & Thyrsodium* \\
\hline Astronium* & Euroschinus & Pistacia* & Pseudospondias & Toxicodendron* \\
\hline \multicolumn{5}{|c|}{ Compuesta imparipinnada } \\
\hline Actinocheita & Dracontomelon & Myracrodruon & Pleiogynium & Sorindeia \\
\hline Amphipterygium* & Harpephyllum & Ochoterenaea & Poupartia & Spondias \\
\hline Astronium* & Koordersiodendron & Operculicarya & Pseudosmodingium* & Tapirira \\
\hline Cardenasiodendron & Lannea & Pachycormus & Pistacia* & Trichoscypha \\
\hline Comocladia & Loxopterygium & Parishia & Rhodosphaera & Thyrsodium* \\
\hline Cyrtocarpa & Loxostylis & Pegia & Sclerocarya & Toxicodendron* \\
\hline Choerospondias & Metopium & Pentaspadon & & \\
\hline \multicolumn{5}{|l|}{ Compuesta trifoliada } \\
\hline Amphipterygium* & Smodingium & Pistacia* & Toxicodendron* & \\
\hline \multicolumn{5}{|l|}{ Simple o compuesta } \\
\hline Lithraea & Mauria & Rhus & Schinopsis & Schinus \\
\hline
\end{tabular}

* Géneros con más de una categoría.

Hou, 1978; Wilkinson, 1983; Hardin \& Phillips, 1985). Contrario a lo esperado, dada la frecuencia con que este carácter es mencionado en la literatura, la mayoría de los géneros observados en este trabajo no presentaron tricomas glandulares (38 de 61; Cuadro 9); sin embargo, una revisión a la literatura indica que otros autores han encontrado tricomas glandulares en géneros que aquí no los presentaron. Wilkinson (1983) por ejemplo, documenta su presencia en Gluta. Dames E. Silva (1973) registró la presencia de estos tricomas en Astronium, Myracrodruon, Schinus, Spondias, Tapirira y Thyrsodium y su ausencia en Schinopsis; en el presente estudio las muestras observadas de Astronium, Spondias y Tapirira carecieron de tricomas, pero fueron observados en Schinopsis. Por otro lado, tanto Torres y Jáuregui (1999) como Roth y Lindorf (2002) registran la presencia de tricomas glandulares en Anacardium occidentale. Torres y Jáuregui (1999) además los registran en Mangifera indica y en Spondias purpurea. En este estudio no se encontraron tricomas glandulares en ninguna de estas tres especies, ni en otras de los mismos géneros. Estas diferencias pueden deberse tanto a causas naturales, como de manejo del material después de haber sido colectado. Hardin y Phillips (1985) en sus descripciones de la superficie foliar de algunas especies de Rhus, mencionan que las formas inmaduras son generalmente más pubescentes y que durante la expansión de la lámina muchos tricomas simplemente se caen.

Caracteres como éste, aunque útiles cuando pueden ser observados, deben tomarse con precaución cuando no se les observa en una muestra determinada ya que su ausencia puede deberse a diversos factores; entre ellos, una verdadera ausencia del carácter en el taxón, cambios ontogenéticos o a las técnicas de colecta, preservación y/o montaje del material. En este respecto, el material ergástico -tanto drusas como cristales prismáticos- caería en la misma categoría ya que ciertas técnicas pueden disolver o modificar los cristales al punto de hacer su identificación difícil sino imposible. Los canales resiníferos estarían en una situación similar; en este trabajo fue posible identificarlos solo cuando había material en su interior que se tiñera de color obscuro, si el canal se encontrara "vacío", entonces pasaría desapercibido utilizando esta técnica de aclarado de hojas.

Las descripciones de la arquitectura foliar de los géneros de Anacardiaceae en este trabajo no comprenden todas las especies de la familia, pero ofrecen un primer acercamiento a la caracterización de los patrones que se presentan en cada género estudiado, que puede ser muy valioso cuando se trata, por ejemplo, de la identificación de material aislado, ya sea fósil o actual. También ofrece un primer acercamiento para estudios morfológicos comparativos a niveles supraespecíficos y por último, proporciona una cantidad de caracteres morfológicos vegetativos que pueden ser analizados en un contexto ecológico-adaptativo, así como en un contexto filogenético. 
Cuadro 7. Géneros de Anacardiaceae incluidos en este estudio según el tipo de venación secundaria que presentan.

\section{Broquidódroma débil}

Lannea

Melanochyla

\section{Cladódroma I}

Blepharocarya

Bonetiella

Воиеа

Buchanania*

Comocladia*

Cladódroma II

Anacardium*

Astronium*

\section{Eucamptódroma}

Anacardium*

Astronium*

Buchanania*

Campnosperma

Craspedódroma

Actinocheita

Amphipterygium
Semecarpus*

Parishia

Pistacia

Pleiogynium

Pseudosmodingium*

Rhodosphaera

Pachycormus

Schinus*

Semecarpus*

Spondias*

Swintonia

Tapirira

Thyrsodium

Myracrodruon*

Pseudosmodingium*

Rhus

位opsis

-

Toxicoden

Sorindeia
Ochoterenaea

Cotinus

Euroschinus

Haplorhus

Lithraea*

Loxopterygium*

Buchanania*

Loxostylis

Cyrtocarpa

Choerospondias

Dracontomelon*

Gluta

Cardenasiodendron

Comocladia*
Pentaspadon

Malosma

Mangifera*

Mauria*

Mosquitoxylum

Myracrodruon*

Mangifera*

Metopium

Koordersiodendron

Mauria*

Nothopegia

Pegia

\section{Laurophyllus}

Loxopterygium*

Pseudospondias

Semicraspedódroma

Antrocaryon

Dracontomelon*

Harpephyllum

Poupartia

Protorhus

Spondias*
Ozoroa

\section{Reticulódroma}

Operculicarya

* Géneros con más de una categoría.

Cuadro 8. Géneros de Anacardiaceae incluidos en este estudio según el tipo de margen que presentan.

\begin{tabular}{|c|c|c|c|c|}
\hline \multicolumn{5}{|c|}{ Sin dientes (entero, erosionado) } \\
\hline Anacardium & Dracontomelon & Mangifera & Parishia & Schinopsis \\
\hline Antrocaryon & Euroschinus & Mauria & Pentaspadon & Sclerocarya \\
\hline Blepharocarya & Gluta & Melanochyla & Pistacia & Semecarpus \\
\hline Bonetiella & Haplorhus & Metopium & Pleiogynium & Sorindeia \\
\hline Bouea & Harpephyllum & Mosquitoxylum & Poupartia & Swintonia \\
\hline Buchanania & Koordersiodendron & Nothopegia & Protorhus & Tapirira \\
\hline Campnosperma & Lannea & Ochoterenaea & Pseudospondias & Thyrsodium \\
\hline Cotinus & Lithraea & Operculicarya & Rhodosphaera & Toxicodendron \\
\hline Cyrtocarpa & Loxostylis & Ozoroa & Rhus & Trichoscypha \\
\hline Choerospondias & Malosma & Pachycormus & & \\
\hline \multicolumn{5}{|c|}{ Con dientes (dentado, serrado o crenado) } \\
\hline Actinocheita & Cardenasiodendron & Myracrodruon & Pegia & Smodingium \\
\hline Amphipterygium & Laurophyllus & & & \\
\hline \multicolumn{5}{|l|}{ Con o sin dientes } \\
\hline $\begin{array}{l}\text { Astronium } \\
\text { Comocladia }\end{array}$ & Loxopterygium & Pseudosmodingium & Schinus & Spondias \\
\hline
\end{tabular}


Cuadro 9. Géneros de Anacardiaceae incluidos en este estudio de acuerdo con la presencia de tricomas glandulares.

\begin{tabular}{|c|c|c|c|c|}
\hline \multicolumn{5}{|c|}{ Sin tricomas glandulares } \\
\hline Actinocheita & Comocladia & Loxostylis & Pegia & Smodingium \\
\hline Anacardium* & Dracontomelon & Malosma & Pleiogynium & Sorindeia \\
\hline Antrocaryon & Gluta* & Mangifera* & Poupartia & Spondias* \\
\hline Astronium* & Haplorhus & Mauria & Pseudosmodingium & Swintonia \\
\hline Blepharocarya & Harpephyllum & Melanochyla & Rhodosphaera & Tapirira* \\
\hline Bouea & Lannea & Metopium & Sclerocarya & Toxicodendron \\
\hline Buchanania & Laurophyllus & Nothopeqia & Semecarpus & Trichoscypha \\
\hline Campnosperma & Lithraea & Operculicarya & & \\
\hline \multicolumn{5}{|c|}{ Con tricomas glandulares } \\
\hline Amphipterygium & Cyrtocarpa & Mosquitoxylum & Parishia & Pseudospondias \\
\hline Bonetiella & Choerospondias & Ochoterenaea & Pentaspadon & Schinopsis \\
\hline Cardenasiodendron & Euroschinus & Ozoroa & Protorhus & Thyrsodium \\
\hline Cotinus & Koordersiodendron & Pachycormus & & \\
\hline \multicolumn{5}{|c|}{ Con o sin tricomas glandulares } \\
\hline Loxopterygium & Myracrodruon & Pistacia & Rhus & Schinus \\
\hline
\end{tabular}

* Géneros en los que no se observaron tricomas glandulares pero cuya presencia se ha registrado en la literatura.

\section{Agradecimientos}

A la Dra. Teresa Terrazas Salgado (Colegio de Postgraduados, Montecillo, Estado de México), al Dr. Jack Wolfe (Department of Geosciences, University of Arizona, Tucson, Arizona) y M. en C. José Luis Ramírez Garduño (Posgrado en Ciencias Biológicas, Instituto de Geología, UNAM) por el material biológico donado. A la M. en C. Rosa María Fonseca Juárez (Herbario de la Facultad de Ciencias FCME, Laboratorio de Plantas Vasculares, Facultad de Ciencias, UNAM) y al M. en C. Mario Sousa Sánchez (Herbario Nacional MEXU, Instituto de Biología, UNAM), por la accesibilidad al material biológico y a las colecciones. Los autores agradecen también a las siguientes personas: Antonio Altamira, por ayuda con el material fotográfico; Alejandra Gandolfo y un revisor anónimo, por sus útiles comentarios al manuscrito. El presente trabajo se realizó gracias al apoyo económico proporcionado por parte de CONACYT (\#158336) y DGEP-UNAM a Marcela Martínez Millán, alumna de la Maestría en Ciencias Biológicas (Sistemática), Posgrado en Ciencias Biológicas, UNAM. Este trabajo forma parte de los proyectos 1005PT de CONACYT e IN207294 e IN205597 de DGAPA-UNAM dirigidos por el Dr. Sergio R. S. Cevallos Ferriz.

\section{Literatura citada}

Airy Shaw, H. K. 1965. Diagnoses of new families, new names, etc., for the seventh edition of Willis' 'Dictionary'. Kew Bulletin 18: 249-273.

Airy-Shaw, H. K. (rev.). 1973. J. C. Willis' a dictionary of the flowering plants and ferns, 8th ed. Cambridge University
Press, Cambridge. 1243 p.

APG (Angiosperm Phylogeny Group). 1998. An ordinal classification of the families of flowering plants. Annals of the Missouri Botanical Garden 85: 531-553.

APG (Angiosperm Phylogeny Group). 2003. An update of the Angiosperm Phylogeny Group classification for the orders and families of flowering plants: APG II. Botanical Journal of the Linnean Society 141: 399-436.

Archer, R. H. 2000. Anacardiaceae. In Seed plants of Southern Africa, Leistner, O. A (ed.). Strelitzia 10. National Botanical Institute, Pretoria. p. 56-59.

Archer, R. y Y. Reynolds. 2001. Plants of South Africa: Loxostylis alata A. Spreng. National Botanical Institute, Pretoria. <http://www.plantzafrica.com/frames/ plantsfram.htm>. Mayo 22, 2002.

Armstrong, W. P. 2001. Economic plant photographs \#9: durian, papaya, mango, cashew, hog plum, kaffir plum and burdekin plum. Palomar College. <http://waynesword. palomar.edu/ ecoph9.htm>. Septiembre 23, 2002.

Barkley, F. A. 1937. A monographic study of Rhus and its immediate allies in North and Central America, including the West Indies. Annals of the Missouri Botanical Garden 24: 265-499.

Barkley, F. A. 1942. A key to the genera of Anacardiaceae. American Midland Naturalist 28: 465-474.

Barkley, F. A. 1943. Anacardiaceae. In Flora of Texas, vol. 3, part II, C. L. Lundell (ed.). University Press, Dallas, Texas. p. 89-108.

Barkley, F. A. 1954. Cardenasiodendron, a new genus of Anacardiaceae (Rhoideae). Lloydia 17: 239-246.

Barkley, F. A. 1957. Generic key to the Sumac family (Anacardiaceae). Lloydia 20: 255-265.

Barkley, F. A. 1965. A criticism of the traditional concept of 
the genus Rhus. Prospects of Iraq Biology 3: 52-58.

Breteler,F.J.2004. The genus Trichoschypha (Anacardiaceae) in lower Guinea and Congolia: A synoptic revision. Adansonia sér. 3 26: 97-127.

Brummitt, R. K. 1992. Vascular plants families and genera. The Royal Botanical Gardens, Kew. <http:// www.rbgkew.org.uk/cgi-bin/web.dbs/genlist. pl?ANACARDIACEAE $>$. Enero 17, 2001.

Christophel, D. C. y B. P. M. Hyland. 1993. Leaf atlas of Australian tropical rain forest trees. CSIRO, Melbourne. $260 \mathrm{p}$.

Clarkson, J. J., M. W. Chase y M. M. Harley. 2002. Phylogenetic relationships in Burseraceae based on plastid rps16 intron sequences. Kew Bulletin 57: 183193.

Cronquist, A. 1981. An integrated system of classification of flowering plants. Columbia University Press, New York. $1262 \mathrm{p}$.

Cronquist, A. 1988. The evolution and classification of flowering plants, 2nd ed. New York Botanical Garden, New York. 555 p.

Cunningham, A. B. 1997. Review of ethnobotanical literature from eastern and southern Africa. People and plants online. The Royal Botanic Gardens, Kew. <http://www. rbgkew.org.uk/ peopleplants/regions/africa/aen1/review. htm>. Septiembre 23, 2002.

Dames E. Silva, J. 1973. Catalogo de nervação foliar das Anacardiaceae da Caatinga - I. Arquivos do Jardim Botânico do Rio de Janeiro 19: 249-256.

Dilcher, D. 1974. Approaches to the identification of angiosperm leaf remains. The Botanical Review 40: 1157.

Ding Hou. 1978. Anacardiaceae. In Flora malesiana, ser 1, vol. 8(3), C. G. G. J. van Steenis (ed.). Sijthoff \& Noordhoff, Alphen van der Rijn. p. 395-548.

Engler, A. 1883. Anacardiaceae. In Monographiae Phanerogamarum, 4, A. y C. DeCandolle (eds.). G. Masson, Paris. p. 170-500.

Engler, A. 1896. Anacardiaceae. In Die natürlichen Pflanzenfamilien, III (5), A. Engler y K. Prantl (eds.). Engelmann, Leipzig. p. 138-178.

Gadek, P. A., E. S. Fernando, C. J. Quinn, S. B. Hoot, T. Terrazas, M. C. Sheahan y Chase M. W. 1996. Sapindales: Molecular delimitation and infraordinal groups. American Journal of Botany 83: 802-811.

Gillis, W. T. 1971. The systematics and ecology of poisonivy and the poison-oaks (Toxicodendron, Anacardiaceae). Rhodora 73: 72-159, 161-237, 370-443, 465-540.

Hardin, J. W y L. L. Phillips. 1985. Atlas of foliar surface features in woody plants, VII. Rhus subg. Rhus (Anacardiaceae) of North America. Bulletin of the Torrey Botanical Club 112: 1-10.

Heimsch, C. Jr. 1942. Comparative anatomy of the secondary xylem in the Gruinales and Terebinthales. Lilloa 8: 82-
198.

Hemsley, W. B. 1906. On the Julianiaceae, a new natural order of plants. Proceedings of the Royal Society of London. Series B. Containing papers of a biological character 78: 231-236.

Hemsley, W. B. 1908. On the Julianiaceae, a new natural order of plants. Philosophical Transactions of the Royal Society of London. Series B. Containing papers of a biological character 199: 169-197.

Hickey, L. J. 1973. Classification of the architecture of dicotyledoneous leaves. American Journal of Botany 60: 17-33.

Hickey, L. J. 1979. A revised classification of the architecture of dicotyledonous leaves. In Anatomy of the dicotyledons, 2nd. ed., vol. 1. Systematic anatomy of leaf and stem, with a brief history of the subject, C. R. Metcalfe y L. Chalk (eds.). Clarendon Press. Oxford. p. 25-39.

Hyland, B. P. M. y T. Whiffin. 1993. Australian tropical rain forest plants: an interactive identification system. CSIRO, Melbourne. $867 \mathrm{p}$.

Hyland, B. P. M., T. Whiffin, D. C. Christophel, B. Gray y R. W. Elick. 2003. Australian tropical rain forest plants: trees, shrubs and vines. CSIRO, Melbourne. CD ROM

Judd, W. S., C. S. Campbell, E. A. Kellogg y P. F. Stevens. 1999. Plant systematics, a phylogenetic approach. Sinauer, Sunderland, Massachusetts. 464 p.

Judd, W. S., C. S. Campbell, E. A. Kellogg, P. F. Stevens y M. J. Donoghue. 2002. Plant systematics, a phylogenetic approach, 2nd ed. Sinauer, Sunderland, Massachusetts. $576 \mathrm{p}$.

Kryn, J. M. 1952. The anatomy of the wood of the Anacardiaceae and its bearing on the phylogeny and relationships of the family. $\mathrm{PhD}$ diss., University of Michigan, Ann Arbor. 331 p.

Leaf Architecture Working Group. 1999. Manual of leaf architecture - morphological description and categorization of dicotyledonous and net-veined monocotyledonous angiosperms. Smithsonian Institution, Washington, D. C. $67 \mathrm{p}$.

Maiden, J. H. 1904. The forest flora of New South Wales, vol. 1, part VIII. Forest Department of New South Wales, Sydney. $472 \mathrm{p}$.

Miller, A. J., D. A. Young y J. Wen. 2001. Phylogeny and biogeography of Rhus (Anacardiaceae) based on ITS sequence data. International Journal of Plant Sciences 162: 1401-1407.

Payne, W. W. 1969. A quick method for clearing leaves. Ward's Bulletin new series 8: 4-5.

Pell, S. K. 2004. Molecular systematics of the cashew family (Anacardiaceae). PhD diss. Department of Biological Sciences, Louisiana State University, Baton Rouge. 193 p.

Pell, S. K. y L. Urbatsch. 2000. Evaluation of evolutionary relationships in Anacardiaceae using matK sequence data. American Journal of Botany 87 (suppl.): 149. 
Pell, S. K. y L. Urbatsch. 2001. Tribal relationships and character evolution in the cashew family (Anacardiaceae): inferences from three regions in the chloroplast genome. In Botany 2001 Abstracts. Botanical Society of America, p.132

Perrier de la Bâthie, H. 1944. Révision des anacardiacées de Madagascar et des Comores. Mémoires du Muséum National d'Histoire Naturelle, nouvelle série 18: $243-$ 270.

Perrier de la Bâthie, H. 1946. Anacardiacées (Anacardiaceae). In Flore de Madagascar et des Comores, 114e famille, H. Humbert (ed.). Imprimerie Officielle, Tananarive, Madagascar, p. 1-85.

Petitjean, A. y J. Samyn. 1999. Flore et plantes médicinales de l'Ocean Indien: Operculicarya decaryi. l'IMRA (Institut Malgache de Recherches Appliquées). <http:// hala.refer.mg/imra/ plantu/ope.html>. Mayo 22, 2002.

Randrianasolo, A. 1998. New taxonomic perspective on three genera of Madagascar Anacardiaceae. American Journal of Botany 85(suppl): 153.

Reveal, J. L. 1998. Indices Nominum Supragenericum Plantarum Project. University of Maryland. <http:// www.inform.umd.edu/PBIO/crofamsyn/Anacardiaceae. html> o <http:// www.life.umd.edu/emeritus/reveal/ PBIO/crofamsyn/Anacardiaceae.html>. Mayo 20, 2002.

Roth, I. and H. Lindorf. 2002. South American medicinal plants. Botany, remedial properties and general use. Springer, Heidelberg. 492 p.

Robertson, H. G. 2000. Biodiversity explorer: Anacardiaceae (Mango, pepper tree, pistachio, cashew family). South African Museum, part of Iziko Museums of Cape Town. $<$ http://www.plantzafrica.com/ frames/plantsfram.htm>. Mayo 20, 2002.

Santin, D. A. y H de F. Leitão F. 1991. Restablecimento e revisão taxonômica do gênero Myracrodruon Freire Allemão (Anacardiaceae). Revista Brasileira de Botânica 14: 133-145.

Soltis, D. E., P. E. Soltis, M. W. Chase, M. E. Mort, D. C. Albach, M. Zanis, V. Savolainen, W. H. Hahn, S. B. Hoot, M. F. Fay, M. Axtell, S. M. Swensen, L. M. Prince, W. J. Kress, K. C. Nixon y J. S. Farris. 2000. Angiosperm phylogeny inferred from 18S rDNA, rbcL, and $a t p B$ sequences. Botanical Journal of the Linnean Society 133: 381-461.

Stern, W. L. 1952. The comparative anatomy of the xylem and the phylogeny of Julianiaceae. American Journal of Botany 39: 220-229.

Terrazas S., T. 1994. Wood anatomy of the Anacardiaceae: ecological and phylogenetic interpretation. $\mathrm{PhD}$ diss. Department of Biology, University of North Carolina, Chapel Hill. 321 p.

Terrazas, T. 1999. Anatomía de la madera de Anacardiaceae con énfasis en los géneros americanos. Boletín de la Sociedad Botánica de México 64: 103-109.

Terrazas, T. y M. W. Chase. 1996. A phylogenetic analysis of Anacardiaceae based on morphology, anatomy and $r b c L$ sequence data. American Journal of Botany 83 (suppl.): 197-198.

Thorne, R. F. 1992. Classification and geography of flowering plants. The Botanical Review 58: 225-348.

Torres M. y D. Jáuregui. 1999. Caracterización anatómica foliar de cuatro especies de árboles frutales: Anacardium occidentale L. (merey); Mangifera indica L. (mango); Spondias purpurea L. (ciruela de huesito) y Psidium guajava L. (guayaba). Ernstia 9: 154-173.

Wannan, B. S. y C. J. Quinn. 1988. Biflavonoids in the Julianiaceae. Phytochemistry 27: 3161-3162.

Wannan, B. S., J. T. Waterhouse y C. J. Quinn. 1987. A taxonomic reassessment of Blepharocarya F. Muell. Botanical Journal of the Linnean Society 95: 61-72.

Weeks, A., Daly, D. C. y B. B. Simpson. 2005. The phylogenetic history and biogeography of the frankincense and myrrh family (Burseraceae) based on nuclear and chloroplast sequence data. Molecular Phylogenetics and Evolution 35: 85-101.

Wilkinson, H. P. 1979. The plant surface (mainly leaf). Part IV Domatia. In Anatomy of the Dicotyledons. 2nd. ed. Vol. 1. Systematic anatomy of leaf and stem, with a brief history of the subject. C. R. Metcalfe y L. Chalk (eds.). Clarendon, Oxford. p. 132-140.

Wilkinson, H. P. 1983. Leaf anatomy of Gluta (L.) Ding Hou (Anacardiaceae). Botanical Journal of the Linnean Society 86: 375-403.

Yi, T., A. J. Miller y J. Wen. 2004. Phylogenetic and biogeographic diversification of Rhus (Anacardiaceae) in the Northern Hemisphere. Molecular Phylogenetics and Evolution 33: 861-879.

Young, D. A. 1976. Flavonoid chemistry and the phylogenetic relationships of the Julianiaceae. Systematic Botany 1: 149-162. 